\title{
Four-membered Metallacycles Arising from an Ambiphilic Ligand: Synthesis and Characterization of Group IX Complexes
}

\author{
Rachael Nichole Pickens
}

Follow this and additional works at: https://researchrepository.wvu.edu/etd

\section{Recommended Citation}

Pickens, Rachael Nichole, "Four-membered Metallacycles Arising from an Ambiphilic Ligand: Synthesis and Characterization of Group IX Complexes" (2016). Graduate Theses, Dissertations, and Problem Reports. 6419.

https://researchrepository.wvu.edu/etd/6419

This Thesis is protected by copyright and/or related rights. It has been brought to you by the The Research Repository @ WVU with permission from the rights-holder(s). You are free to use this Thesis in any way that is permitted by the copyright and related rights legislation that applies to your use. For other uses you must obtain permission from the rights-holder(s) directly, unless additional rights are indicated by a Creative Commons license in the record and/ or on the work itself. This Thesis has been accepted for inclusion in WVU Graduate Theses, Dissertations, and Problem Reports collection by an authorized administrator of The Research Repository @ WVU. For more information, please contact researchrepository@mail.wvu.edu. 


\title{
Four-membered Metallacycles Arising from an Ambiphilic Ligand: Synthesis and Characterization of Group IX Complexes
}

\author{
Rachael Nichole Pickens \\ Thesis submitted to the Eberly College of Arts and Sciences \\ at West Virginia University \\ in partial fulfillment of the requirements \\ for the degree of \\ Master of Science \\ In \\ Chemistry \\ Brian V. Popp, Ph.D., Chair \\ Carsten Milsmann, Ph.D. \\ Björn C. Söderberg, Ph.D. \\ C. Eugene Bennett Department of Chemistry \\ Morgantown, West Virginia \\ 2016
}

Keywords: ambiphilic, metallacycle

Copyright 2016 Rachael Nichole Pickens 


\section{Abstract \\ Four-membered Metallacycles Arising from an Ambiphilic Ligand: Synthesis and Characterization of Group IX Complexes \\ by Rachael Pickens}

The reactivity of transition metal complexes is greatly affected by the complex structure and the nature of the coordinated ligands. Ambiphilic ligands, a class of molecule termed a frustrated Lewis pair that possesses non-interacting functional groups of both Lewis acidic and basic character, are of particular interests few reports of their application to organometallic catalysis have emerged and their full potential has not been achieved. Exploring the bifunctionality and the potential applications of such ligand frameworks with group IX transition

metals with phosphino-borane $\left(\mathrm{Ph}_{2} \mathrm{PCH}_{2} \mathrm{CH}_{2} \mathrm{~B}^{\mathrm{BBN}}\right)$ complexes resulted in interesting reactivity. When treated with bases such as silver or lithium reagents, the metal-FLP ligated complexes generated four-membered metallacycles for the group IX metal series. NMR experiments were used to characterize such structures, and the synthesis and characterization of these metallacycles are discussed herein. 


\section{Acknowledgements}

I would like to begin by acknowledging my advisor, Dr. Brian Popp. I am extremely grateful for his guidance and advice as a researcher and could not have hoped for someone better to oversee my experience at West Virginia University. It is not only his knowledge of chemistry but his honesty and sincerity towards others that makes an irreplaceable advisor.

I would also like to thank my committee members, Dr. Carsten Milsmann and Dr. Björn Söderberg, for all of their help and guidance throughout my time in graduate school.

My lab members deserve a special thank you as each of them has helped me along the way and taught me about teamwork. I know I could not have asked for a better group of individuals to help me grow as a researcher.

The faculty and staff of the department have been of upmost importance as their willingness for discussion and advice was always available. Thank you all for the friendly and welcoming attitude you present as a chemistry department. A special thanks is extended to Dr. Jefferey Petersen and Dr. Novruz Akhmedov for assistance with X-ray structure determination and 2D NMR experiments, respectively.

Most of all, I would like to thank my friends and family, without whom I know I could not have made it this far. Their unwavering support is something for which I will always be grateful. 


\section{Table of Contents}

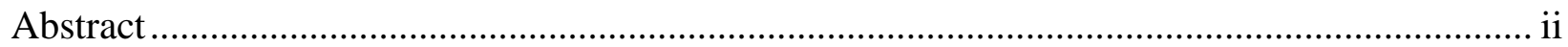

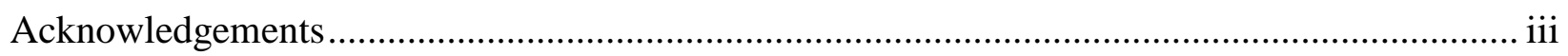

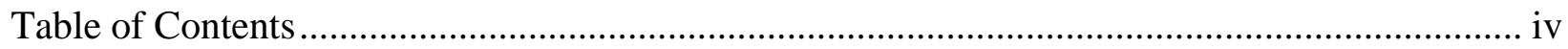

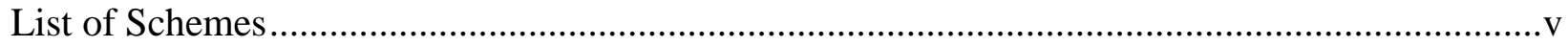

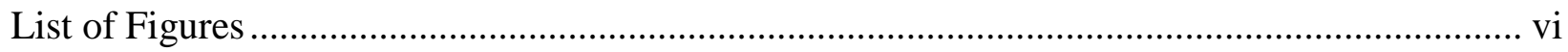

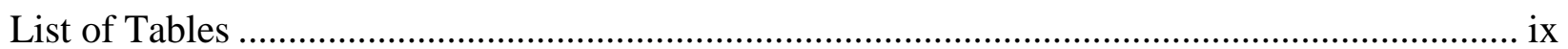

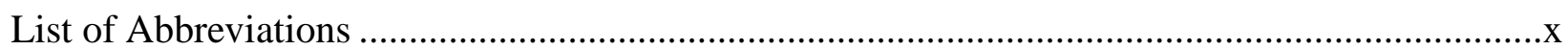

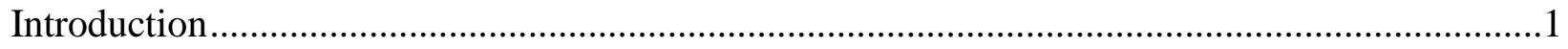

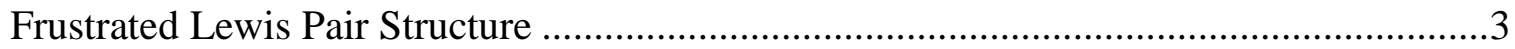

Coordination Chemistry of Frustrated Lewis Pairs ....................................................

Frustrated Lewis Pair Reactivity........................................................................ 10

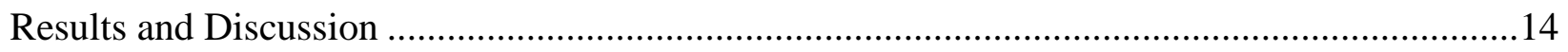

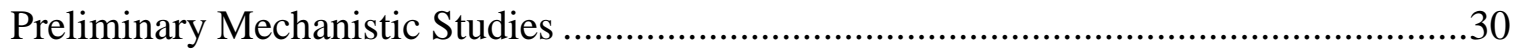

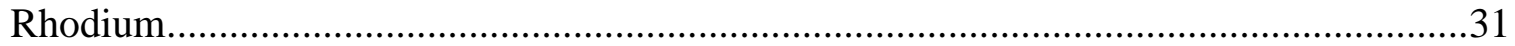

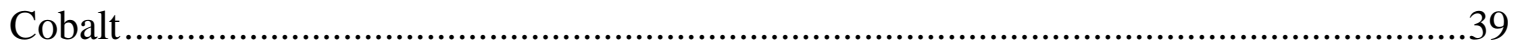

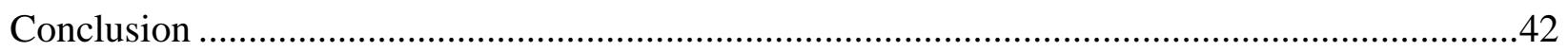

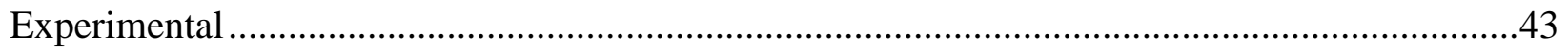

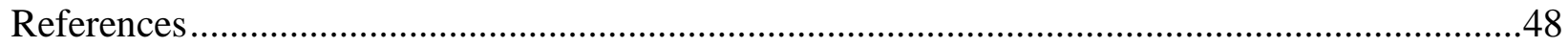

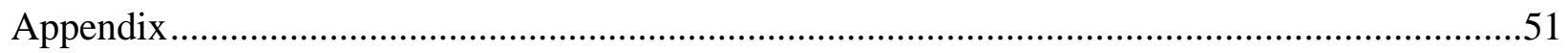




\section{List of Schemes}

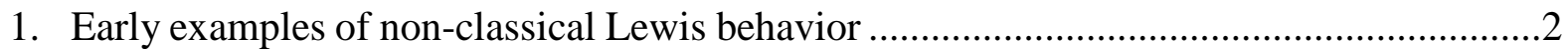

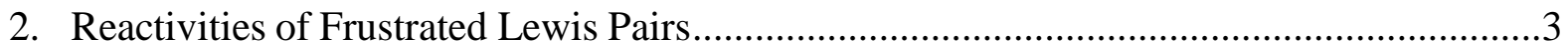

3. Coordination mode A of phosphino-borane ………….................................................

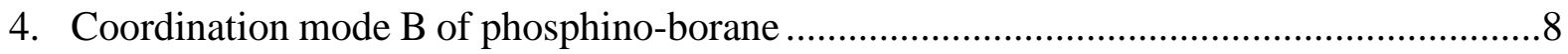

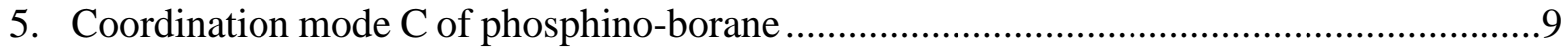

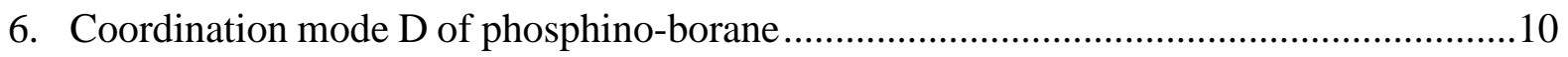

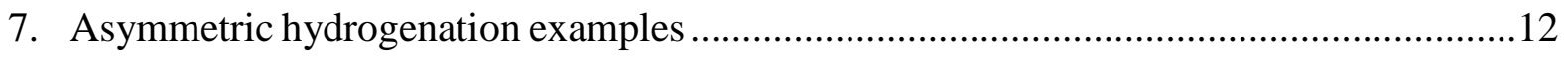

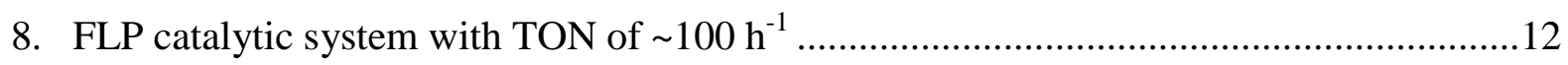

9. Examples of metal coordinated FLP reactivity. a.) Rhodium P/Al ligand methyl abstraction at metal center b.) Platinum with an N/B ligand activating $\mathrm{H}_{2}$ and

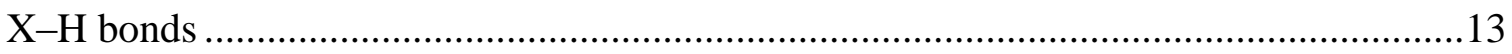

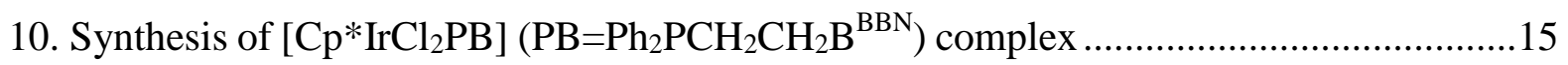

11. $\mathrm{Cp}^{*} \mathrm{IrCl}_{2} \mathrm{~PB}$ reaction with $\mathrm{AgOAc}$ that resulted in a new complex .................................16

12. Generating four-membered metallacycle from $\mathrm{Cp} * \mathrm{IrCl}_{2}\left(\mathrm{Ph}_{2} \mathrm{PCH}_{2} \mathrm{CH}_{2} \mathrm{~B}^{\mathrm{BBN}}\right) \ldots \ldots \ldots \ldots \ldots \ldots . .24$

13. Generating four-membered metallacycle from ( $p$-cymene) $\mathrm{RuCl}_{2}\left(\mathrm{Ph}_{2} \mathrm{PCH}_{2} \mathrm{CH}_{2} \mathrm{BR}_{2}\right) \ldots \ldots .30$

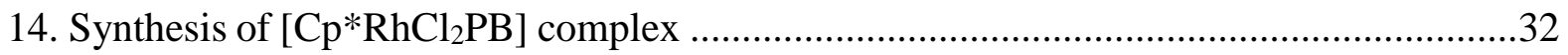

15. Generating four-membered metallacycle from $\mathrm{Cp} * \mathrm{RhCl}_{2}\left(\mathrm{Ph}_{2} \mathrm{PCH}_{2} \mathrm{CH}_{2} \mathrm{~B}^{\mathrm{BBN}}\right)$...............33

16. Generating four-membered metallacycle from $\mathrm{Cp} * \mathrm{CoCl}_{2}\left(\mathrm{Ph}_{2} \mathrm{PCH}_{2} \mathrm{CH}_{2} \mathrm{~B}^{\mathrm{BBN}}\right) \ldots \ldots \ldots \ldots \ldots . . .40$ 


\section{List of Figures}

1. Possible structures of phosphino-boranes .................................................................

2. Structures of $\mathrm{C}_{1}$ linkers and their ${ }^{31} \mathrm{P}$ and ${ }^{11} \mathrm{~B}$ NMR data ...........................................

3. $\mathrm{C}_{2}$ ethenyl-linked phosphino-borane ${ }^{31} \mathrm{P}$ and ${ }^{11} \mathrm{~B}$ NMR data.........................................

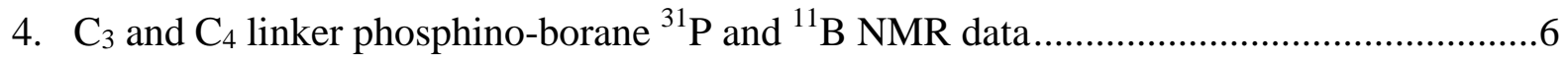

5. Four coordination modes of phosphino-boranes with transition metals ..........................

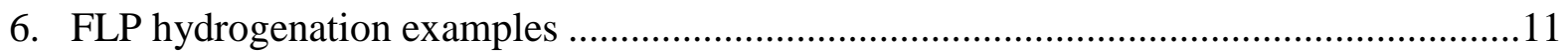

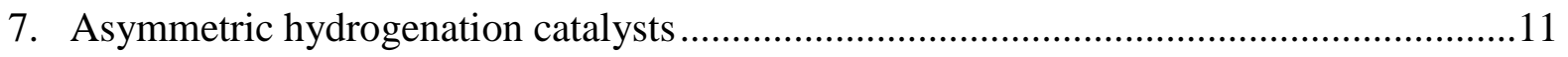

8. FLP small molecule capture products of $\mathrm{CO}_{2}, \mathrm{~N}_{2} \mathrm{O}, \mathrm{NO}$, and $\mathrm{SO}_{2}$ using the corresponding

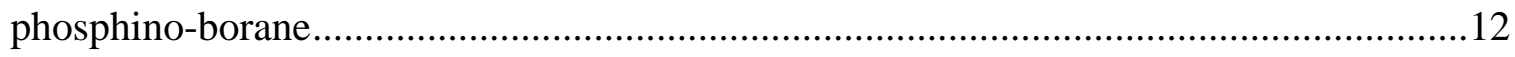

9. ${ }^{31} \mathrm{P}$ NMR of free phosphino-borane frustrated Lewis pair ligand $\mathrm{Ph}_{2} \mathrm{PCH}_{2} \mathrm{CH}_{2}\left(\mathrm{~B}^{\mathrm{BBN}}\right) \ldots . .15$

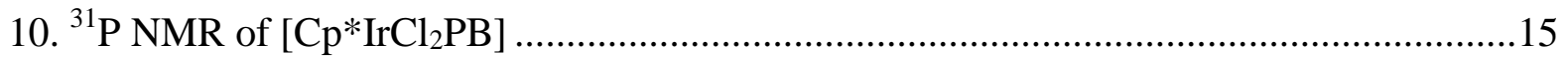

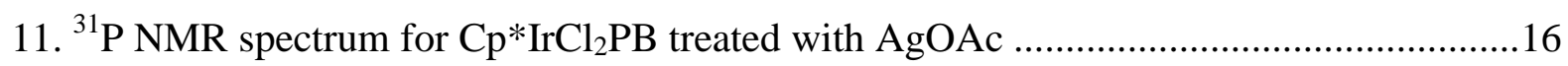

12.

a. Calculated HRMS of $\mathrm{Cp}^{*} \mathrm{IrCl}_{2} \mathrm{PPh}_{2} \mathrm{CH}_{2} \mathrm{CH}_{2}$ metallacycle. Expected mass $=576.13$

b. Experimental HRMS of $\mathrm{Cp}^{*} \mathrm{IrCl}_{2} \mathrm{PPh}_{2} \mathrm{CH}_{2} \mathrm{CH}_{2}$. Expected mass $=576.13 \ldots \ldots \ldots \ldots . .17$

13. 1D TOCSY experiment of $\mathrm{Cp}^{*} \mathrm{IrCl}_{2} \mathrm{PPh}_{2} \mathrm{CH}_{2} \mathrm{CH}_{2}$ .18

14. Calculated (b) vs. experimental (a) splitting patterns of methylene protons of iridium metallacycle and coupling constants between each nuclei 19

15. ${ }^{31} \mathrm{P}$ NMR Cp* $\operatorname{IrCl} 2(\mathrm{Ph} 2 \mathrm{PCH} 2 \mathrm{CH} 2 \mathrm{BBBN})+1$ eq. AgOAc . 20 
16. Expanded portion of a gCOSY spectrum showing correlations between methylene protons of iridium metallacycle .21

17.

a. DPFGSENOE spectrum of iridium metallacycle exciting $\mathrm{H}_{2}$

b. DPFGSENOE spectrum of iridium metallacycle exciting $\mathrm{H}_{2 b}$

c. DPFGSENOE spectrum of iridium metallacycle exciting $\mathrm{H}_{1 \mathrm{~b}}$

d. DPFGSENOE spectrum of iridium metallacycle exciting $\mathrm{H}_{1}$

18. gHMBCAD correlations between $\mathrm{C} 1$ protons and the ipso carbon of phenyl ring on phosphorus atom .24

19. ${ }^{31} \mathrm{P} \mathrm{NMR} \mathrm{Cp} * \mathrm{IrCl}_{2} \mathrm{~PB}+1$ eq. $\mathrm{LiH}$. 26

20. ${ }^{31} \mathrm{P} \mathrm{NMR} \mathrm{Cp}^{*} \mathrm{IrCl}_{2} \mathrm{~PB}+1$ eq. $\mathrm{PhLi}$ .26

21. ${ }^{31} \mathrm{P}$ NMR Cp* $\mathrm{IrCl}_{2} \mathrm{~PB}+1$ eq. $\mathrm{NaBH}_{4}$

22. ${ }^{31} \mathrm{P} \mathrm{NMR} \mathrm{Cp} * \mathrm{IrCl}_{2} \mathrm{~PB}+1$ eq. $\mathrm{NaEt}_{3} \mathrm{BH}$

23. ${ }^{31} \mathrm{P} \mathrm{NMR} \mathrm{Cp}^{*} \mathrm{IrCl}_{2} \mathrm{~PB}+1$ eq. $\mathrm{AgOBz}$ .28

24. ${ }^{31} \mathrm{P} \mathrm{NMR} \mathrm{Cp}^{*} \mathrm{IrCl}_{2} \mathrm{~PB}+1$ eq. $\mathrm{AgOCF}_{3}$. .28

25. ${ }^{31} \mathrm{P} \mathrm{NMR} \mathrm{Cp} * \mathrm{IrCl}_{2} \mathrm{~PB}+1$ eq. AgOTf

26. ${ }^{31} \mathrm{P}$ NMR Cp* $\mathrm{IrCl}_{2} \mathrm{~PB}+1$ eq. $\mathrm{AgBF}_{4}$

27. ORTEP structure of ruthenium $(\mathrm{Ru})$ metallacycle reported in 2008 .30

28. Perspective view of the molecular structure of $\mathrm{Cp}^{*} \operatorname{IrCl}_{2}\left(\mathrm{PPh}_{2} \mathrm{CH}_{2} \mathrm{CH}_{3}\right)$ with the atom labeling scheme for the non-hydrogen atoms. The thermal ellipsoids are scaled to enclose $30 \%$ probability 
29. ORTEP structures of $\mathrm{Cp} * \mathrm{RhCl}_{2} \mathrm{~PB}$ complex with coordinated boron-coordinated THF and $\mathrm{CH}_{3} \mathrm{CN}$ .32

30. ${ }^{31} \mathrm{P}$ NMR spectrum of Rh metallacycle with Rh-P coupling constant.

31. 1D TOCSY of methylene protons of Rh(III) metallacycle. Excited $\mathrm{H}_{1 \mathrm{a}} / \mathrm{H}_{1 \mathrm{~b}}$ signals

32.

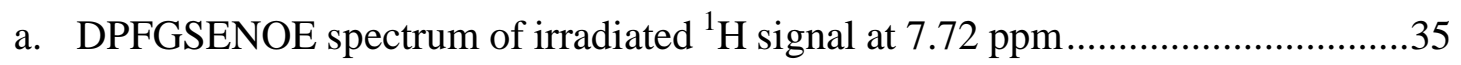

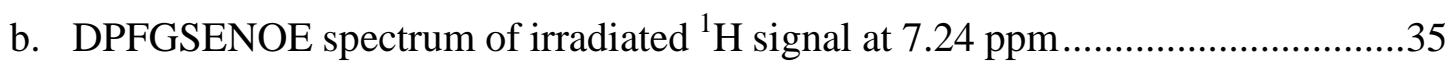

c. DPFGSENOE spectrum of irradiated ${ }^{1} \mathrm{H}$ signal at $2.48 \mathrm{ppm}$.................................36

33. Calculated vs. Experimental coupling constants for methylene protons of rhodium metallacycle 37

34. ${ }^{2} \mathrm{~J}$ and ${ }^{3} \mathrm{~J}$ coupling constants of each ${ }^{1} \mathrm{H}$ signal generated from methylene protons of the rhodium metallacycle

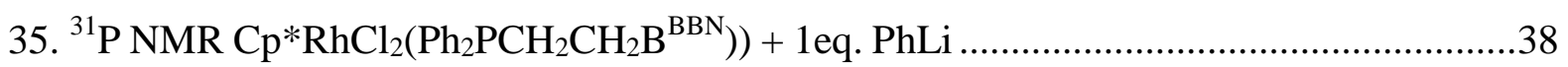

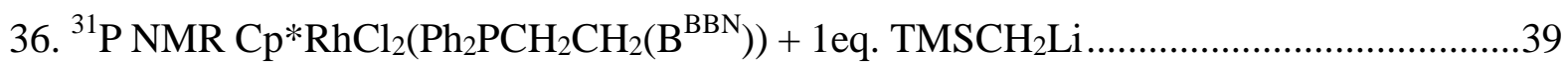

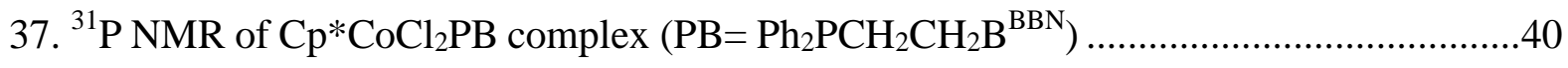

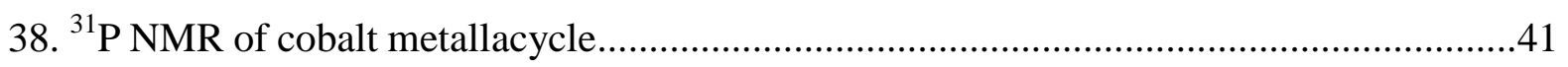

39. ${ }^{1} \mathrm{H}$ NMR of cobalt metallacycle generated and ${ }^{1} \mathrm{H}\left\{{ }^{31} \mathrm{P}\right\}$ NMR of cobalt metallacycle .......41 


\section{List of Tables}

1. Additives reacted with $\left[\mathrm{Cp} * \operatorname{IrCl}_{2} \mathrm{~PB}\right]$ with corresponding metallacycle yields

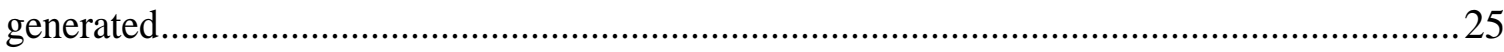

2. Additives reacted with $\left[\mathrm{Cp} * \mathrm{RhCl}_{2} \mathrm{~PB}\right]$ with corresponding metallacycle yields

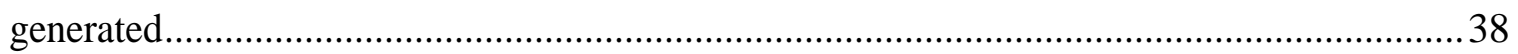

3. ${ }^{31}$ P NMR shifts for group IX phosphino-borane and metallacycle complexes....................42 


\section{List of Abbreviations}

$\begin{array}{ll}\text { 1) frustrated Lewis pair } & \text { FLP }\end{array}$

2) nuclear magnetic resonance $\quad$ NMR

3) pentamethylcyclopentadiene C $\mathrm{Cp}^{*}$

4) electrospray ionization mass spectrometry $\quad$ ESI-MS

5) high-resolution mass spectrometry $\quad$ HRMS

6) atomic mass units amu

$\begin{array}{ll}\text { 7) total correlation spectroscopy } & \text { TOCSY }\end{array}$

8) gradient homonuclear correlation spectroscopy gCOSY

9) nuclear Overhauser effect spectroscopy $\quad$ NOESY

10) double pulse field gradient spin-echo nuclear overhauser effect $\quad$ DPFGSENOE

11) heteronuclear multiple-bond correlation spectroscopy $\quad$ HMBC

12) Oak Ridge thermal ellipsoid plot $\quad$ ORTEP 


\section{Introduction}

The behavior of acids and bases plays a significant role, and in many instances, is the driving force throughout various chemical reactions. Work performed by Gilbert Lewis in 1923 led to electron acceptors and electron donors being more commonly referred to as "Lewis acids and bases." The energies of the HOMO of the base and LUMO of the acid allowed for the formation of an adduct between the two compounds, a common example being the adduct between borane and ammonia. In 1942, Brown and coworkers noted that although combinations of lutidene (2,6-dimethylpyridine) and trifluoroborane $\left(\mathrm{BF}_{3}\right)$ formed the expected acid-base adduct, combinations of lutidene and trimethylborane $\left(\mathrm{BMe}_{3}\right)$ did not (Scheme 1a). It was noted that this non-traditional behavior may be due to steric hindrance from the methyl groups that were not present in fluorinated borane. However, this observation was not investigated further. ${ }^{2}$

In 1950, Wittig noticed that although $\mathrm{Ph}_{3} \mathrm{~B} \bullet \mathrm{THF}$ and $\mathrm{Na}\left[\mathrm{CPh}_{3}\right]$ were combined and expected to react, the less basic tetrahydrofuran (THF) was not replaced by the trityl anion $\left(\mathrm{CPh}_{3}\right)$ as expected. Instead of achieving the desired substitution of a stronger base for a weaker one, the result was the cleavage of a $\mathrm{C}-\mathrm{O}$ bond in the THF ring (Scheme 1b). ${ }^{3}$ In 1959 , Wittig and Benz observed unexpected reactivity upon addition of benzyne to $\mathrm{PPh}_{3}$ and $\mathrm{BPh}_{3}$, resulting in a zwitterionic product (Scheme 1c). ${ }^{4}$ Subsequent studies by Tochtermann in 1966 showed that butadiene when mixed with trityl anion nucleophile and $\mathrm{BPh}_{3}$ electrophile yielded interesting 1,2- and 1,4-nucleophile/electrophile addition products (Scheme 1d). Tochtermann described the phenomenon as "antagonishtiches Paar", meaning "antagonistic couple" in German. Unfortunately, this description was not commonly adopted by the broader scientific community because it was not reported in the English version of the publication. 
a.

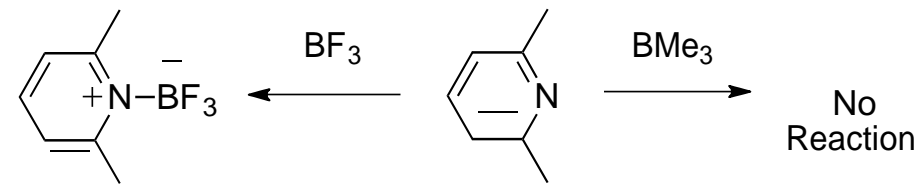

b.
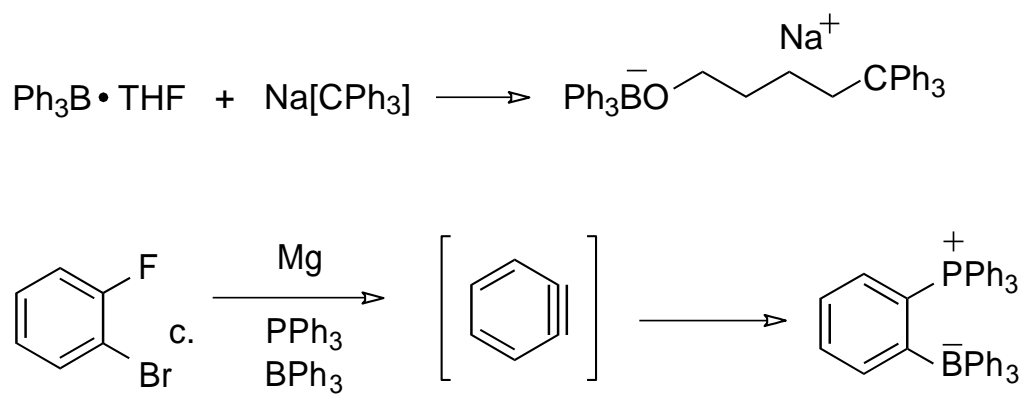

d. $\left[\mathrm{Ph}_{3} \mathrm{C}\right] \mathrm{Na}$

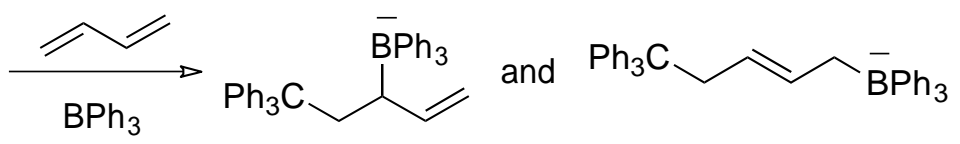

Scheme 1. Early examples of non-classical Lewis behavior

Broad interest in non-traditional Lewis pairs was reignited in 2006 when Stephan and coworkers reported the discovery that a phosphine and borane containing arene that could reversibly cleave and reform the $\mathrm{H}-\mathrm{H}$ bond of dihydrogen via a heterolytic cleavage pathway (Scheme 2a). ${ }^{6}$ In 2007 , Stephan showed that a simpler system of only $\mathrm{PR}_{3}$ and $\mathrm{B}\left(\mathrm{C}_{6} \mathrm{~F}_{5}\right)_{3}$ also activated dihydrogen (Scheme $2 b){ }^{7}$ That same year, he developed yet another system to activate $\mathrm{H}_{2}$ when his group created the first ethylene-bridged Lewis acid/base pair of its type (Scheme 2c). ${ }^{8}$ Similar zwitterionic compounds to those described in Tochtermann's studies were observed when olefins were reacted with $\mathrm{P}^{t} \mathrm{Bu}_{3}$ and $\mathrm{B}\left(\mathrm{C}_{6} \mathrm{~F}_{5}\right)_{3}$ (Scheme $\left.2 \mathrm{~d}\right) .{ }^{9}$ This prompted Stephan to classify combinations of Lewis donors and acceptors that were sterically prevented from forming a classical Lewis adduct as "frustrated Lewis pairs" (FLP) and has become the common term used to describe this behavior in literature. 
a.

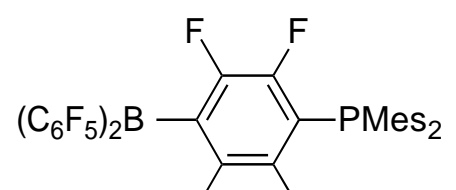

F $\quad F$

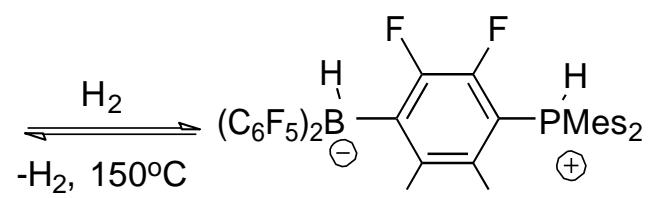

F $\quad F$

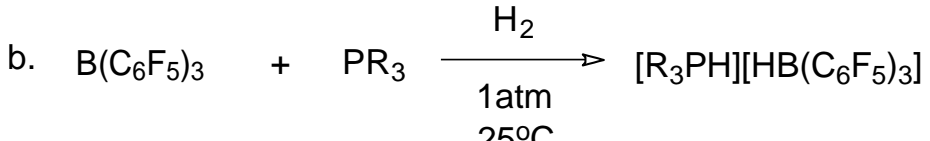

$25^{\circ} \mathrm{C} \quad \mathrm{R}=\mathrm{tBu}, \mathrm{C} \mathrm{H} \mathrm{Me}$

$\begin{array}{lll}6 & 2 & 3\end{array}$

c.

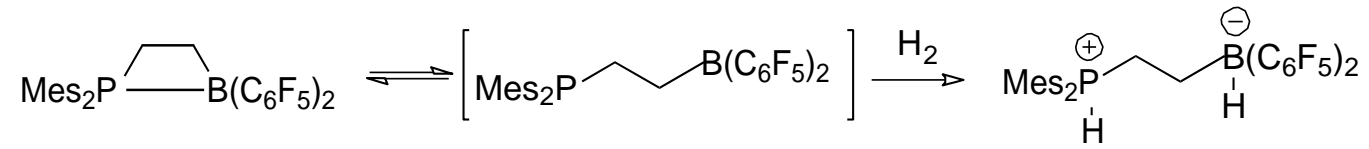



$$
\mathrm{R}=\mathrm{H}, \mathrm{CH}_{3}, \mathrm{C}_{4} \mathrm{H}_{7}
$$

Scheme 2. Reactivities of Frustrated Lewis Pairs

\section{Frustrated Lewis Pair Structure}

The reactivity of FLPs is highly dependent upon the structure of the adduct and whether classical Lewis adducts are possible. For example, the bridge between the donor and acceptor as well as Lewis acidity and basicity can be tuned by choice of substituent. These structural and electronic modifications can then lead to an observable change in overall structure. Possible structures achieved by these variations in the bridge include head-to-tail dimers (Figure 1a), a polymeric chain (Figure 1b), strong intramolecular "closed" interactions between the phosphorus and boron (Figure 1c), and weak "open" interactions between phosphorus and boron (Figure 1d). ${ }^{10}$ 


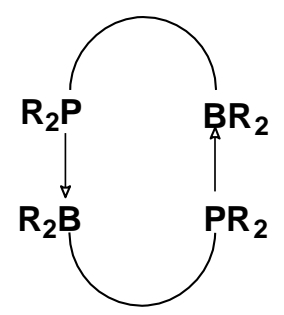

a.

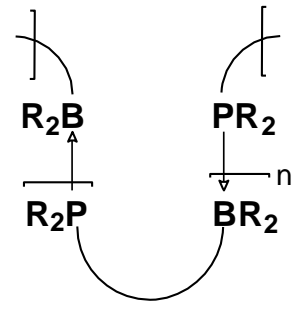

b.

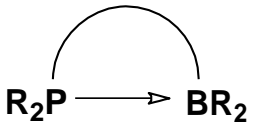

c.

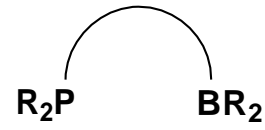

d.

Figure 1. Possible structures of phosphino-boranes

The identities of each structure are obtained most often with NMR spectroscopy. The ${ }^{31} \mathrm{P}(I=1 / 2)$ and ${ }^{11} \mathrm{~B}(I=3 / 2)$ nuclei are both NMR active and are routinely used in structure identification. For example, an upfield shift in ${ }^{11} \mathrm{~B}$ NMR and a ${ }^{1} \mathrm{~J}_{\mathrm{PB}}$ coupling constant of $55.4 \mathrm{~Hz}$ indicates a $\mathrm{P}-\mathrm{B}$ interaction, as seen in Figure 2a. Typical ranges for this coupling are 40-150 Hz. ${ }^{11}$ A short methylene bridge between the phosphine and borane helps eliminate intramolecular interactions by avoiding the strained three-membered ring (Figure 2). Compound $2 \mathbf{b}$ disfavors intermolecular $\mathrm{P}-\mathrm{B}$ interactions due to the lowered strength of the boron Lewis acidity from the donating substituents on the nitrogen, allowing for a monomeric structure. ${ }^{12}$ By making the boron less acidic, its interactions with the phosphorus become less favorable.



$\mathrm{Me}_{2} \mathrm{~B} \smile \mathrm{PMe}_{2}$

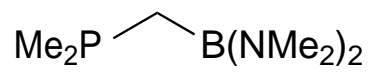

b.

b $\quad 31.0$

$-48.8$

Figure 2. Stuctures of $\mathrm{C}_{1}$ linkers and their ${ }^{31} \mathrm{P}$ and ${ }^{11} \mathrm{~B} \mathrm{NMR}$ data 
The ethylene-bridged species also exhibits varying structure types. The donating pinacol group on boron (Figure 3a) has lowered the boron Lewis acidity, which make it less favorable to form a classical Lewis adduct. The X-ray structure shows a trigonal planar environment around the boron and a distance between the phosphorus and boron atoms of $4.231(2) \AA .{ }^{14}$ The expected distance between the two atoms is around 2.0-2.2 $\mathrm{A}$, indicating the lack of interaction between phosphorus and boron in this structure type. When the boron is equipped with an electron withdrawing substituent, such as pentafluorophenyl (Figure $3 \mathbf{b}$ ), an upfield shift of the ${ }^{11} \mathrm{~B}$ and a downfield shift in the ${ }^{31} \mathrm{P}$ NMR occurs, indicating a P-B interaction. Although an X-ray structure was unable to be obtained for this complex, the DFT-calculated structure predicted the P-B distance to be $2.21 \AA$, which is very close to the expected $2.0-2.2 \AA{ }^{15}$ The room temperature NMR data of $3 \mathbf{c}$ indicated that both the boron and phosphorus signals were within the ranges expected for each element to be three-coordinate. The broadening present in the phosphorus and boron resonances indicated possible fluxional $\mathrm{P}-\mathrm{B}$ interactions. Indeed, the $\mathrm{X}$-ray structure showed an infinite link of polymeric chains with a P-B distance of $2.056(2) \AA$ and a geometry about the boron that is not trigonal planar, but pyramidalized. ${ }^{16}$

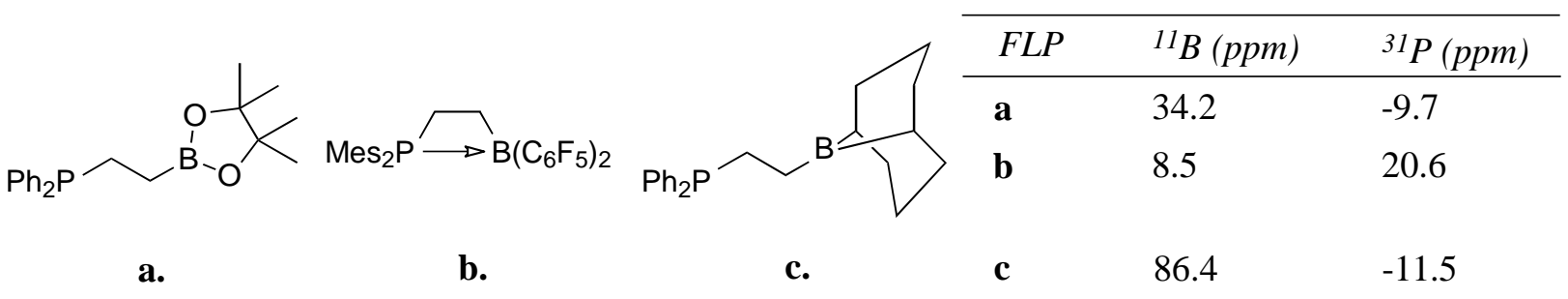

Figure 3. $\mathrm{C}_{2}$ ethenyl-linked phosphino-borane ${ }^{31} \mathrm{P}$ and ${ }^{11} \mathrm{~B}$ NMR data 
FLPs with 3C or 4C alkane linkers have been found to form intramolecular, closed interactions (Figure 4a-b) as the five- and six-membered rings have less ring strain. Interestingly enough, the X-ray structure of $4 \mathbf{b}$ shows a shorter P-B distance (2.092(7) $\AA$ vs. $2.21 \AA$ respectively) when compared to the corresponding $2 \mathrm{C}$ linker compound (Figure $3 \mathbf{b}$ ). This indicates that the linker between the $\mathrm{P}$ and $\mathrm{B}$ plays an important role in the degree of interactions between the two atoms. As the chain length increases (Figure 4c), the likelihood of interactions becomes greater as the ring strain lessens.

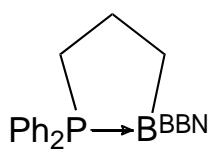

a.

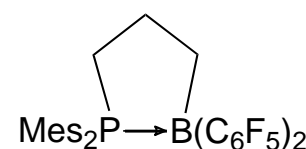

b.

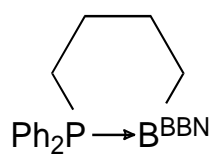

c.

\begin{tabular}{lll}
\hline FLP & ${ }^{11} B(\mathrm{ppm})$ & ${ }^{31} \mathrm{P}(\mathrm{ppm})$ \\
\hline $\mathbf{a}$ & 0.0 & 10.3 \\
$\mathbf{b}$ & -2.7 & 20.8
\end{tabular}

c $-5.0$ $-1.8$

Figure 4. $\mathrm{C}_{3}$ and $\mathrm{C}_{4}$ linker phosphino-borane ${ }^{31} \mathrm{P}$ and ${ }^{11} \mathrm{~B}$ NMR data

The structure of the FLP allows for variation in substitution patterns which ultimately leads to differences in the phosphine-borane interactions. The length of the bridge and the size of the substituents on the acid and base pair can also be modified to prohibit the interaction between the two atoms and prevent the formation of a traditional adduct. By adjusting the strength of donating/accepting abilities of the respective base/acid, the interactions between the $\mathrm{P}$ and $\mathrm{B}$ atoms can be strengthened or blocked entirely. 


\section{Coordination Chemistry of Frustrated Lewis Pairs}

Transition metal coordinated FLPs are also being explored as a possible route for new catalytic activity. There are four main binding modes for the transition metal coordinated FLPs, which are illustrated using phosphino-boranes in Figure 5.



A

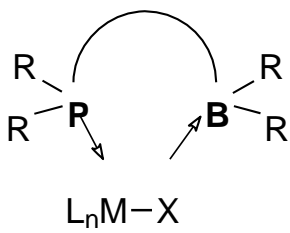

B

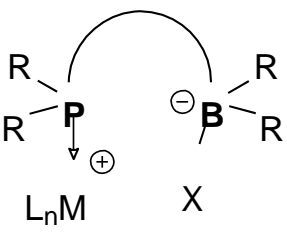

C

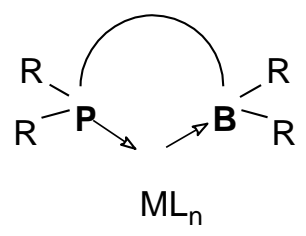

D

Figure 5. Four coordination modes of phosphino-boranes with transition metals

When Braunschweig described the synthesis of coordinated phosphino-borane metalcarbonyl complexes, the coordination mode $\mathbf{A}$ was identified as the predominant structure (Scheme 3). ${ }^{18}$ As can be seen in the structure, the donating amino groups and short linker between the phosphorus and boron prevent coordination of the boron to the metal. The ${ }^{31} \mathrm{P}$ NMR resonance shifted by $\sim 100 \mathrm{ppm}$ while the ${ }^{11} \mathrm{~B}$ NMR resonance remained unchanged upon coordination. In addition to NMR spectroscopic evidence, carbonyl infrared stretching frequencies for boron-free $\mathrm{PMe}_{3}$ complexes were found to be very similar to those found on the phosphino-borane coordinated complexes found in Scheme 3. This was further evidence that the phosphorus atom was coordinated to the metal center and little interaction was observed with the boron atom. 


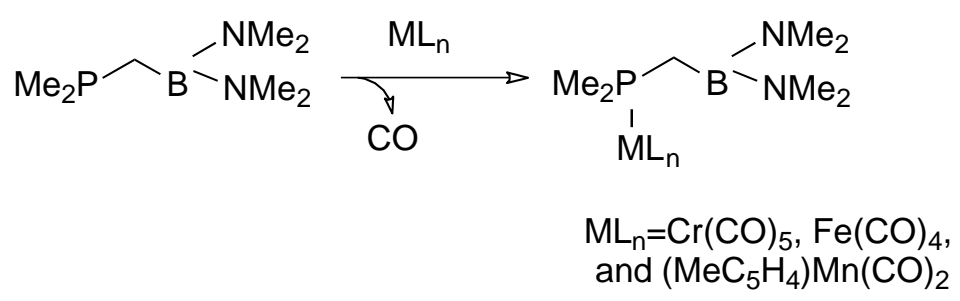

Scheme 3. Coordination mode A of phosphino-borane

In 2009, Bourissou reported a complex with coordination mode B (Scheme 4). ${ }^{19}$ In this work, the $i-\mathrm{Pr}_{2} \mathrm{P}-o\left(\mathrm{C}_{6} \mathrm{H}_{4}\right)-\mathrm{BCy} 2$ ligand was shown to exhibit a $\mu^{2}$-chloride bridged palladiumborane complex. The ${ }^{31} \mathrm{P}$ resonance of the ligand shifted from 7.6 to $39.2 \mathrm{ppm}$, suggestive to phosphorus atom coordination. The ${ }^{11} \mathrm{~B}$ NMR resonance at $\partial=47 \mathrm{ppm}$ was shielded in comparison to the ligand $(\partial=76 \mathrm{ppm})$ and still higher in frequency than that expected with a $\mathrm{B}-$ $\mathrm{Cl}(\partial=\sim 20 \mathrm{ppm})$. Due to this, the bridging mode was suspected. The X-ray structure of this complex showed a short interaction between boron and chlorine $(2.165(2) \AA)$ and also a pyramidalization around the boron, further supporting the bridging mode as the correct structure.

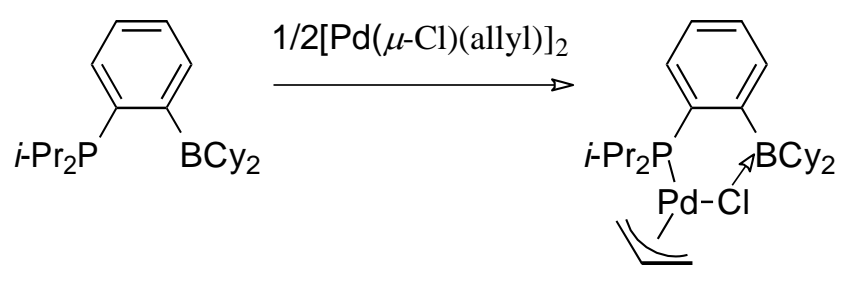

Scheme 4. Coordination mode $\mathbf{B}$ of phosphino-borane

When Tilley treated $\left[\mathrm{NiMe}_{2}(\mathrm{dmpe})\right](\mathrm{dmpe}=1,2$-bis(dimethylphosphino)ethane) with the $\mathrm{CH}_{2} \mathrm{CH}_{2}$-bridged phosphino-borane ligand, he observed coordination mode $\mathbf{C}$. He found that the ambiphilic ligand coordinated to the nickel center through the phosphorus to generate the corresponding zwitterionic nickel complex. (Scheme 5). ${ }^{16}$ The X-ray structure of the complex showed the retention of the square planar geometry around the $\mathrm{Ni}$ (II) center and no interaction of 
the methyl group on the boron with the metal. The ${ }^{11} \mathrm{~B}$ resonance $\partial=-15 \mathrm{ppm}$ was in the range of a typical tetraalkylborate.

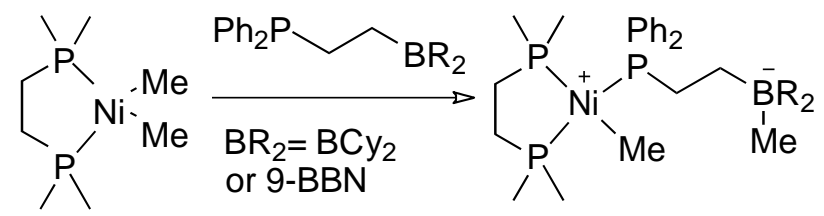

Scheme 5. Coordination mode $\mathbf{C}$ of phosphino-borane

The last example of coordination modes comes from another publication by Bourissou. In 2010, coordination mode D was observed when he used a gold system to determine if metalborane coordination could occur with only one phosphorus donor in the structure. ${ }^{20}$ The idea was to use the linear geometry of a general $\mathrm{LAuCl}$ complex to prevent $\mu^{2}$-chloride bridged palladiumborane complex formation previously seen with other metals. Complexes $6 \mathbf{a}^{\prime}\left(\mathrm{BR}_{2}=\mathrm{BCy}_{2}\right)$ and $6 \mathbf{b}^{\prime}\left(\mathrm{BR}_{2}=\mathrm{BFlu}=9\right.$-borafluorenyl $)$ in Scheme 6 were characterized by X-ray diffraction. The Au-B distance in complex 6a' (2.903(6) $\mathrm{A})$ was longer than the expected covalent radii $(2.20 \AA)$. However, with the addition of more electrophilic and less sterically demanding substituents as shown in $6 \mathbf{b}^{\prime}$ gave a significantly shorter $\mathrm{Au}-\mathrm{B}$ distance $(2.663(8) \AA)$. The upfield shift of ${ }^{11} \mathrm{~B}$ NMR resonance from 75 to $55 \mathrm{ppm}$ for $\mathbf{a}$ ' to $\mathbf{b}$ ' indicates a stronger $\mathrm{Au}-\mathrm{B}$ interaction when using a more electrophilic boron. 


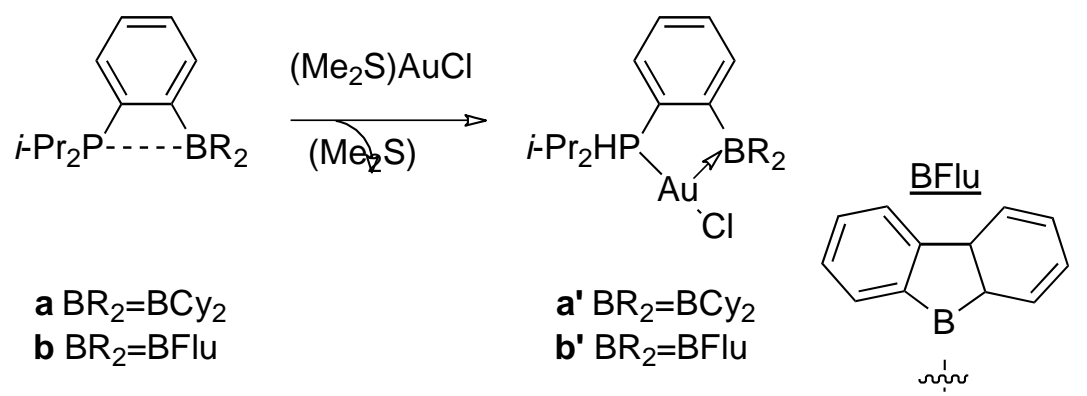

Scheme 6. Coordination mode $\mathbf{D}$ of phosphino-borane

\section{Frustrated Lewis Pair Reactivity}

In continuation of the work with $\mathrm{H}_{2}$ activation, hydrogenations using FLPs were explored further as more researchers became interested in the area. Substrates for hydrogenations have been expanded to now include imines, olefins, alkynes, aromatics, ketones and aldehydes. ${ }^{21}$ Some select examples of hydrogenation substrates and products are shown in Figure $6 .{ }^{22}$ The carbonyl groups were initially thought to be harder to reduce because of the oxophilicity of boron, but when performed in ethereal solvents at lower temperatures, hydrogenations of ketones and aldehydes became possible. ${ }^{22, f}$ In the case of some aromatic substrates, like acetophenone N-phenylimine found in Figure 6, some degree of selectivity was achieved when it was observed that the distal arene bound to the iminyl carbon were unreactive to hydrogenation and remained unchanged. ${ }^{21}$ 


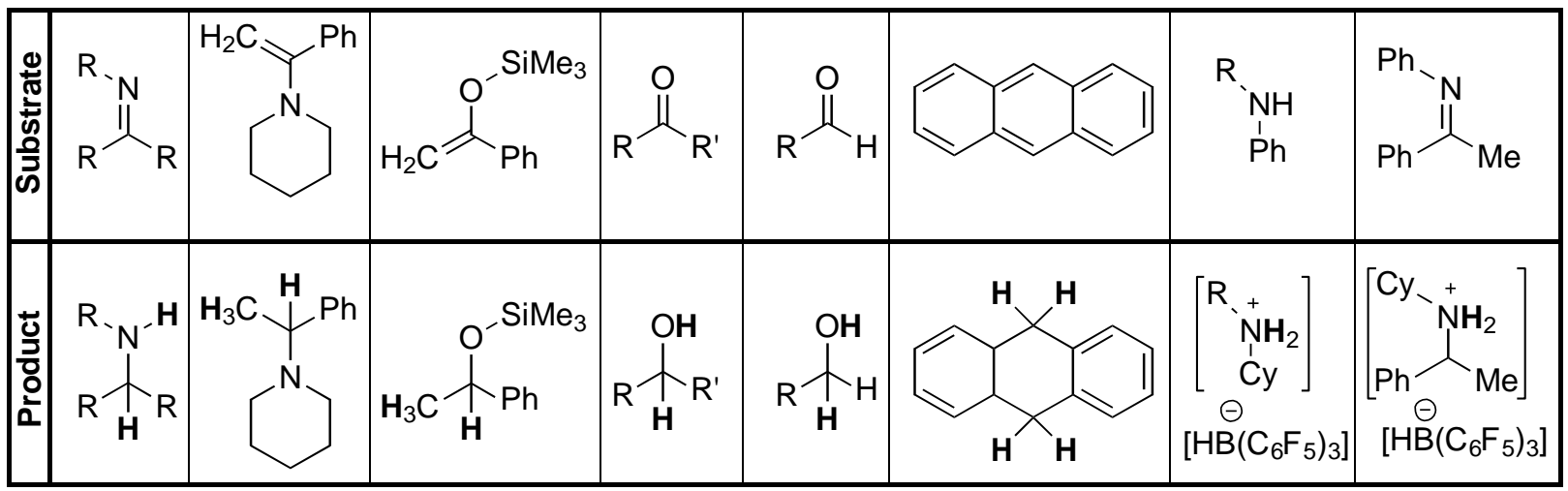

Figure 6. FLP hydrogenation examples

Hydrogenations by FLPs have also been achieved asymmetrically with a variety of catalysts (Figure 7). Klankermayer was the first to demonstrate asymmetric hydrogenations, although with only a $13 \%$ enantiomeric excess (ee) (Scheme 7a). ${ }^{23}$ Klankermayer was able to improve to $>80 \%$ ee with an $\alpha$-pinene catalyst derivative ${ }^{24}$ and achieve $70 \%$ ee with a phosphino-borane catalyst (Figure 7b). ${ }^{25}$ The Repo group was able to hydrogenate imines and achieve 99\% ee with a nitrogen-borane FLP containing a binaphthyl backbone (Scheme 7c). ${ }^{26}$ The reactivity of FLPs has also been utilized in the capture of other small molecules. The electrophiles able to react with FLPs have included $\mathrm{CO}_{2}, \mathrm{~N}_{2} \mathrm{O}, \mathrm{NO}$, and $\mathrm{SO}_{2}$ (Figure 8). ${ }^{27-30}$
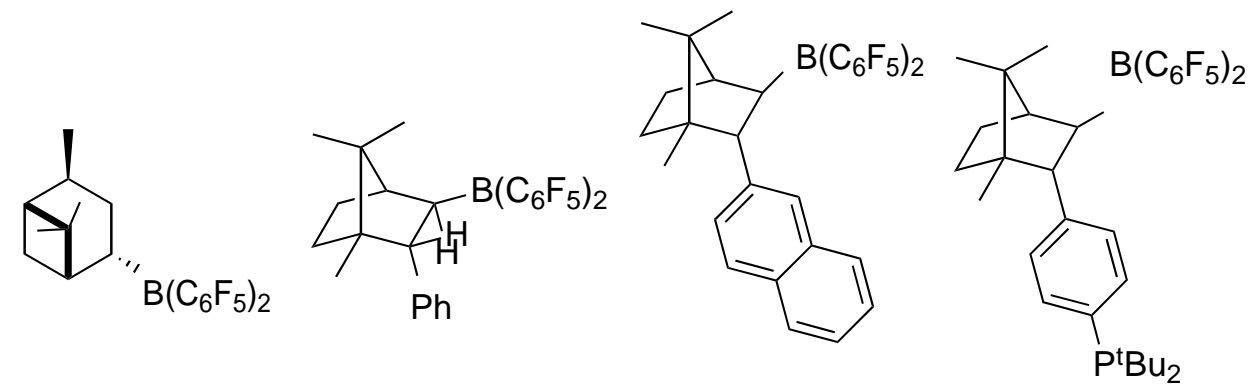<smiles>FC(F)(F)c1ccc2ccccc2c1-c1c(-c2cccc3ccccc23)ccc2ccccc12</smiles>

Figure 7. Asymmetric hydrogenation catalysts 


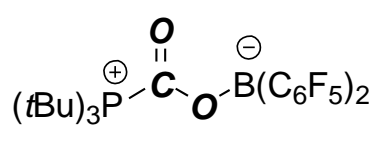

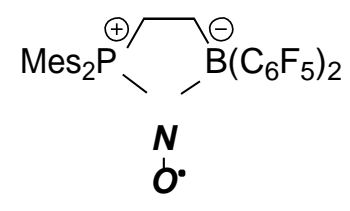

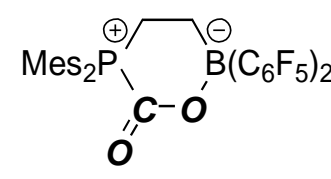

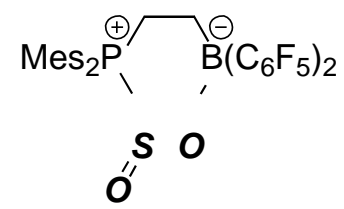

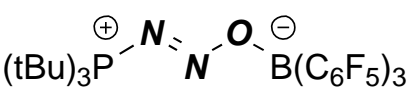

$\oplus_{-}^{\mathcal{S}}, \mathrm{B}(\mathrm{C} F)$

$(t \mathrm{Bu})_{3} \mathrm{P} \quad \mathrm{O} \quad 6 \quad 52$

Figure 8. FLP small molecule capture products of $\mathrm{CO}_{2}, \mathrm{~N}_{2} \mathrm{O}, \mathrm{NO}$, and $\mathrm{SO}_{2}$ using the corresponding phosphino-borane

A novel FLP catalytic system to activate $\mathrm{H}_{2}$ incorporates the use of N-heterocyclic carbenes and three-coordinate borenium cations (Scheme 8). ${ }^{31}$ Although the optimized system achieved turn over number of $\sim 1000 \mathrm{~h}^{-1}$, this still did not compare to the reactivity achieved by metal-based systems.

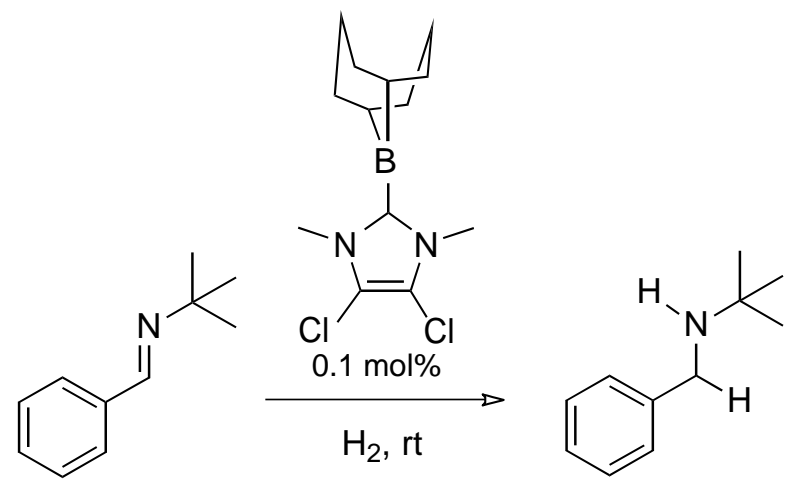

Scheme 8. FLP catalytic system with TON of $\sim 1000 \mathrm{~h}^{-1}$

When coordinated to metals, frustrated Lewis pairs have also been shown to participate in different reactivity with non-ligated counterparts. Examples of select reactivity are shown in Scheme 9. The Lewis acidic aluminum portion of $\mathrm{Cp} * \mathrm{RhMe}_{2} \mathrm{PAl}$ complex was found to conduct a methyl abstraction from the metal center, forming a zwitterionic complex. ${ }^{34}$ More examples of 
FLP metal coordinated complexes include the activation of dihydrogen and $\mathrm{X}-\mathrm{H}$ bonds, where 
$\mathrm{X}=\mathrm{OH}, \mathrm{OMe}$, and $\left(p-\mathrm{NO}_{2} \mathrm{C}_{6} \mathrm{H}_{4}\right) \mathrm{NH}^{35}$ A phosphino-borane ligand coordinated ruthenium complex was found to form dihydride complexes and dihydrogen complexes when protonated with $\mathrm{HBF}_{4}{ }^{36}$ The field of the FLP coordinated metal systems continues to be studied but the scope of the its reactivity has yet to be fully explored.

a.

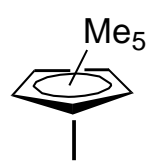<smiles>CCP(C)C</smiles><smiles>CO[AlH]C</smiles>
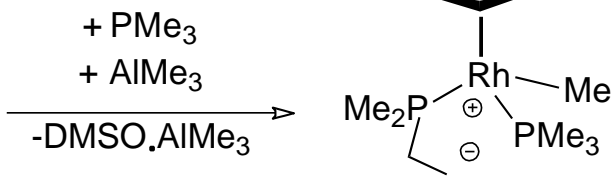

$\mathrm{Me}{ }_{\mathrm{Me}}^{\mathrm{Al}^{-} \mathrm{Me}}$

b.

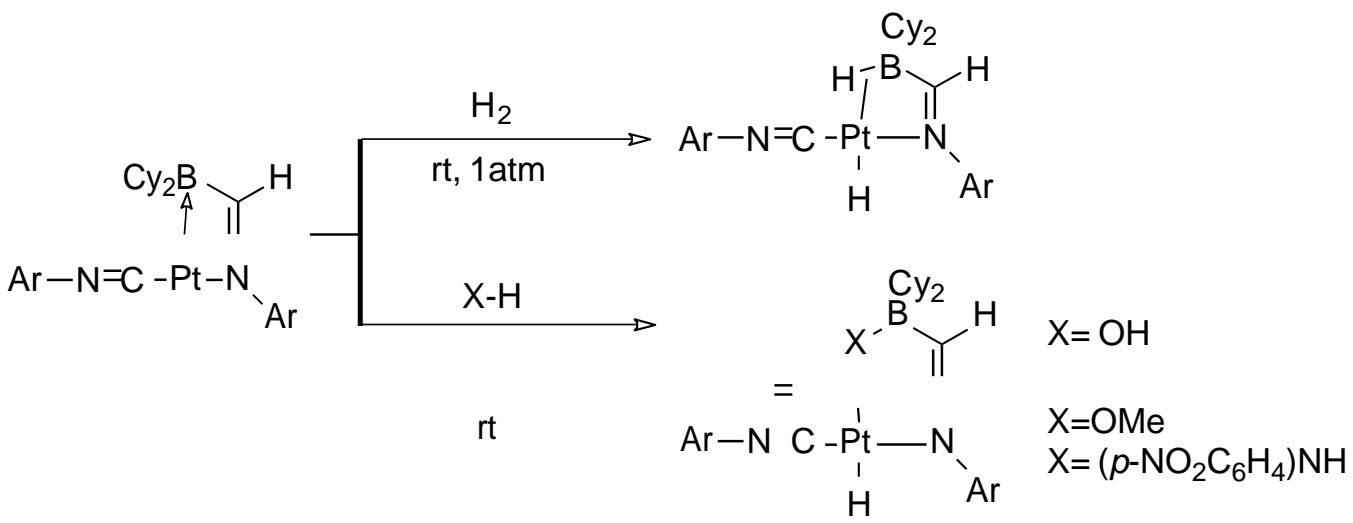

c.

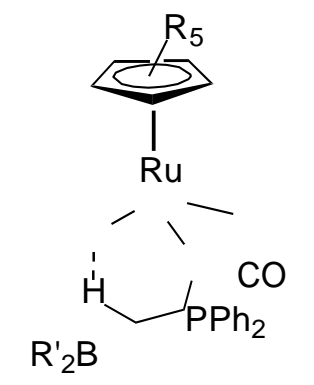

1. $\mathrm{R}=\mathrm{H}, \mathrm{R}^{\prime}=9-\mathrm{BBN}$

2. $\mathrm{R}=\mathrm{H}, \mathrm{R}^{\prime}=\mathrm{C}_{6} \mathrm{~F}_{5}$

3. $\mathrm{R}=\mathrm{CH}_{3}, \mathrm{R}^{\prime}=\mathrm{C}_{6} \mathrm{~F}_{5}$

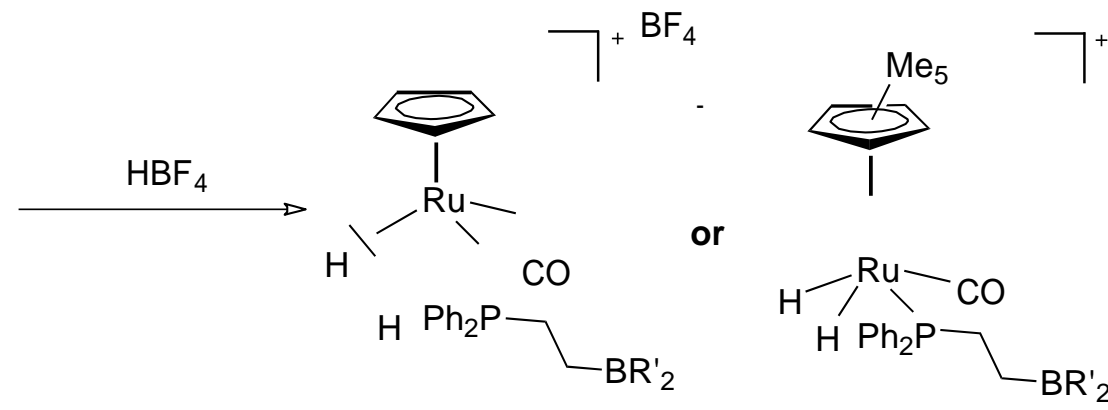

4. $R^{\prime}=9-B B N$

5. $\mathrm{R}^{\prime}=\mathrm{C}_{6} \mathrm{~F}_{5}$
6. $\mathrm{R}^{\prime}=\mathrm{C}_{6} \mathrm{~F}_{5}$

Scheme 9. Examples of metal coordinated FLP reactivity. a.) Rhodium P/Al ligand methyl abstraction at metal center b.) Platinum with an N/B ligand activating $\mathrm{H}_{2}$ and $\mathrm{X}-\mathrm{H}$ bonds c.) Ruthenium hydride $\mathrm{P} / \mathrm{B}$ complex protonated and formed dihydrogen(4-5) or dihydride 
complexes(6) 


\section{$\underline{\text { Results/Discussion }}$}

The interest in researching the uses of FLPs reactivity is still a growing field in organometallics, in which many researchers find interest. Frustrated Lewis pairs have demonstrated that they can be used to achieve certain reactivity with small molecules, but this recent application of frustrated Lewis pairs has yet to be fully explored. Group IX rhodium and iridium complexes have an established history of useful catalysis and thus became a starting point for new reactivity using the frustrated Lewis pairs as a ligand framework. Reactivity of FLPs ligated to metals has been reported; however, there is still opportunity to investigate these systems to establish their properties and behavior. Understanding behavior of FLPs will aide in the exploration of new catalyst systems.

The synthesis of an iridium pentamethylcyclopentadiene complex was the first to be investigated. The $\left[\mathrm{Cp}^{*} \mathrm{IrCl}_{2}\right]_{2}$ dimer was treated with a previously synthesized phosphino-borane (PB) ligand in acetonitrile at room temperature to afford $\mathrm{Cp}^{*} \mathrm{IrCl}_{2} \mathrm{Ph}_{2} \mathrm{PCH}_{2} \mathrm{CH}_{2}\left(\mathrm{~B}^{\mathrm{BBN}}\right)\left(\mathrm{B}^{\mathrm{BBN}}=9\right.$ Borabicyclo[3.3.1]nonane) (Scheme 9). The free PB ligand showed a ${ }^{31} \mathrm{P}$ NMR singlet at -11 ppm compared to the $0 \mathrm{ppm}$ resonance on the iridium coordinated complex (Figure 9-10). The

shift in ${ }^{31} \mathrm{P}$ NMR resonance agrees with a change in structure, indicating a coordination of the ligand through the phosphorus atom. 


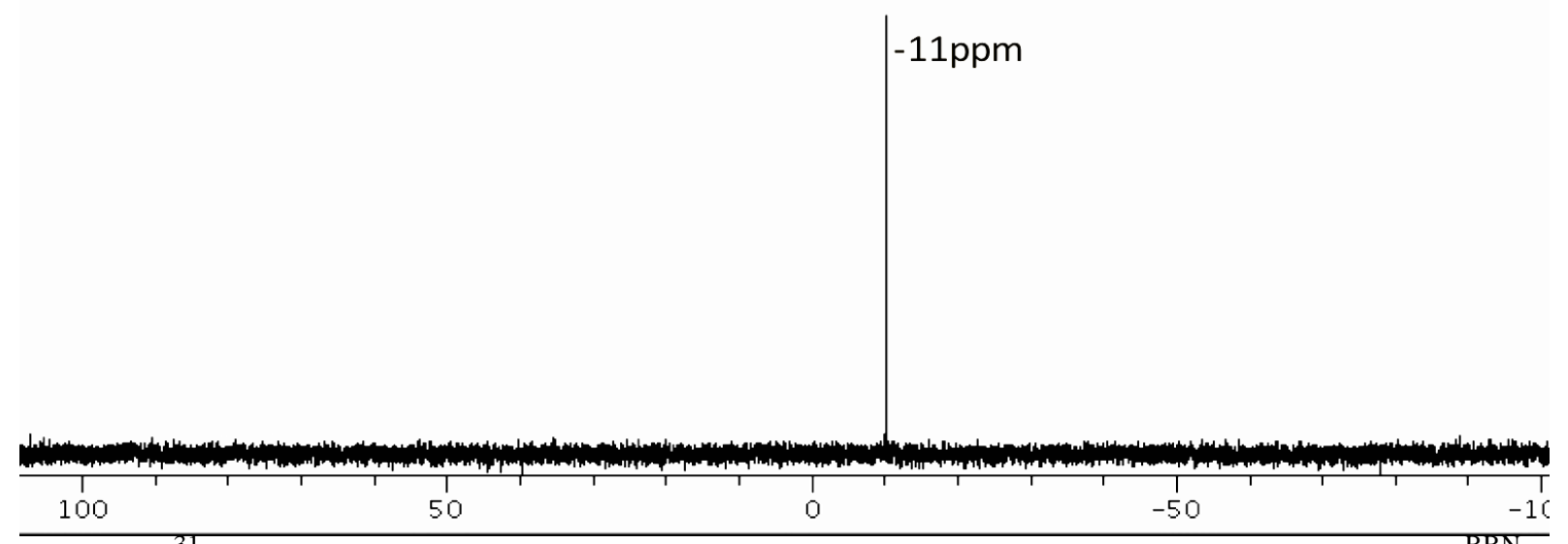

Figure 9. ${ }^{31} \mathrm{P}$ NMR of free phosphino-borane frustrated Lewis pair ligand $\mathrm{Ph}_{2} \mathrm{PCH}_{2} \mathrm{CH}_{2}\left(\mathrm{~B}^{\mathrm{BBN}}\right)$

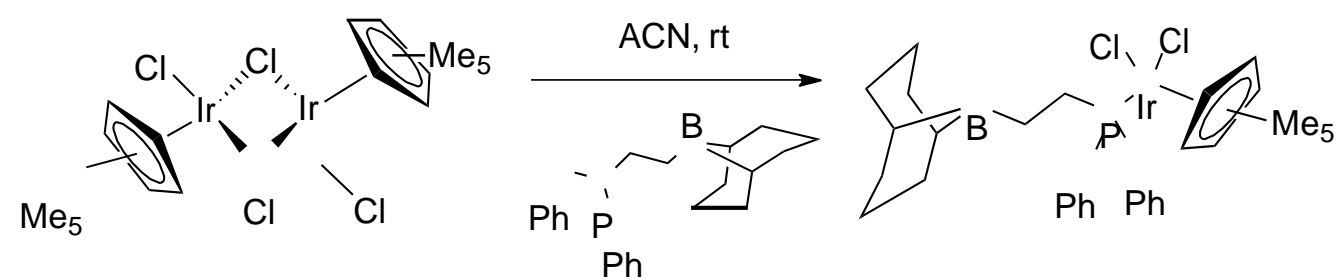

Scheme 10. Synthesis of $\left[\mathrm{Cp} * \mathrm{IrCl}_{2} \mathrm{~PB}\right]\left(\mathrm{PB}=\mathrm{Ph}_{2} \mathrm{PCH}_{2} \mathrm{CH}_{2}\left(\mathrm{~B}^{\mathrm{BBN}}\right)\right)$ complex

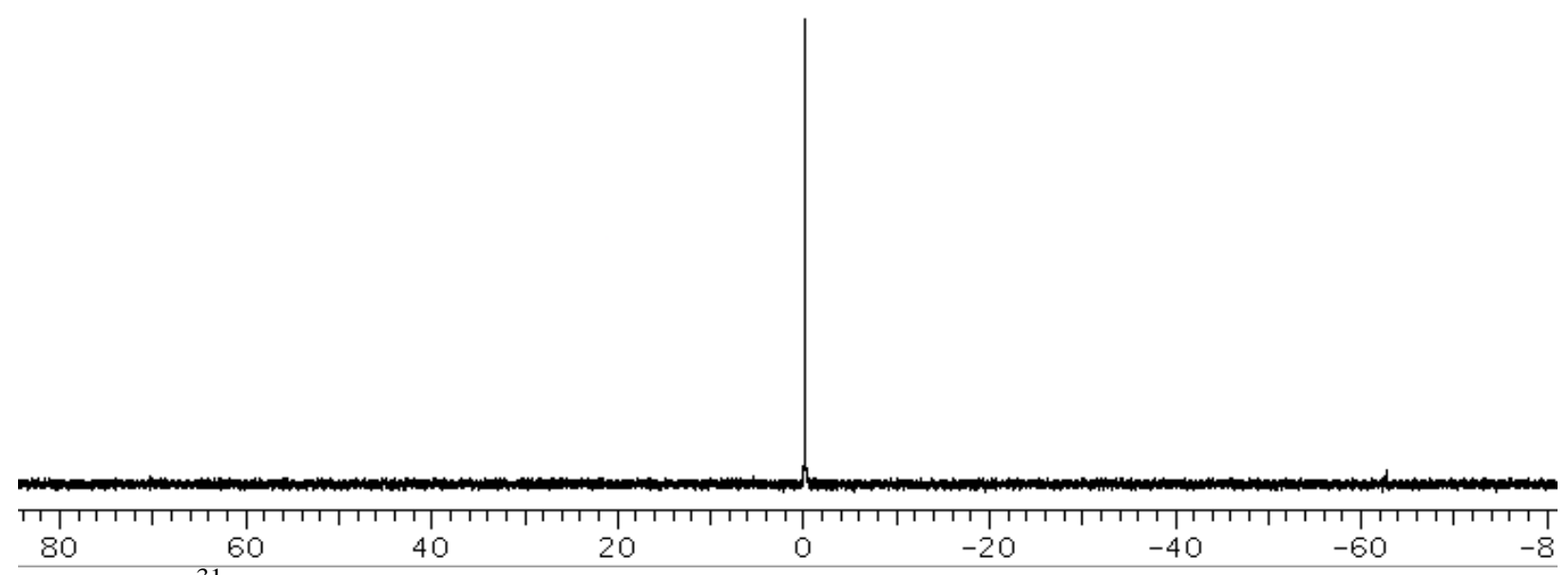

Figure 10. ${ }^{31} \mathrm{P}$ NMR of $\left[\mathrm{Cp}^{*} \mathrm{IrCl}_{2} \mathrm{~PB}\right]$

The initial efforts in reactivity included treating the $\mathrm{Cp}^{*} \operatorname{IrCl}_{2} \mathrm{~PB}$ complex with an equivalent of silver acetate (AgOAc) (Scheme 10). The ${ }^{31} \mathrm{P}$ NMR showed an upfield shift in resonance to $-65 \mathrm{ppm}$ (Figure 11). ESI-MS results indicated a loss in the $\mathrm{B}^{\mathrm{BBN}}$ fragment (Figure 
12a-b). The mass of the $\mathrm{Cp}^{*} \operatorname{IrCl}_{2} \mathrm{~PB}$ formula is expected to be 732.22 amu while the observed mass was $577.139 \mathrm{amu}$, indicating a change in structure that was found to agree with the loss of the $\mathrm{B}^{\mathrm{BBN}}$ fragment.



Scheme 11. $\mathrm{Cp}^{*} \mathrm{IrCl}_{2} \mathrm{~PB}$ reaction with $\mathrm{AgOAc}$ that resulted in a new complex

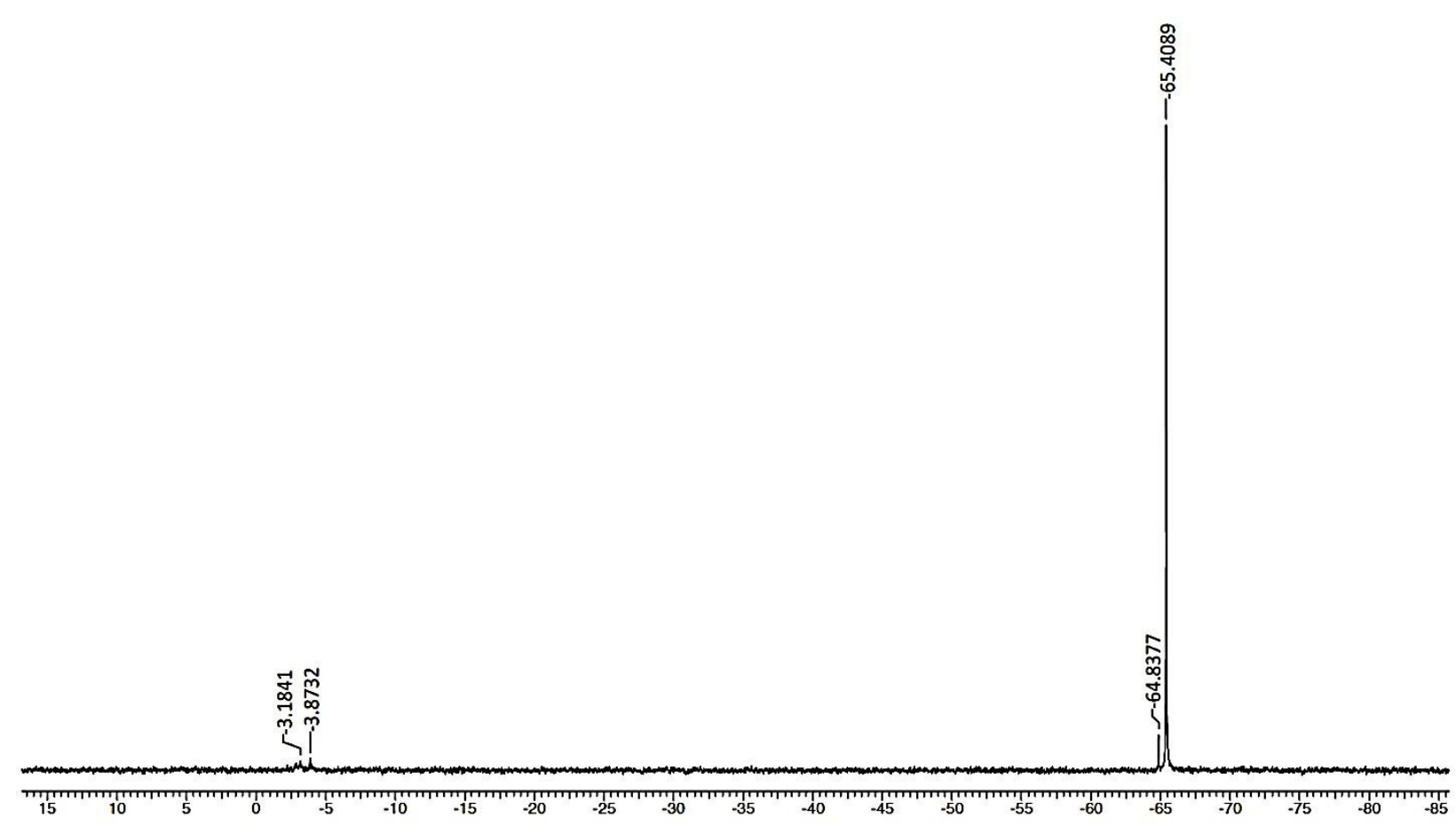

Figure 11. ${ }^{31} \mathrm{P}$ NMR spectrum for $\mathrm{Cp} * \mathrm{IrCl}_{2} \mathrm{~PB}$ treated with $\mathrm{AgOAc}$ 


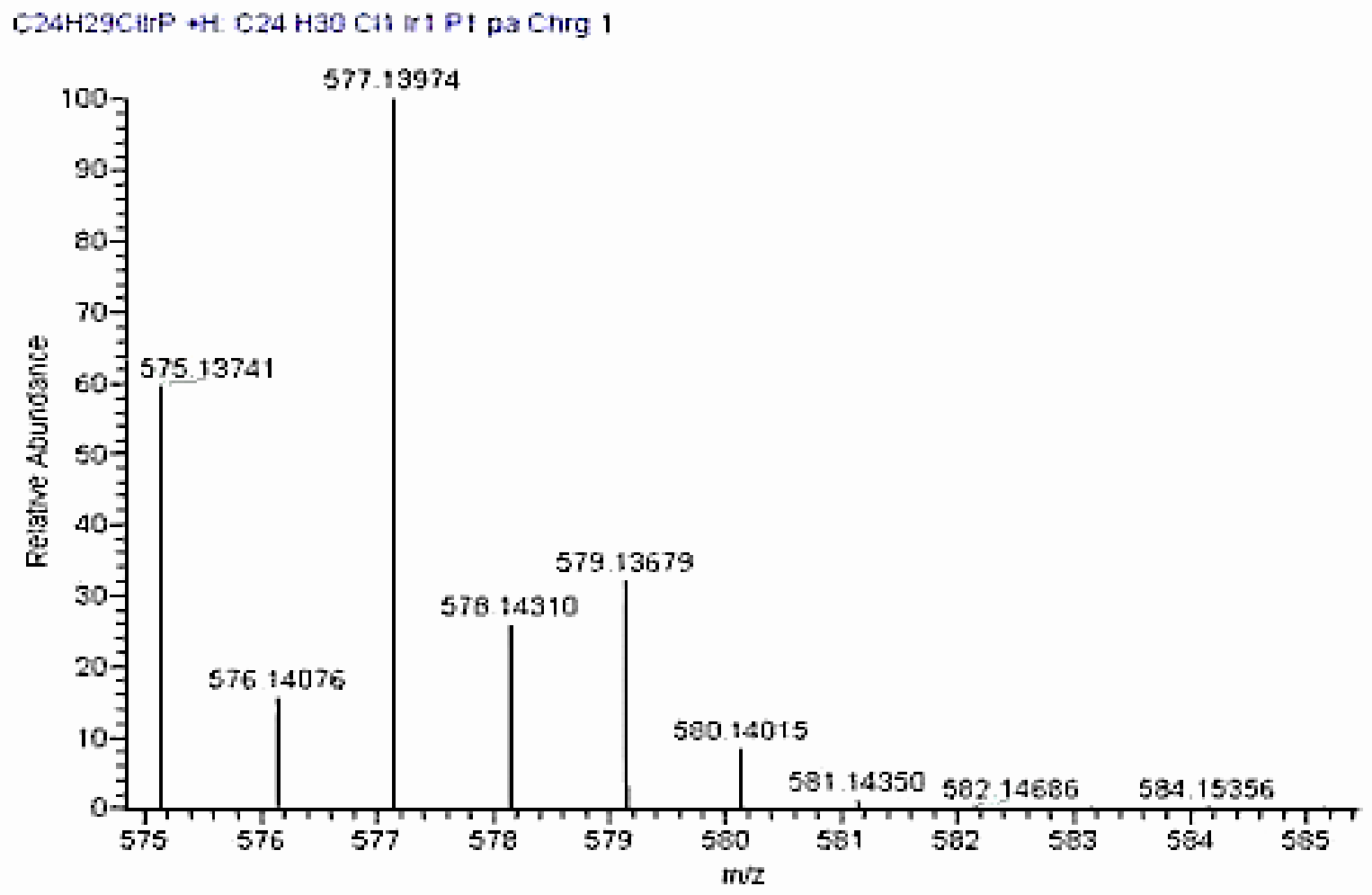

Figure 12a. Simulated HRMS of $\mathrm{Cp}^{*} \mathrm{IrCl}_{2} \mathrm{PPh}_{2} \mathrm{CH}_{2} \mathrm{CH}_{2}$ metallacycle. Expected mass= $576.132483 \mathrm{amu}$

T: FTMS + p ES I Full ms [50 00-1000 00]



Figure 12b. Experimental HRMS of $\mathrm{Cp}^{*} \mathrm{IrCl}_{2} \mathrm{PPh}_{2} \mathrm{CH}_{2} \mathrm{CH}_{2}$. Expected mass $=576.132483 \mathrm{amu}$ 
A series of NMR experiments helped to characterize the final structure of the resulting complex. Upon treatment with $\mathrm{AgOAc}$, the product was determined to be a four-membered metallacycle. The ${ }^{1} \mathrm{H}$ NMR showed complex splitting patterns present for each of the methylene protons on the metallacycle due to coupling with each of the other methylene protons and the phosphorus. Phosphorus was proven to still be present and part of the metallacycle as the ${ }^{1} \mathrm{H}\left\{{ }^{31} \mathrm{P}\right\}$ decoupling experiments showed a less complex splitting pattern for the methylene proton resonances. The spin system of the diastereotopic methylene protons of the metallacycle was identified with 1D TOCSY (Figure 13). As one proton is irradiated, only protons which coupled to the irradiated one will be shown as seen in Figure 13a. A reference ${ }^{1} \mathrm{H}$ spectrum is shown in Figure 13b.

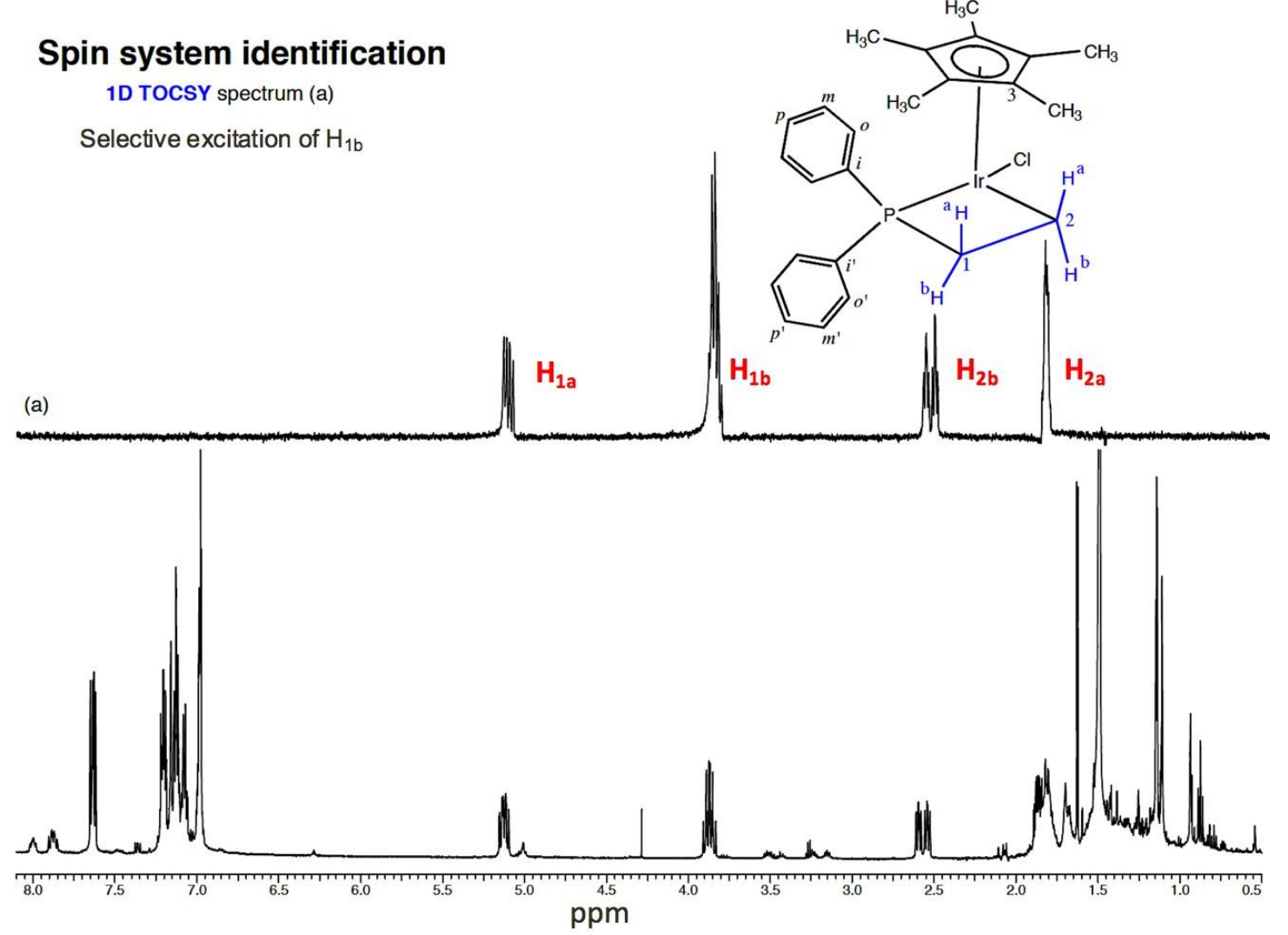

Figure 13. 1D TOCSY experiment of $\mathrm{Cp}^{*} \mathrm{IrCl}_{2} \mathrm{PPh}_{2} \mathrm{CH}_{2} \mathrm{CH}_{2}$. 
Further analysis of the complex splitting patterns revealed a doublet of doublet of doublet of doublets, and the coupling constants for each proton are shown in Figure 14. The ${ }^{1} \mathrm{H}\left\{{ }^{31} \mathrm{P}\right\}$ decoupled experiment showed a simplification in coupling patterns for the methylene protons of the metallacycle in comparison to a reference proton spectrum below (Figure 15).

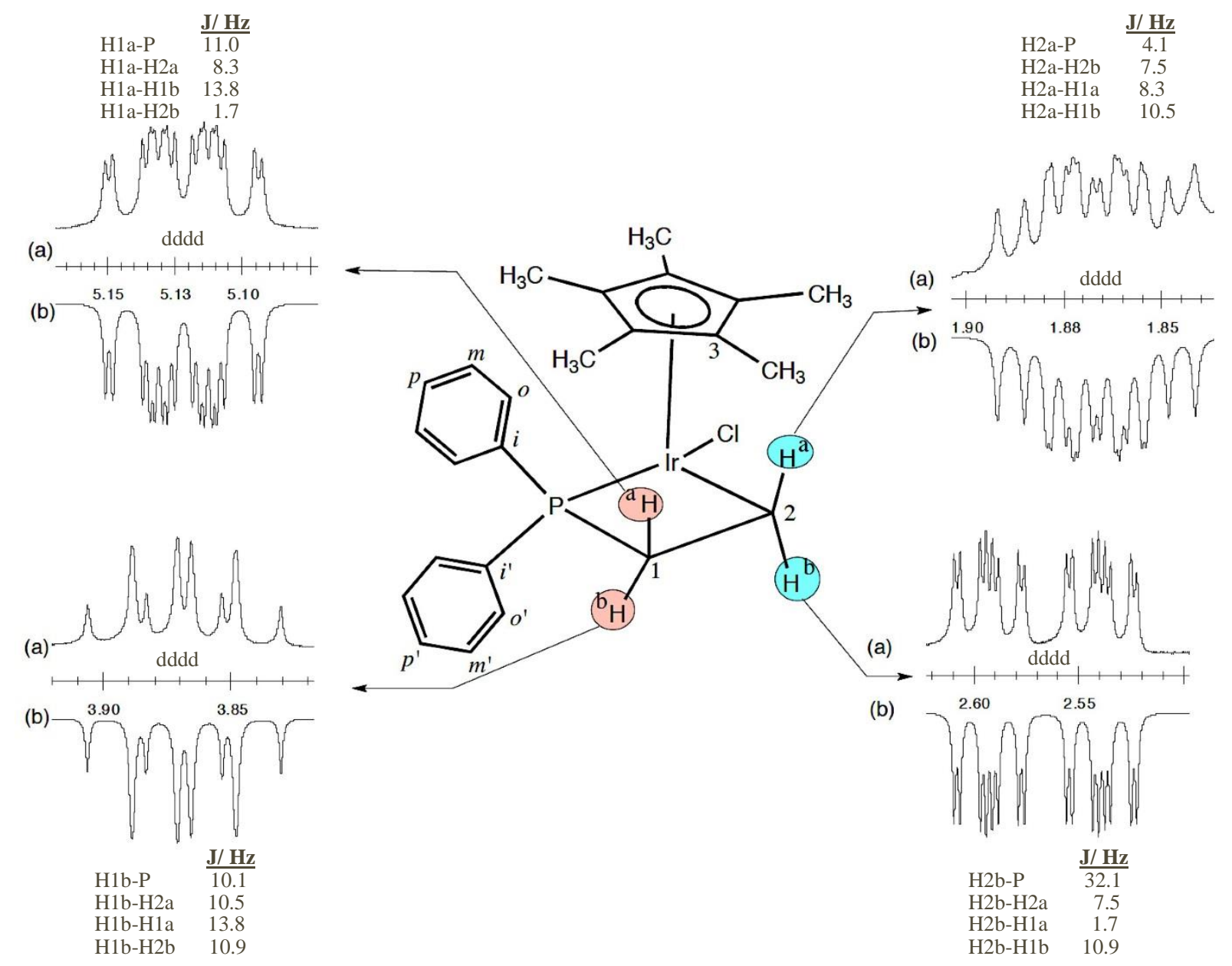

Figure 14. Simulated (b) vs. experimental (a) splitting patterns of methylene protons of iridium metallacycle and coupling constants between each nuclei 


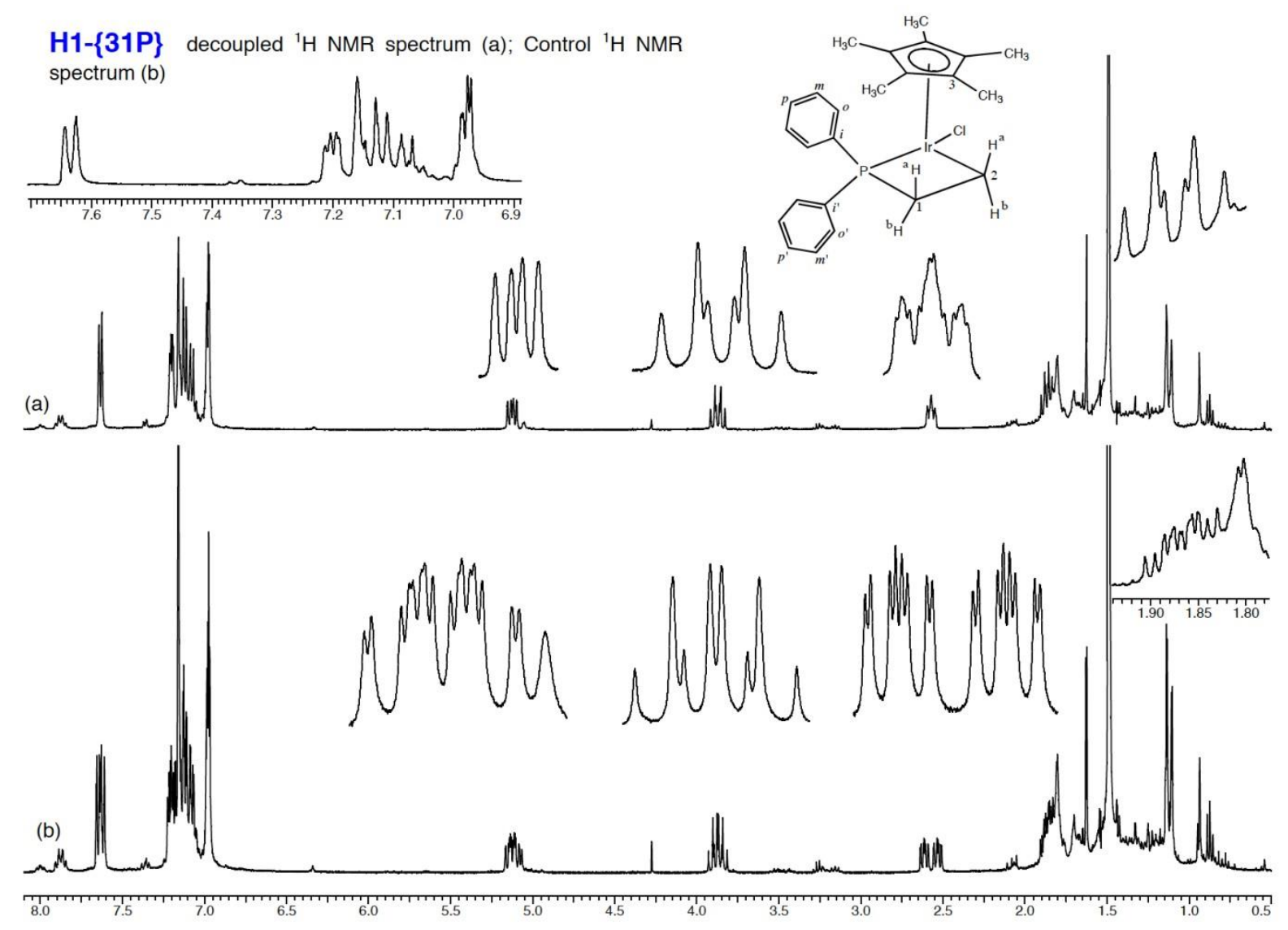

Figure 15. ${ }^{31} \mathrm{P}$ NMR $\left.\mathrm{Cp}^{*} \mathrm{IrCl}_{2} \mathrm{Ph}_{2} \mathrm{PCH}_{2} \mathrm{CH}_{2} \mathrm{~B}^{\mathrm{BBN}}\right)+1$ eq. $\mathrm{AgOAc}$

The correlations between the methylene protons are shown again in an expanded portion of a gCOSY spectrum. These through-bond couplings are in agreement with the correlations seen in the TOCSY spectrum as each of the methylene protons of the metallacycle are found to correlate with each other (Figure 16). 


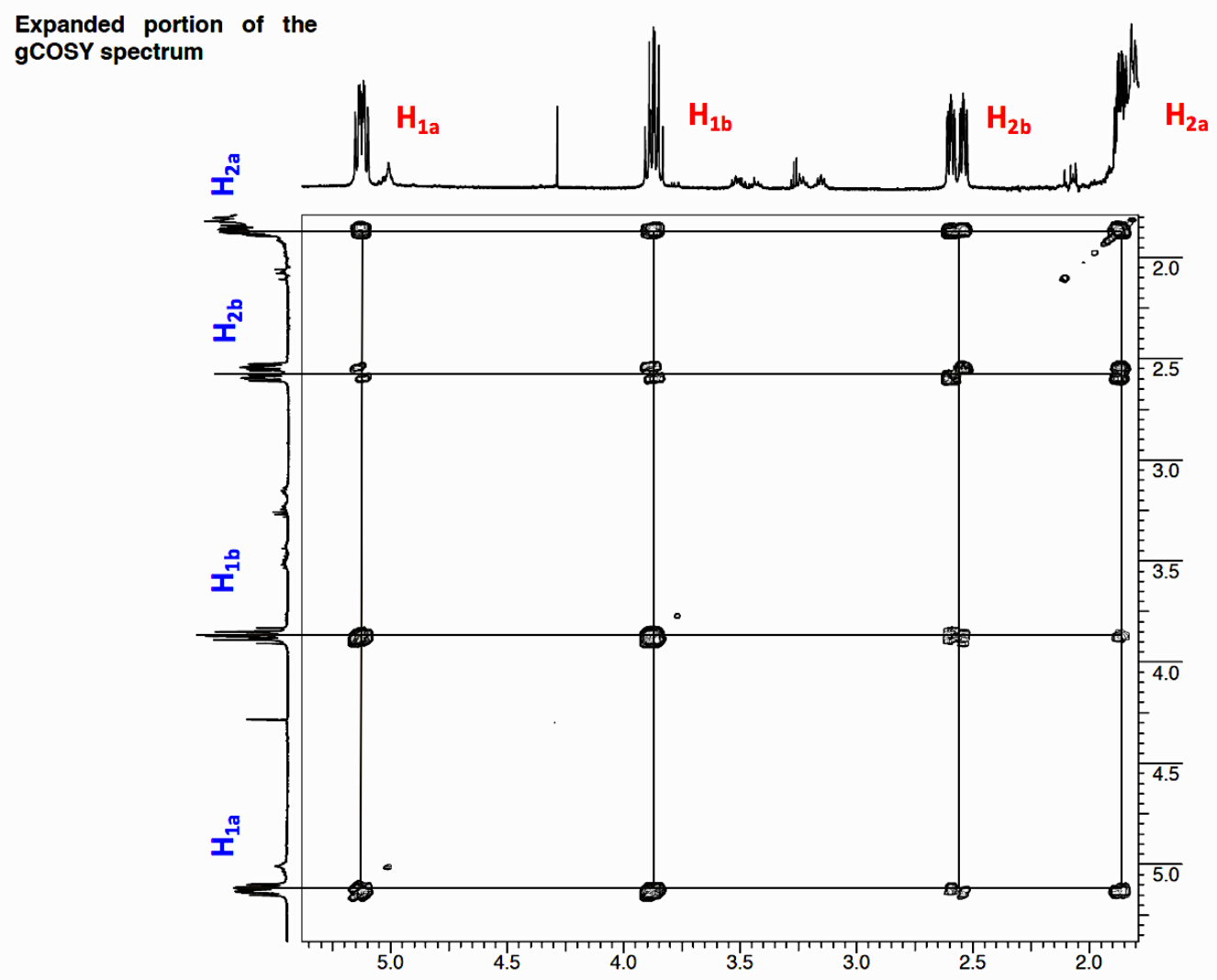

Figure 16. Expanded portion of a gCOSY spectrum showing correlations between methylene protons of iridium metallacycle

Similar correlations were observed in through-space interactions using NOESY experiments. For correlations to be drawn in a COSY experiment, the atoms must be connected through bonds; however, NOESY experiments can show correlations of atoms that are not directly bonded together, but rather are close in proximity. Analogous to the TOCSY experiment, there are also spectra shown in Figures $17 \mathrm{a}$-d that reveal a reference ${ }^{1} \mathrm{H}$ spectrum on the bottom with the correlated spectrum above. A selected proton is irradiated and is shown as a negative resonance on the spectrum. Nuclei that correlate through space to the selected proton signal show up as positive resonances. 


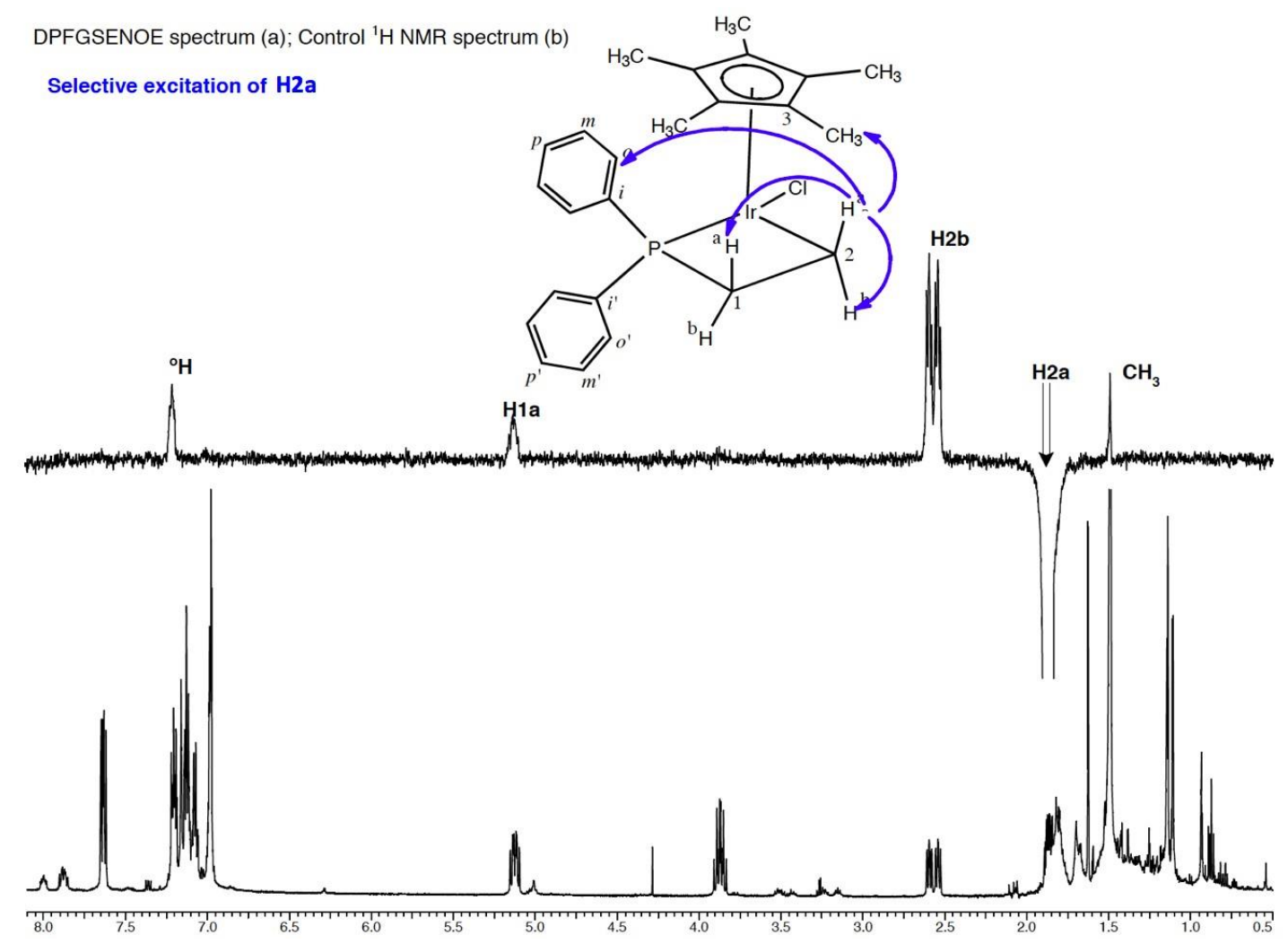

Figure 17a. DPFGSENOE spectrum of iridium metallacycle exciting $\mathrm{H}_{2 a}$

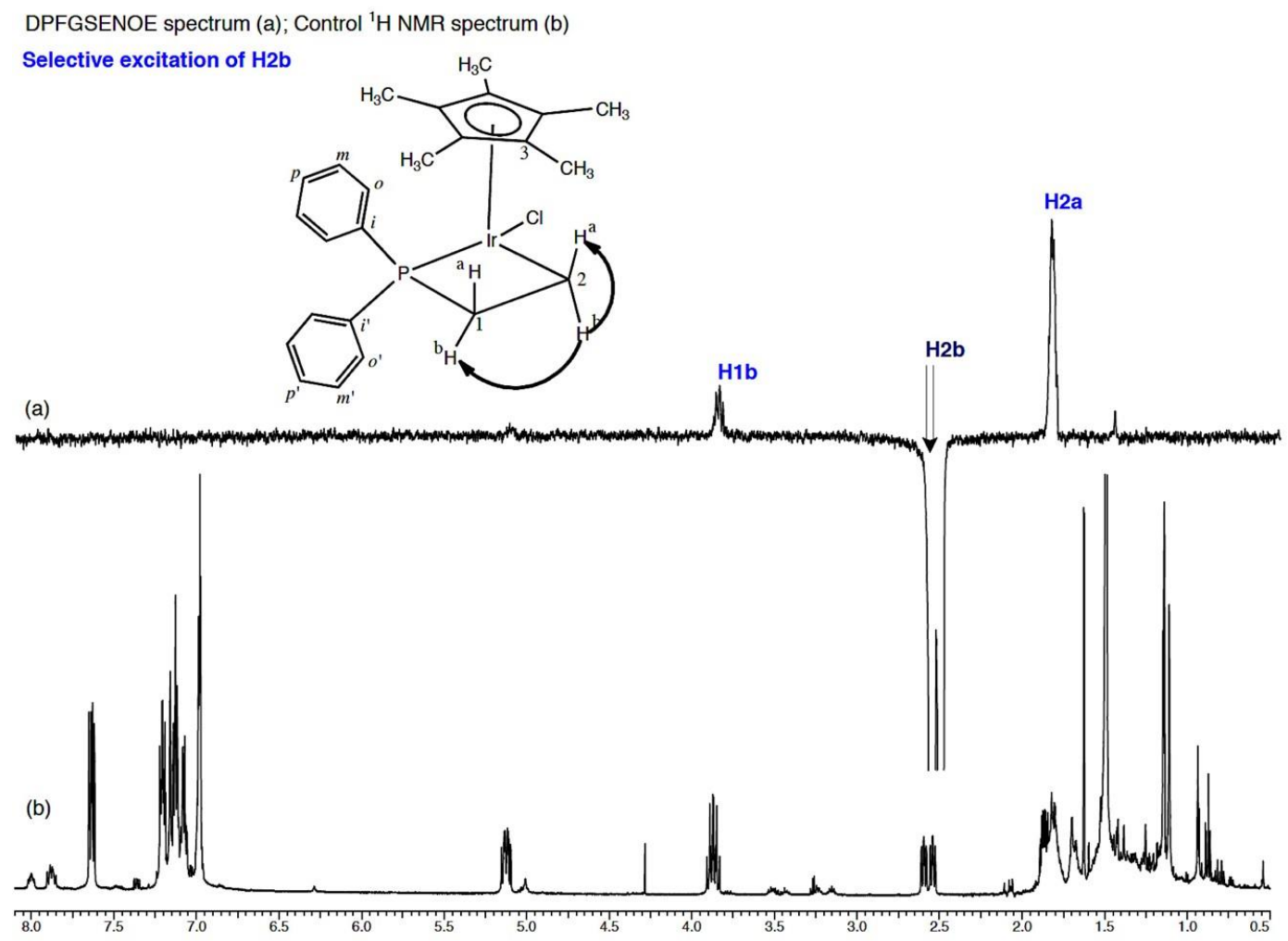

Figure 17b. DPFGSENOE spectrum of iridium metallacycle exciting $\mathrm{H}_{2 b}$ 


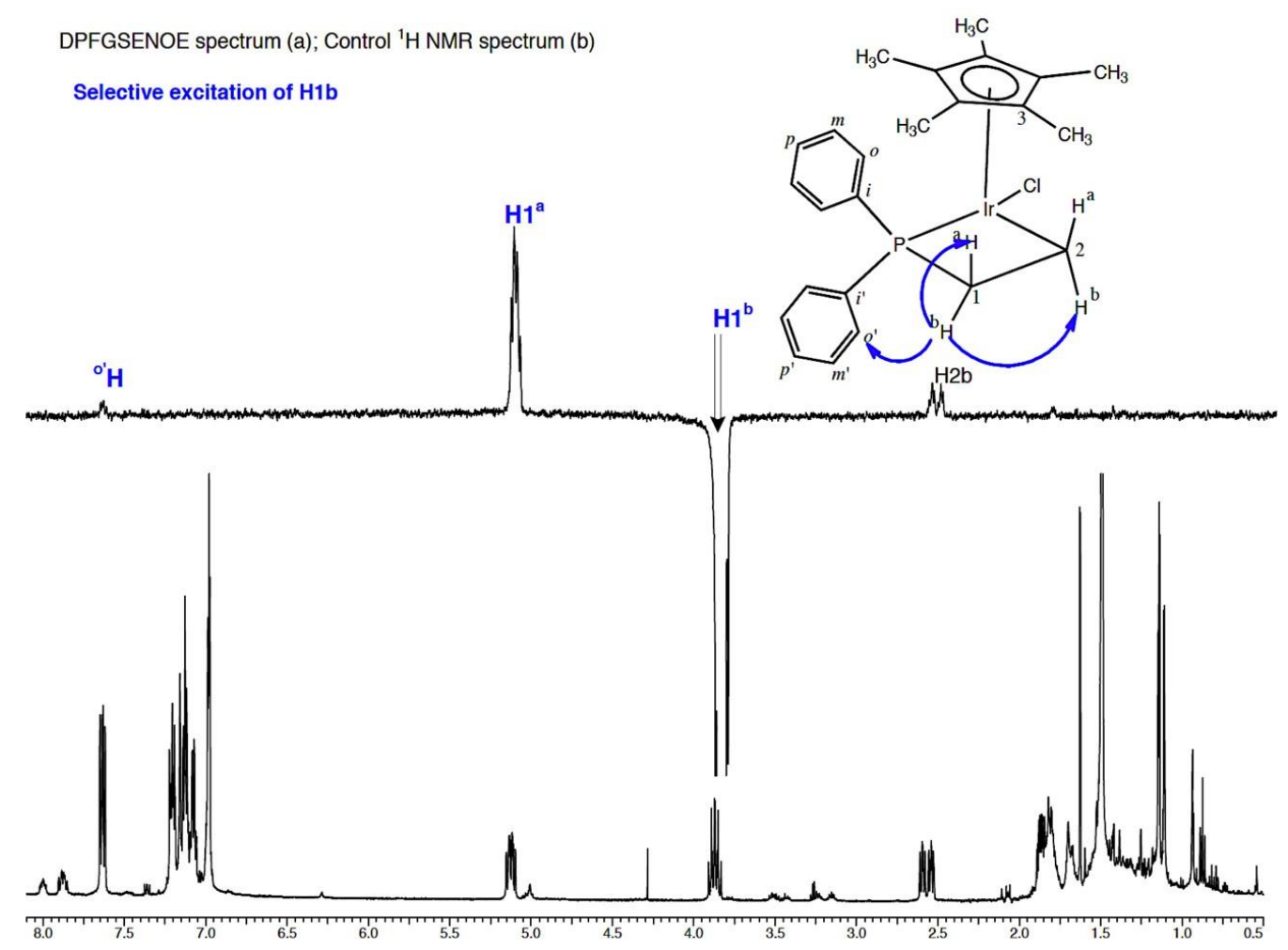

Figure 17c. DPFGSENOE spectrum of iridium metallacycle exciting $\mathrm{H}_{1 b}$

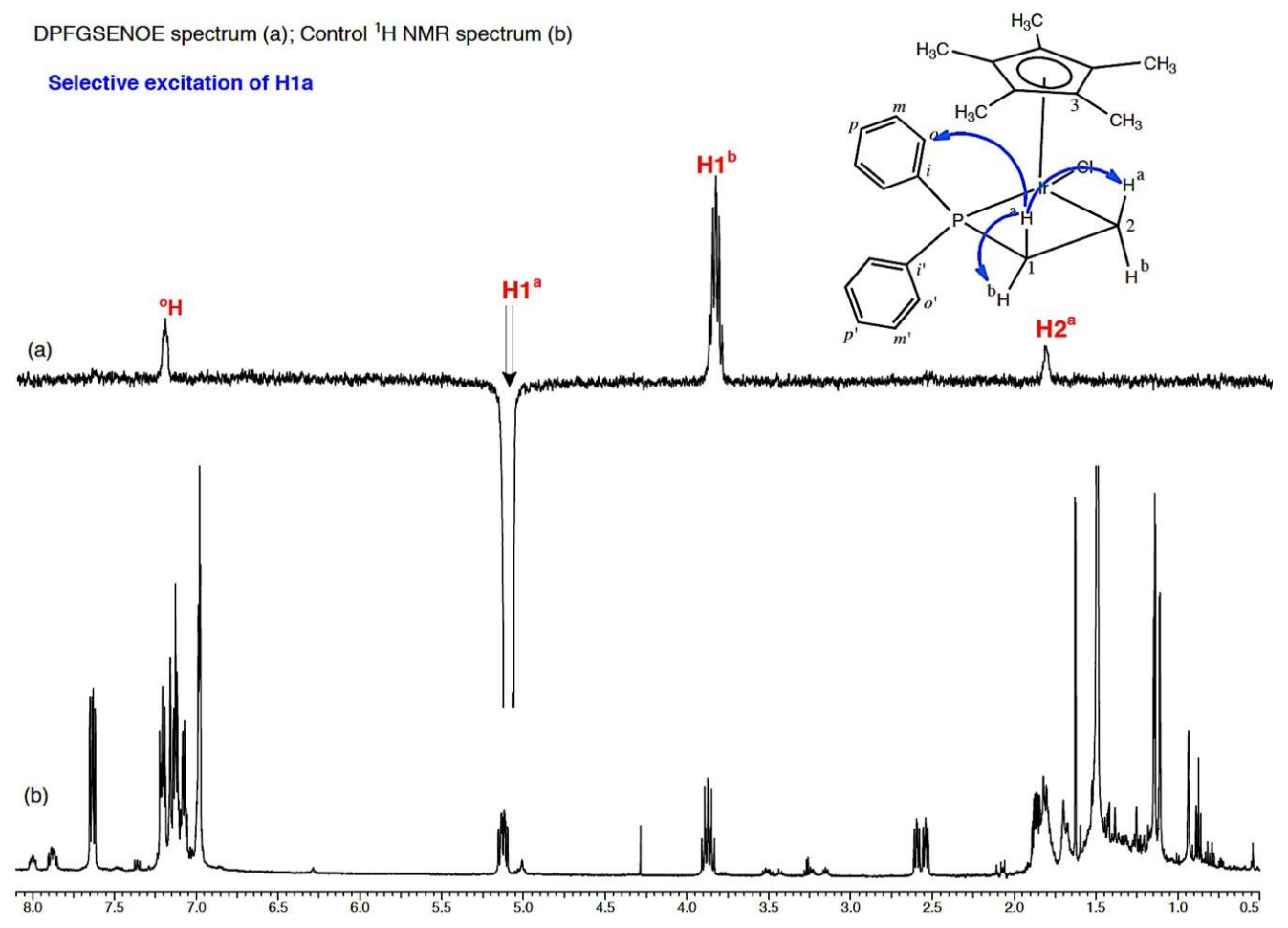

Figure 17d. DPFGSENOE spectrum of iridium metallacycle exciting $\mathrm{H}_{1 \mathrm{a}}$ 
A gHMBCAD experiment, which shows two- and three-bond correlations, reveals the ipso carbon of the phenyl ring on the phosphorus correlating to the methylene protons on $\mathrm{C} 1$ of the metallacycle (Figure 18).

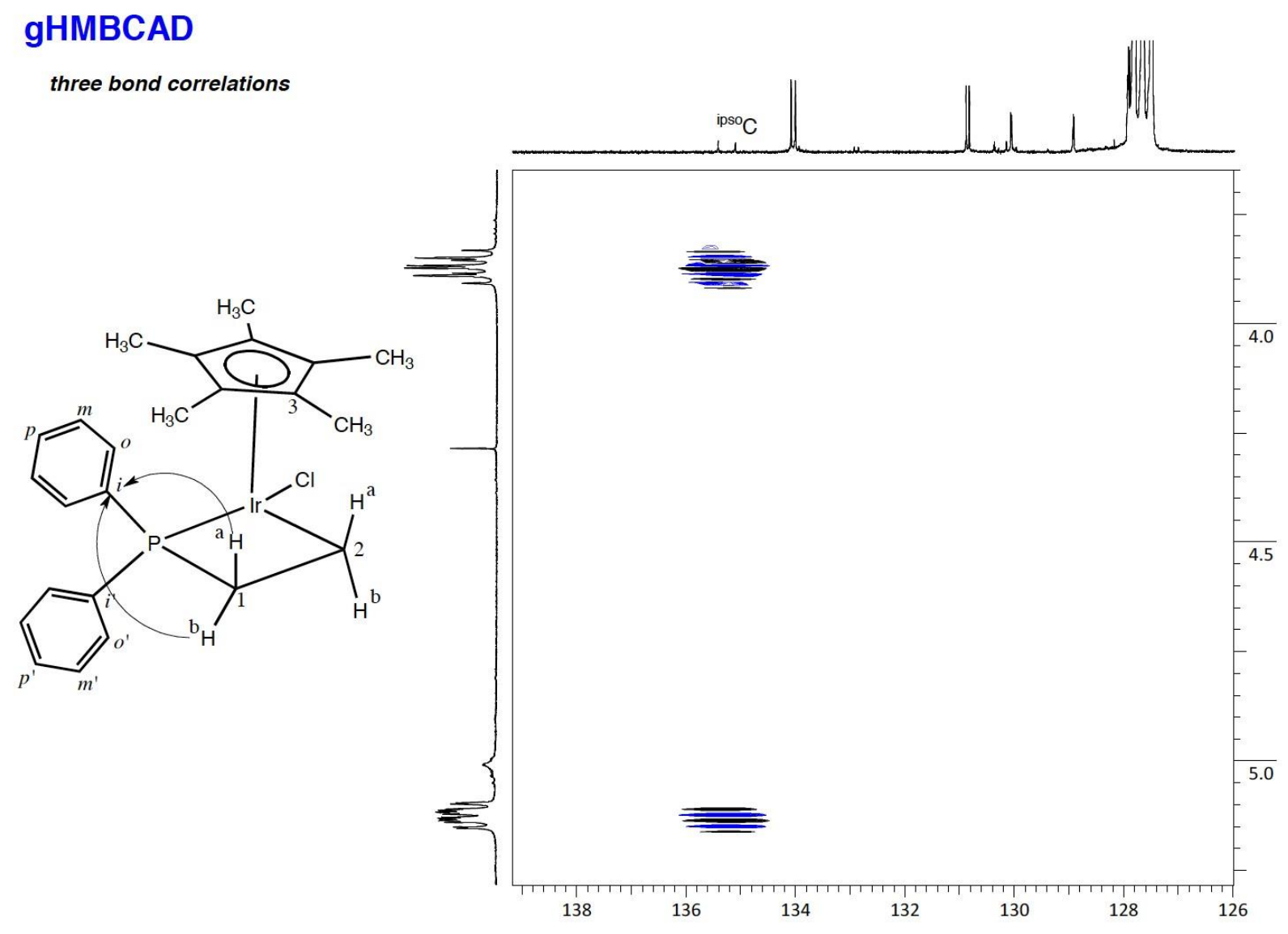

Figure 18. gHMBCAD correlations between $\mathrm{C} 1$ protons and the ipso carbon of phenyl ring on phosphorus atom

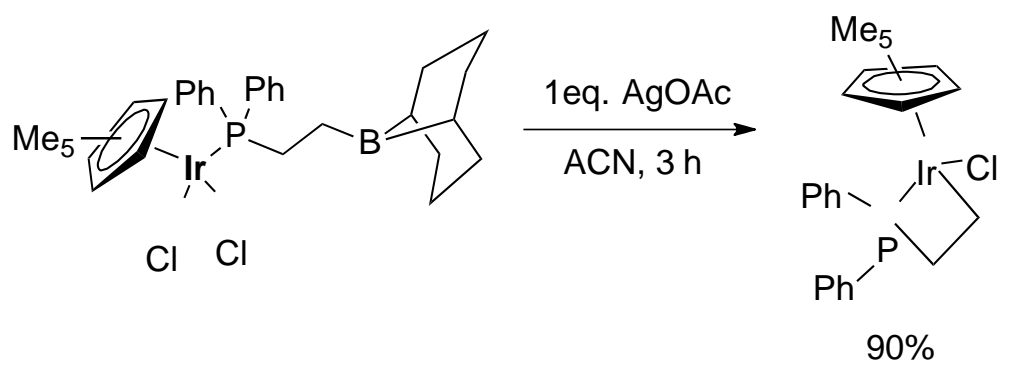

Scheme 12. Generating four-membered metallacycle from $\mathrm{Cp}^{*} \operatorname{IrCl}_{2}\left(\mathrm{Ph}_{2} \mathrm{PCH}_{2} \mathrm{CH}_{2} \mathrm{~B}^{\mathrm{BBN}}\right)$ 
Treatment of the same $\mathrm{Cp}^{*} \mathrm{IrCl}_{2} \mathrm{~PB}$ complex with bases such as $\mathrm{PhLi}$ and other silver salts also resulted in a metallacycle product in varying yields (Table 1). ${ }^{31} \mathrm{P}$ NMR spectra for these experiments show different degrees of conversion as the resonance at $0 \mathrm{ppm}$ for the $\mathrm{Cp}^{*} \mathrm{IrCl}_{2} \mathrm{~PB}$ complex has not completely disappeared. Some downfield resonances showed that different products other than the metallacycle were synthesized (Figures 19-26).

Table 1. Additives reacted with $\left[\mathrm{Cp}^{*} \mathrm{IrCl}_{2} \mathrm{~PB}\right]$ and corresponding metallacycle yields generated

\begin{tabular}{cll} 
Entry & Additive & Yield $^{a}$ \\
\hline 1 & $\mathrm{LiH}$ & $17 \%$ \\
2 & $\mathrm{PhLi}$ & $57 \%$ \\
3 & $\mathrm{NaBH}_{4}$ & $3 \%$ \\
4 & $\mathrm{NaEt}_{3} \mathrm{BH}$ & $49 \%$ \\
5 & $\mathrm{AgOAc}$ & $90 \%$ \\
6 & $\mathrm{AgOBz}$ & $92 \%$ \\
7 & $\mathrm{AgOCF}_{3}$ & $\mathrm{nd}$ \\
8 & $\mathrm{AgOTf}$ & $\mathrm{nd}$ \\
9 & $\mathrm{AgBF}_{4}$ & $5 \%$
\end{tabular}

${ }^{a}$ Yields determined from ${ }^{31} \mathrm{P}$ NMR of metallacycle resonance 


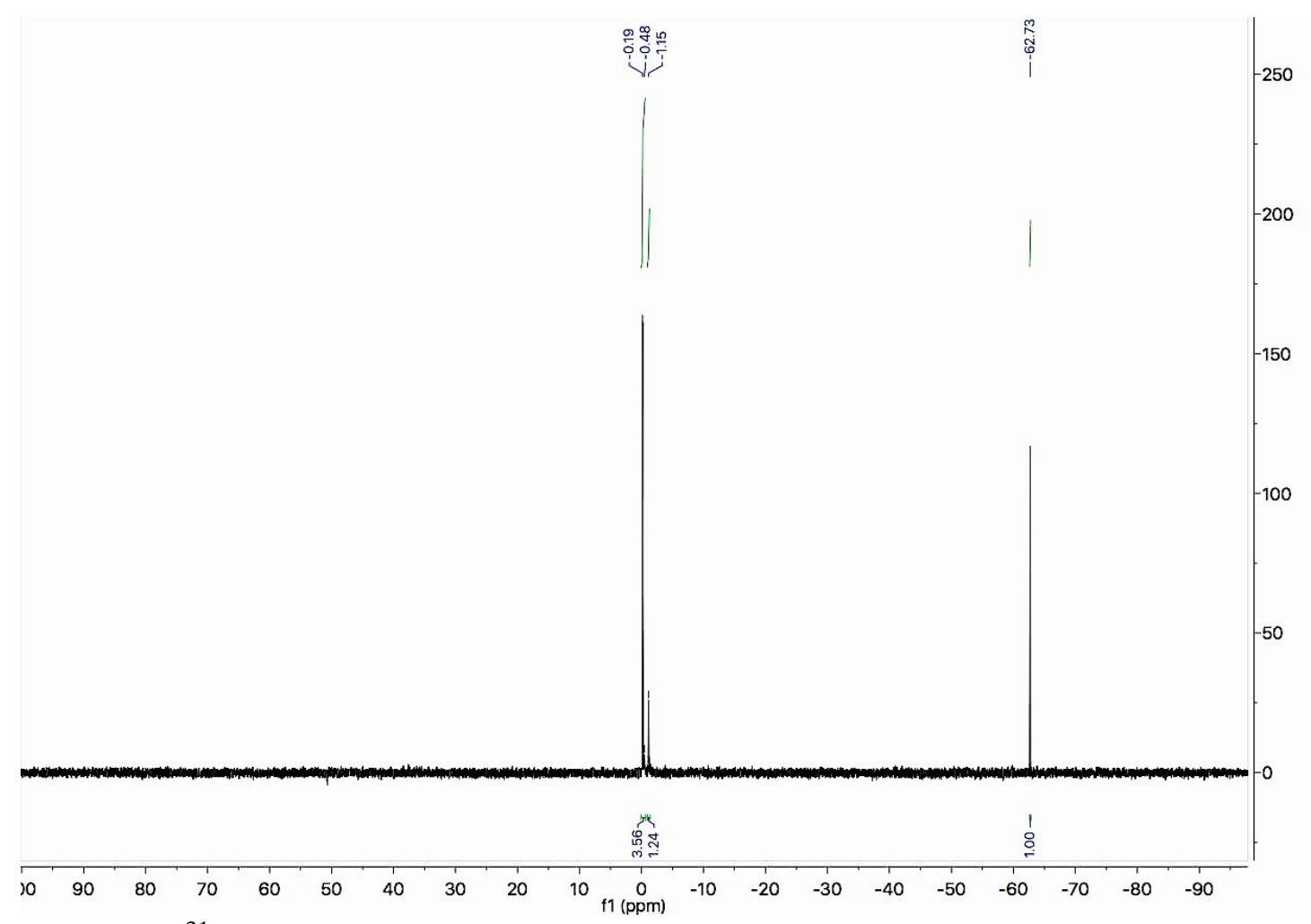

Figure 19. ${ }^{31} \mathrm{P} \mathrm{NMR} \mathrm{Cp}^{*} \mathrm{IrCl}_{2} \mathrm{~PB}+1$ eq. $\mathrm{LiH}$

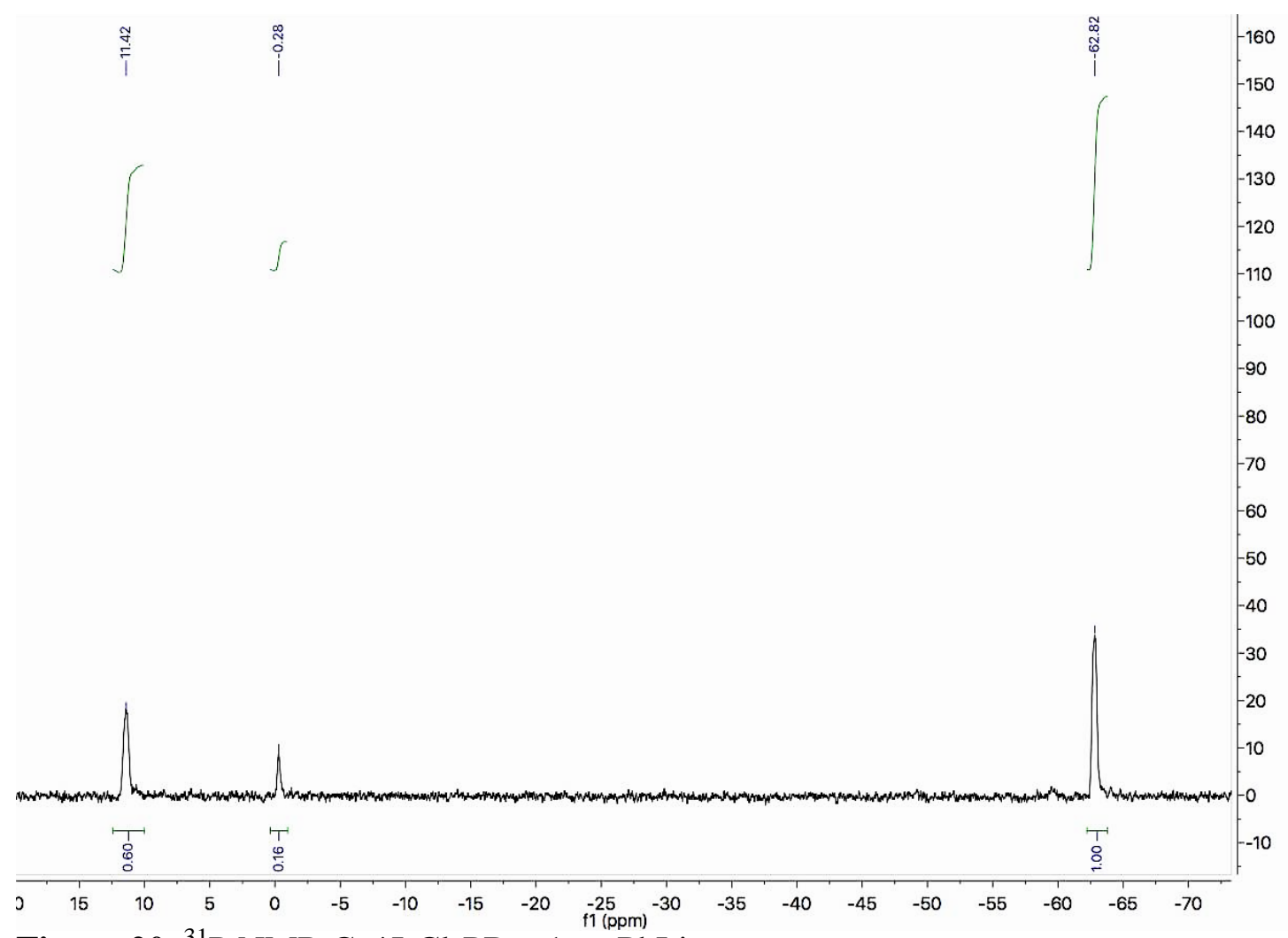

Figure 20. ${ }^{31} \mathrm{P} \mathrm{NMR} \mathrm{Cp} * \mathrm{IrCl}_{2} \mathrm{~PB}+1$ eq. $\mathrm{PhLi}$ 


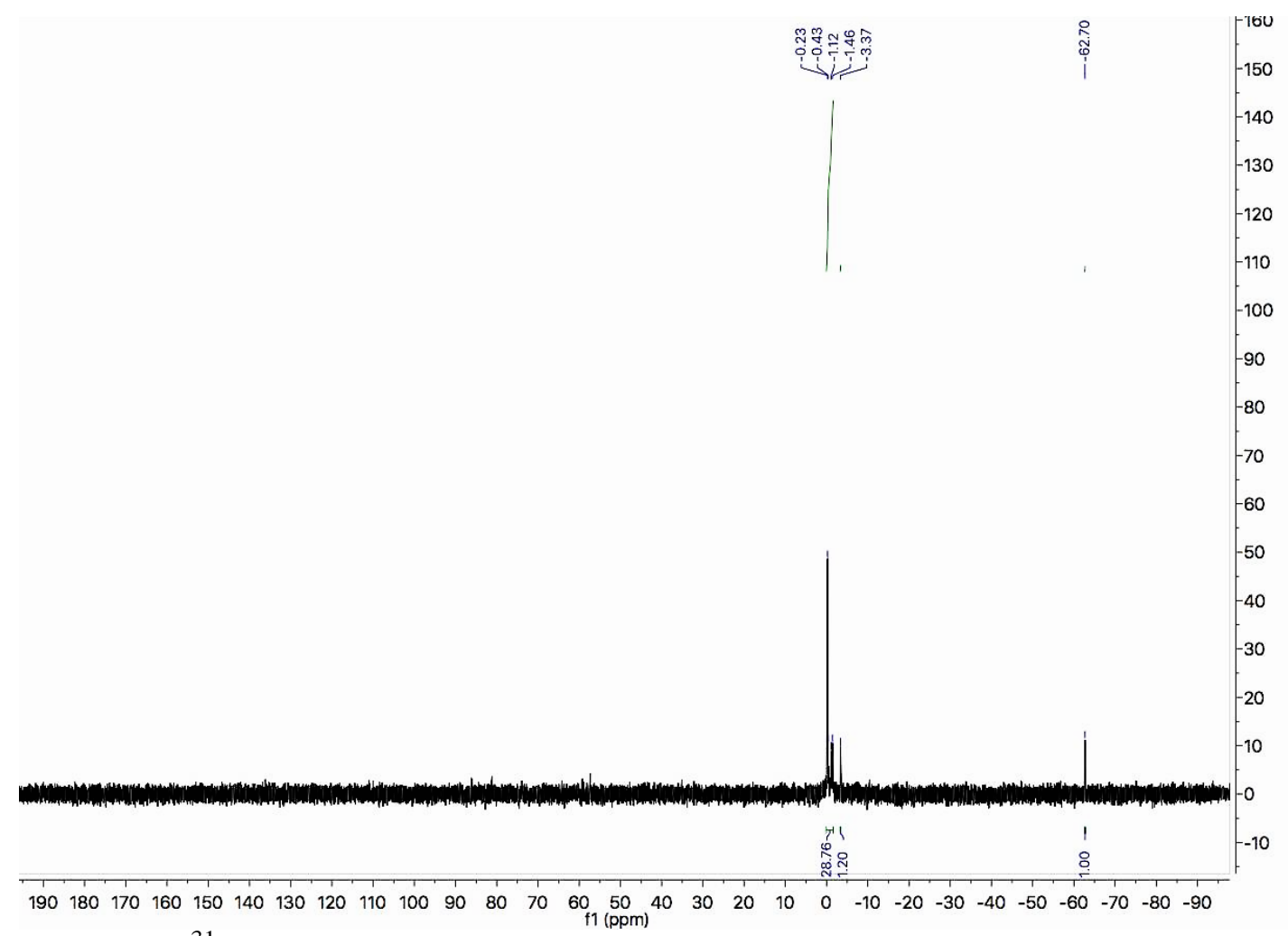

Figure 21. ${ }^{31} \mathrm{P} \mathrm{NMR} \mathrm{Cp} * \mathrm{IrCl}_{2} \mathrm{~PB}+1$ eq. $\mathrm{NaBH}_{4}$

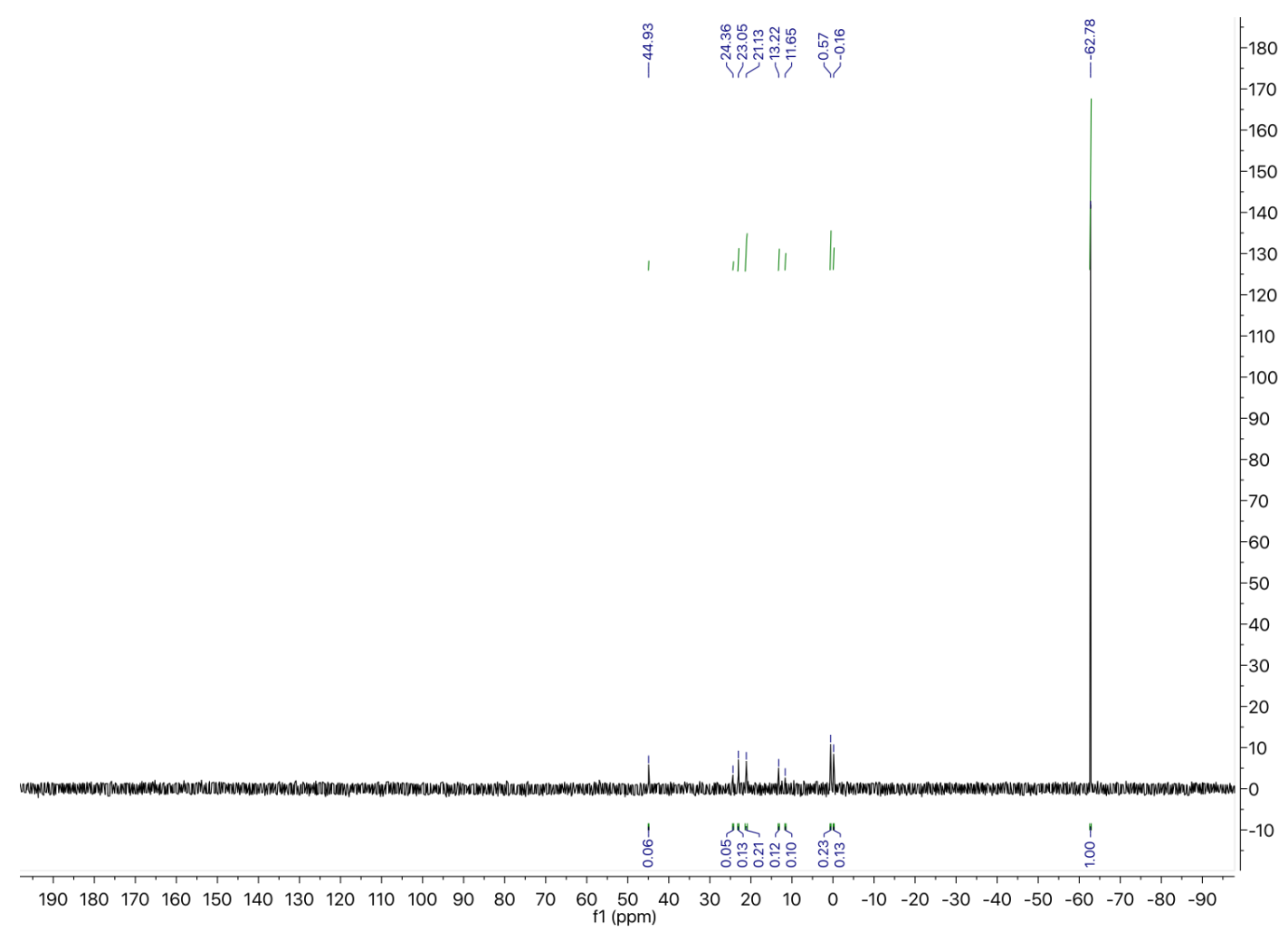

Figure 22. ${ }^{31} \mathrm{P} \mathrm{NMR} \mathrm{Cp}^{*} \mathrm{IrCl}_{2} \mathrm{~PB}+1$ eq. $\mathrm{NaEt}_{3} \mathrm{BH}$ 


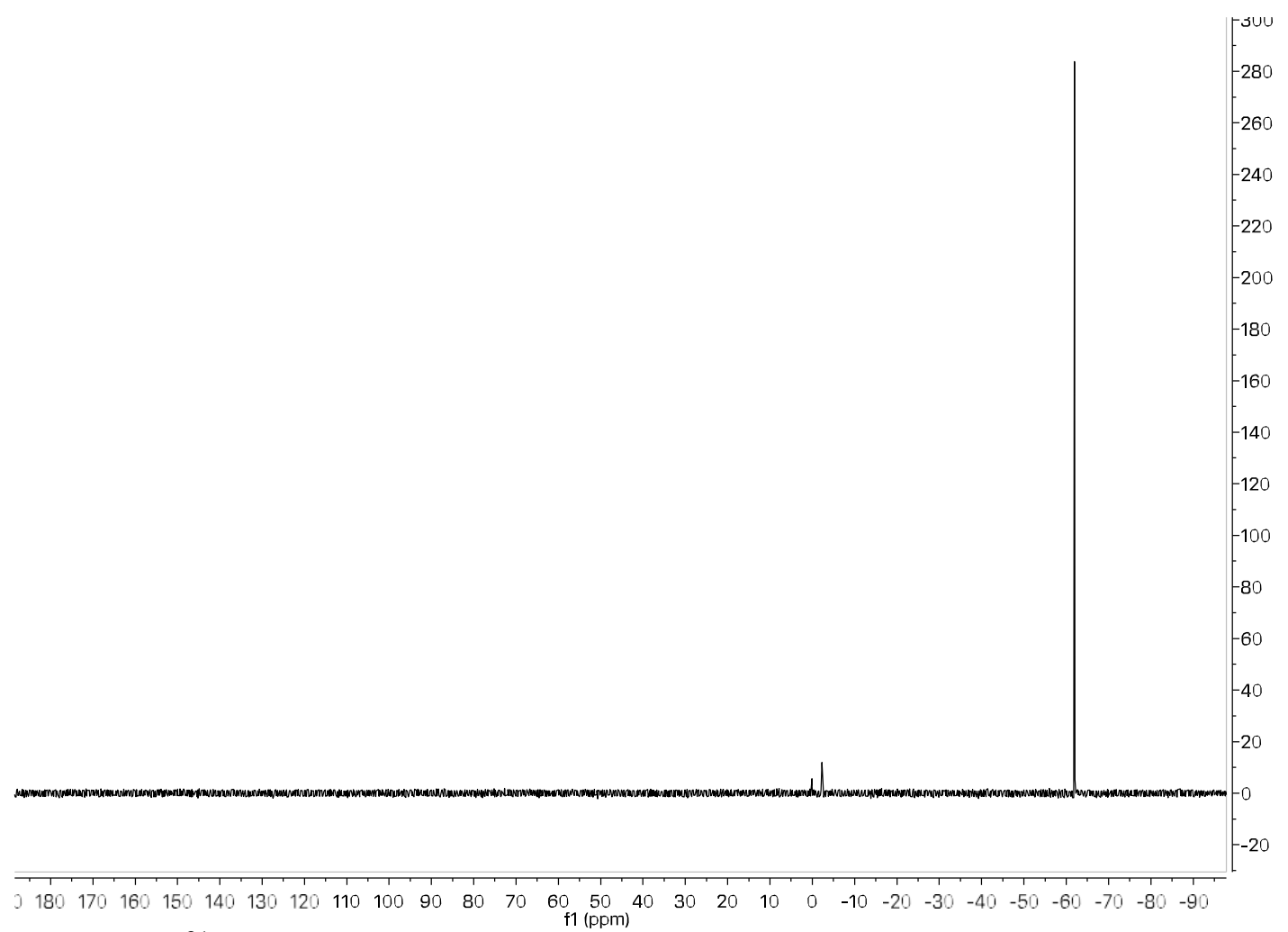

Figure 23. ${ }^{31} \mathrm{P}$ NMR Cp* $\mathrm{IrCl}_{2} \mathrm{~PB}+1$ eq. $\mathrm{AgOBz}$

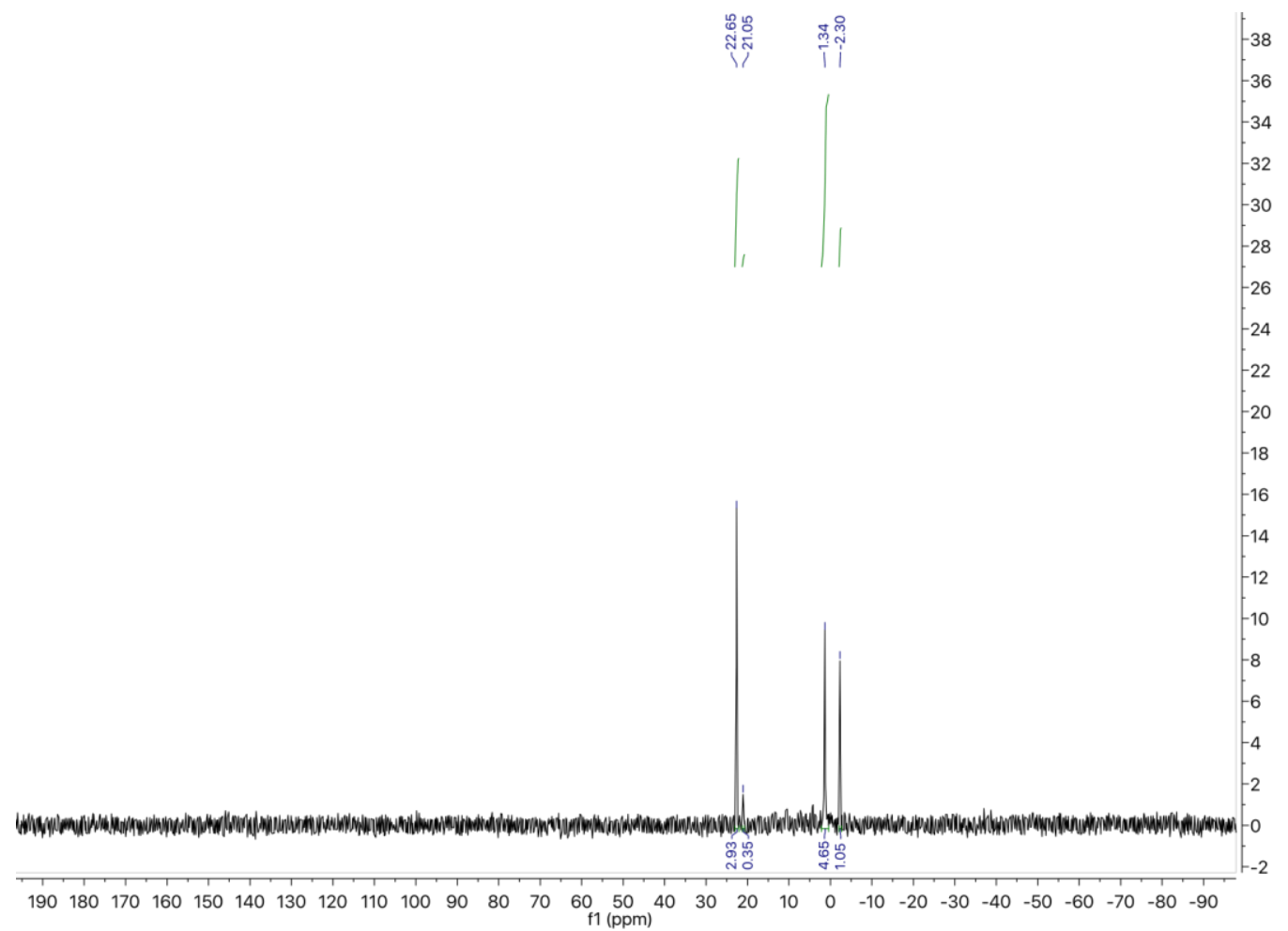

Figure 24. ${ }^{31} \mathrm{P} \mathrm{NMR} \mathrm{Cp} * \mathrm{IrCl}_{2} \mathrm{~PB}+1$ eq. $\mathrm{AgOCF}_{3}$ 


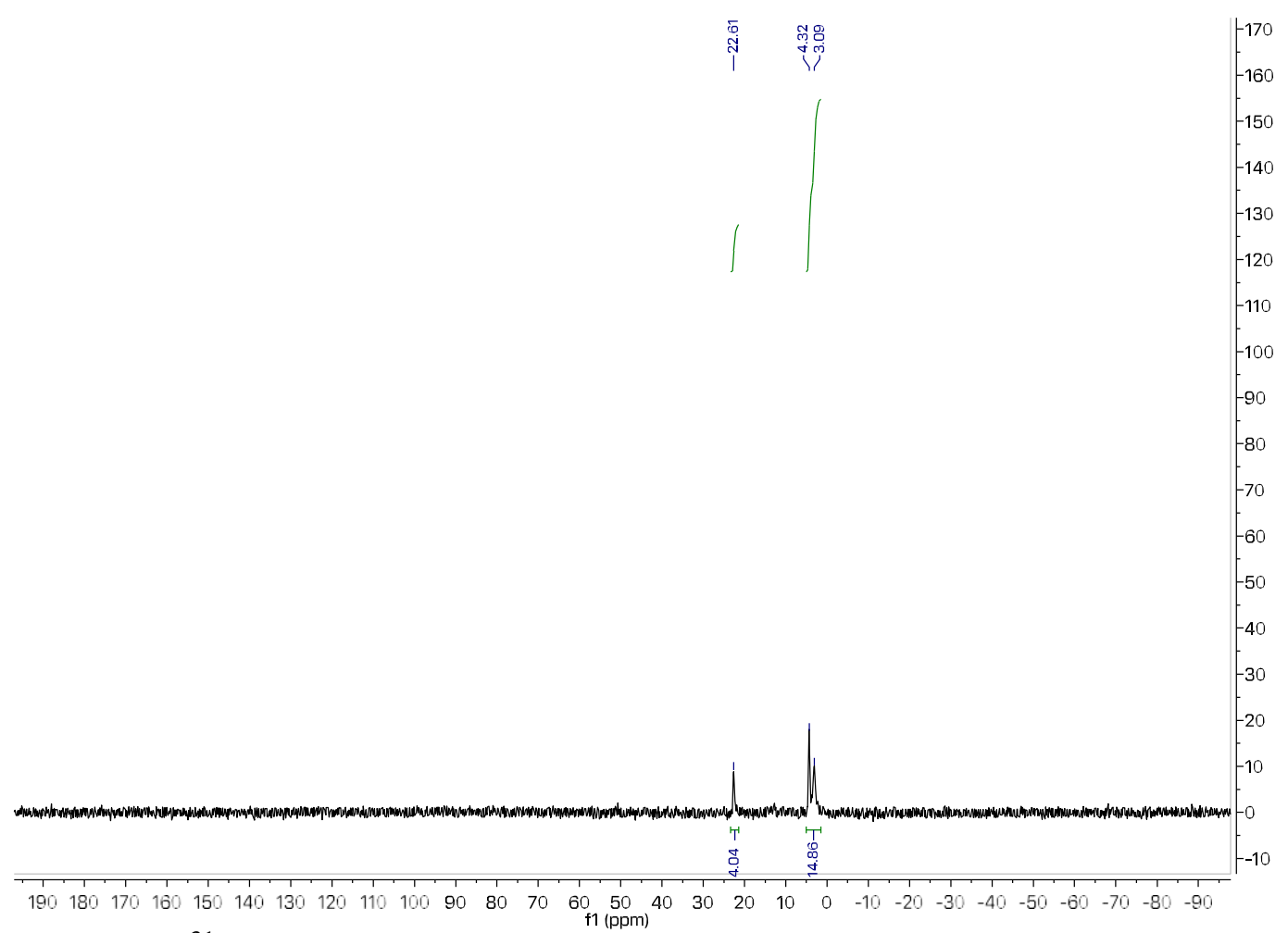

Figure 25. ${ }^{31} \mathrm{P}$ NMR Cp* $\mathrm{IrCl}_{2} \mathrm{~PB}+1$ eq. AgOTf

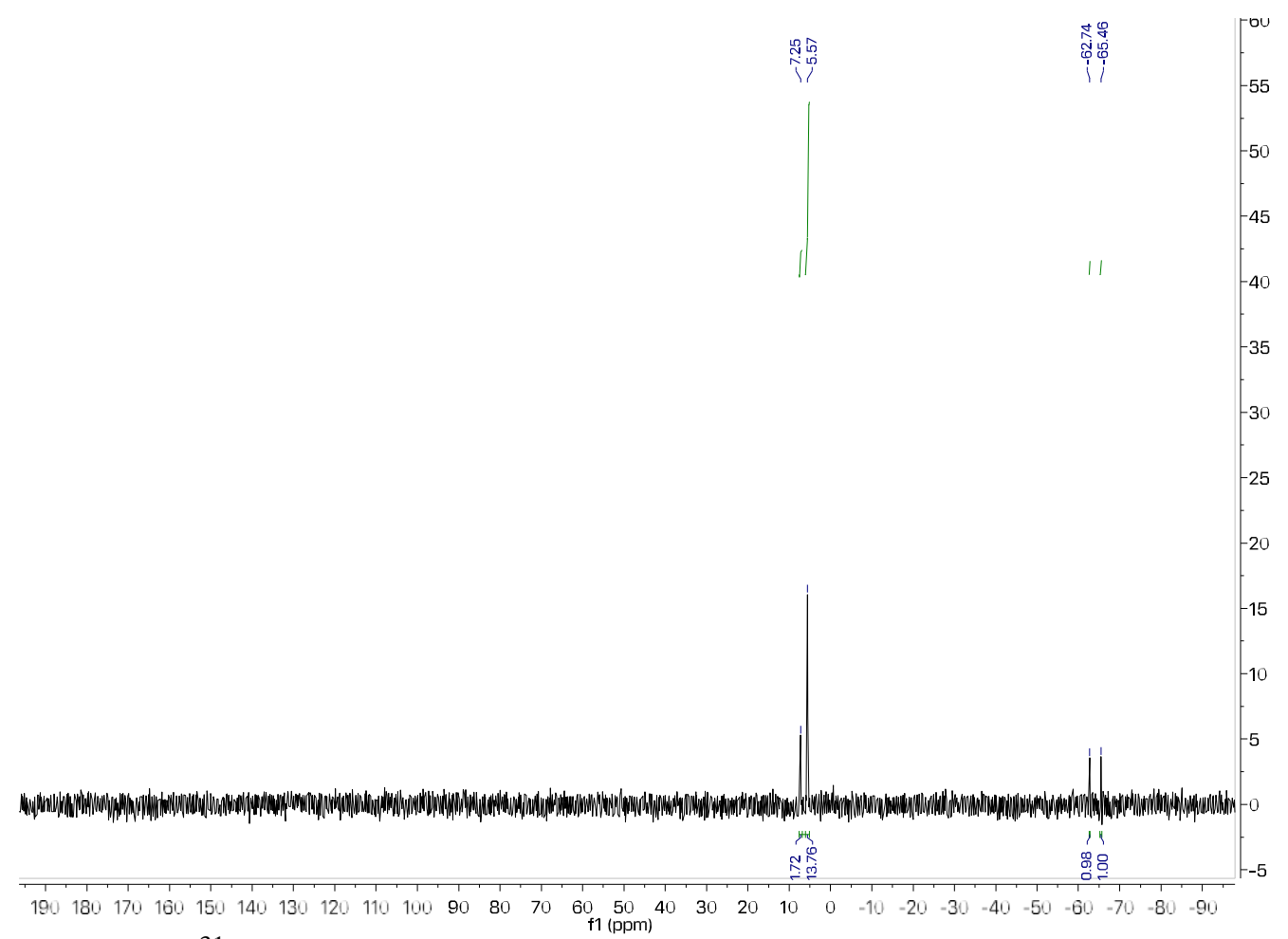

Figure 26. ${ }^{31} \mathrm{P} \mathrm{NMR} \mathrm{Cp} * \mathrm{IrCl}_{2} \mathrm{~PB}+1$ eq. $\mathrm{AgBF}_{4}$ 


\section{Preliminary Mechanistic Studies}

Bourissou reported a similar case of reactivity in 2008 when a metallacycle was generated upon the reaction of the ( $p$-cymene) $\mathrm{RuCl}_{2} \mathrm{~PB}\left(\mathrm{~PB}=\mathrm{Ph}_{2} \mathrm{PCH}_{2} \mathrm{CH}_{2}\left(\mathrm{~B}^{\mathrm{BBN}}\right)\right)$ complex and $\mathrm{AgOAc}$ (Scheme 13). ${ }^{32}$ Their generated metallacycle complex was confirmed with X-ray crystallography data (Figure 27). This is in agreement with that of our generated metallacycle structure.

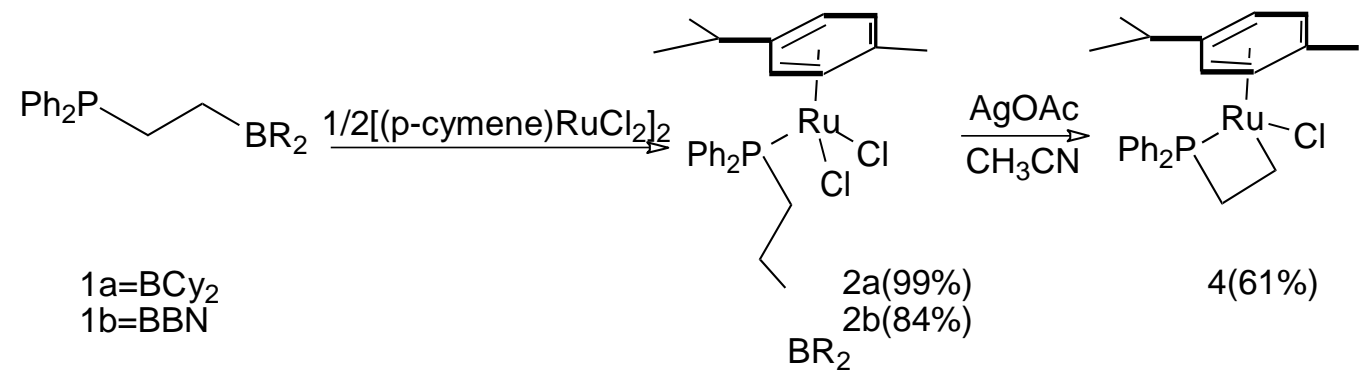

Scheme 13. Generating four-membered metallacycle from ( $p$-cymene) $\mathrm{RuCl}_{2}\left(\mathrm{Ph}_{2} \mathrm{PCH}_{2} \mathrm{CH}_{2} \mathrm{BR}_{2}\right)$

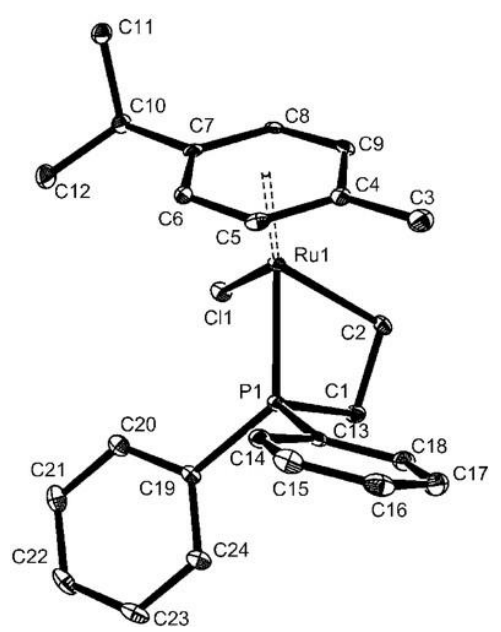

Figure 27. ORTEP structure of ruthenium metallacycle reported in 2008

A UV-Visible spectroscopy time-course study previously conducted with Me-, $i \mathrm{Pr}-$, secbutyl-, $\mathrm{tBu}-$, and $\mathrm{PhLi}$ reagents indicated a rapid conversion with no apparent change in rate. ${ }^{33}$ 
After standing in solution for a prolonged period of time, an X-ray quality crystal was grown of a hydrogenation product of the $\mathrm{Cp} * \mathrm{IrCl}_{2} \mathrm{~PB}$ complex giving the structure presented in Figure 28. An X-ray quality structure of the $\mathrm{Cp} * \mathrm{IrCl}_{2} \mathrm{~PB}$ was not obtained.

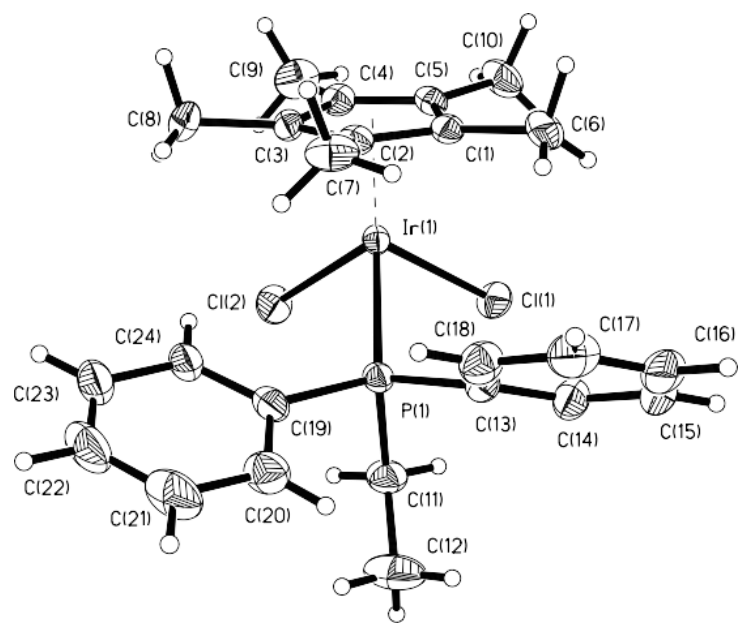

Figure 28. Perspective view of the molecular structure of $\mathrm{Cp}^{*} \mathrm{IrCl}_{2}\left(\mathrm{PPh}_{2} \mathrm{CH}_{2} \mathrm{CH}_{3}\right)$ with the atom labeling scheme for the non-hydrogen atoms. The thermal ellipsoids are scaled to enclose $30 \%$ probability.

\section{Rhodium}

The metallacycle synthesis was then attempted with two additional group IX metals, rhodium and cobalt. First, $\left[\mathrm{Cp} * \mathrm{RhCl}_{2}\right]_{2}$ was treated with $\mathrm{Ph}_{2} \mathrm{PCH}_{2} \mathrm{CH}_{2} \mathrm{~B}^{\mathrm{BBN}}$ to give the respective rhodium-PB complex (Scheme 14). Two X-ray structures were obtained with tetrahydrofuran and acetonitrile coordinated to the boron respectively (Figure 29). 


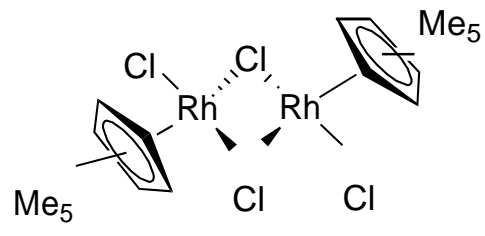

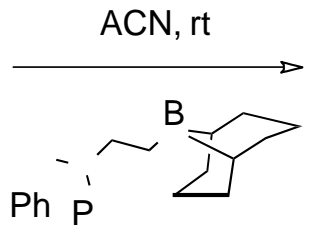

$\mathrm{Ph}$

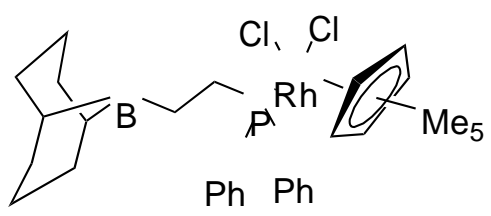

$98 \%$

Scheme 14. Synthesis of $\left[\mathrm{Cp}^{*} \mathrm{RhCl}_{2} \mathrm{~PB}\right]$ complex
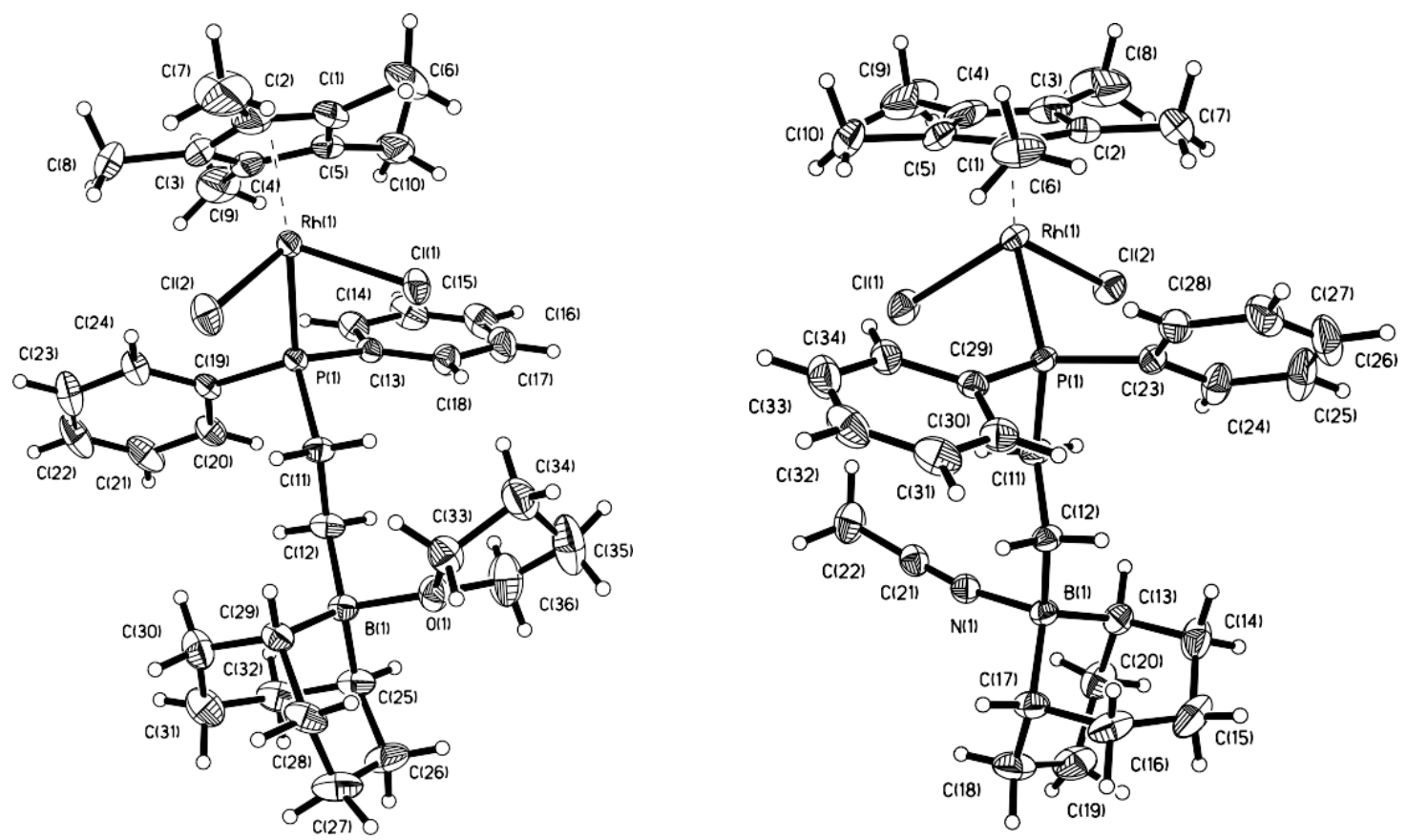

Figure 29. ORTEP structures of $\mathrm{Cp}^{*} \mathrm{RhCl}_{2} \mathrm{~PB}$ complex with coordinated boron-coordinated THF and $\mathrm{CH}_{3} \mathrm{CN}$

The metallacycle generated from the treatment of $\mathrm{Cp}^{*} \mathrm{RhCl}_{2}\left(\mathrm{Ph}_{2} \mathrm{PCH}_{2} \mathrm{CH}_{2}\left(\mathrm{~B}^{\mathrm{BBN}}\right)\right)$ with AgOAc was characterized and described herein (Scheme 15). The ${ }^{31} \mathrm{P}$ NMR spectrum showed an upfield shifted resonance at $-34 \mathrm{ppm}$ and a doublet due to the rhodium-phosphorus coupling present (Figure 30). 


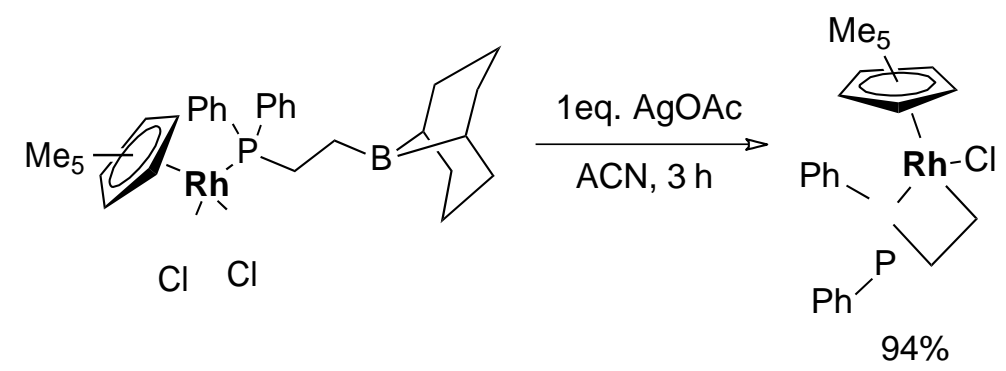

Scheme 15. Generating four-membered metallacycle from $\mathrm{Cp} * \mathrm{RhCl}_{2}\left(\mathrm{Ph}_{2} \mathrm{PCH}_{2} \mathrm{CH}_{2} \mathrm{~B}^{\mathrm{BBN}}\right)$

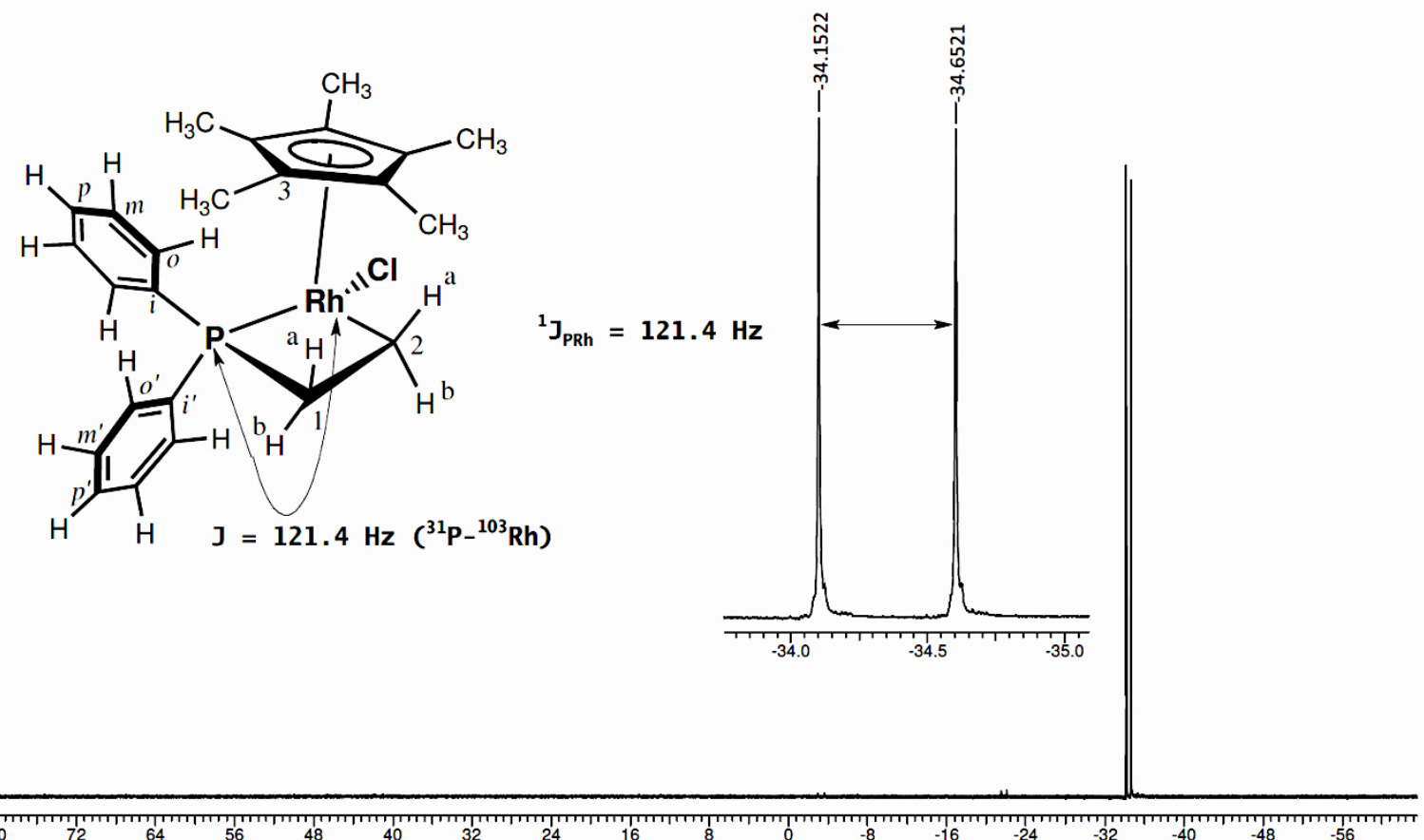

Figure 30. ${ }^{31} \mathrm{P}$ NMR spectrum of rhodium metallacycle with $\mathrm{Rh}-\mathrm{P}$ coupling constant

As observed in the reference ${ }^{1} \mathrm{H}$ NMR spectrum (Figure 31a), the splitting patterns for each methylene proton have become more complex. This is due not only to the coupling to each proton in the metallacycle, but also the phosphorus and rhodium which are NMR active nuclei. This resulted in a doublet of doublet of doublet of doublet of doublets splitting pattern for each methylene proton. The shifts of two proton resonances, $\mathrm{H}_{1 \mathrm{a}}$ and $\mathrm{H}_{1 \mathrm{~b}}$ are slightly overlapping at 
approximately $3.75 \mathrm{ppm}$. The $1 \mathrm{D}$ TOCSY of the irradiated $\mathrm{H}_{1 \mathrm{a}} / \mathrm{H}_{1 \mathrm{~b}}$ resonances showed the spin system of the methylene protons in the $\mathrm{Rh}$ (III) metallacycle (Figure $31 \mathrm{~b}$ ).
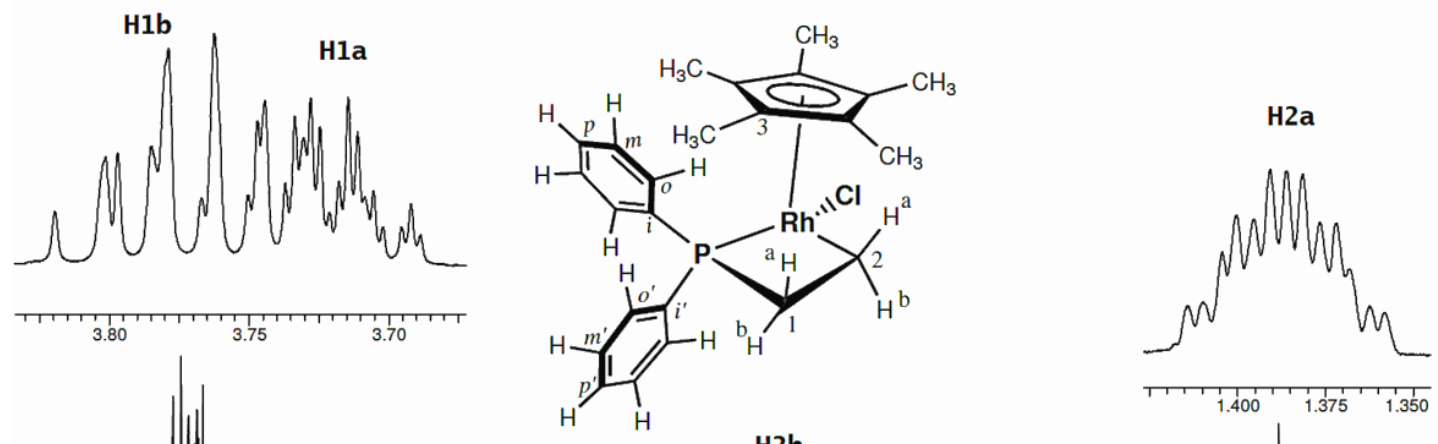

(b)

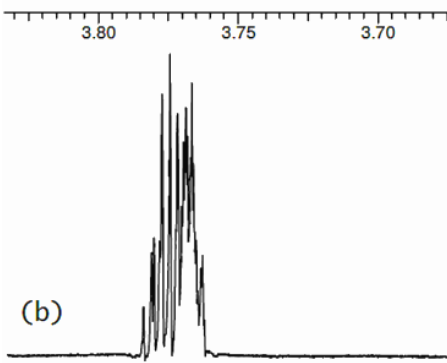

2b

(a)
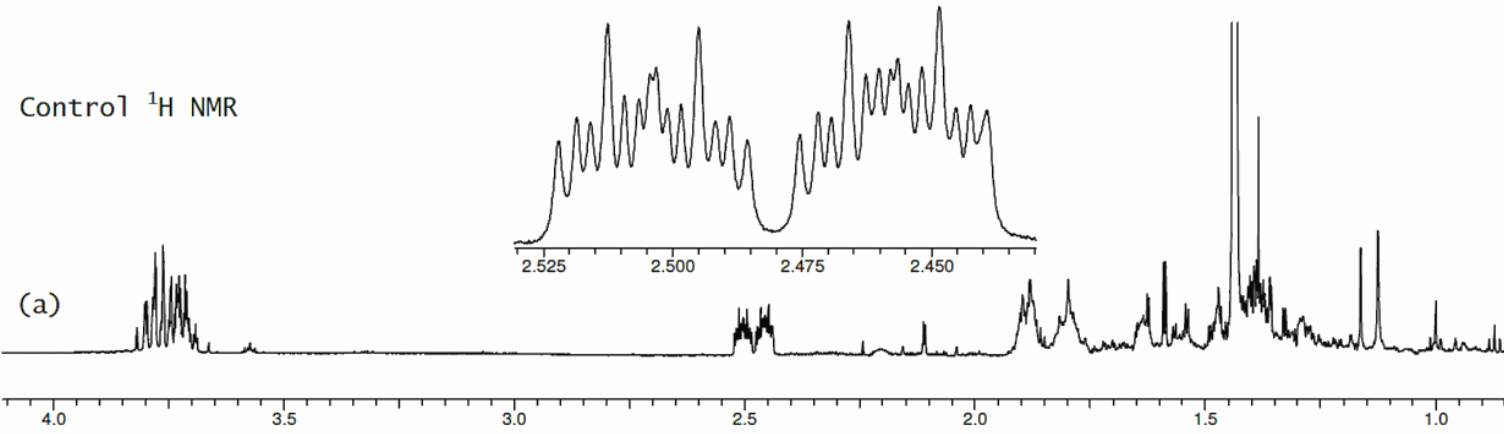

Figure 31. 1D TOCSY of methylene protons of Rh(III) metallacycle. Excited $\mathrm{H}_{1 a} / \mathrm{H}_{1 b}$ signals.

NOE experiments (Figure 32a-c) show irradiated resonances and their respective correlated peaks. Protons on $\mathrm{C} 1$ closest to the phosphorus in the metallacycle were shown to correlate to ortho protons of separate phenyl ring substituents. 


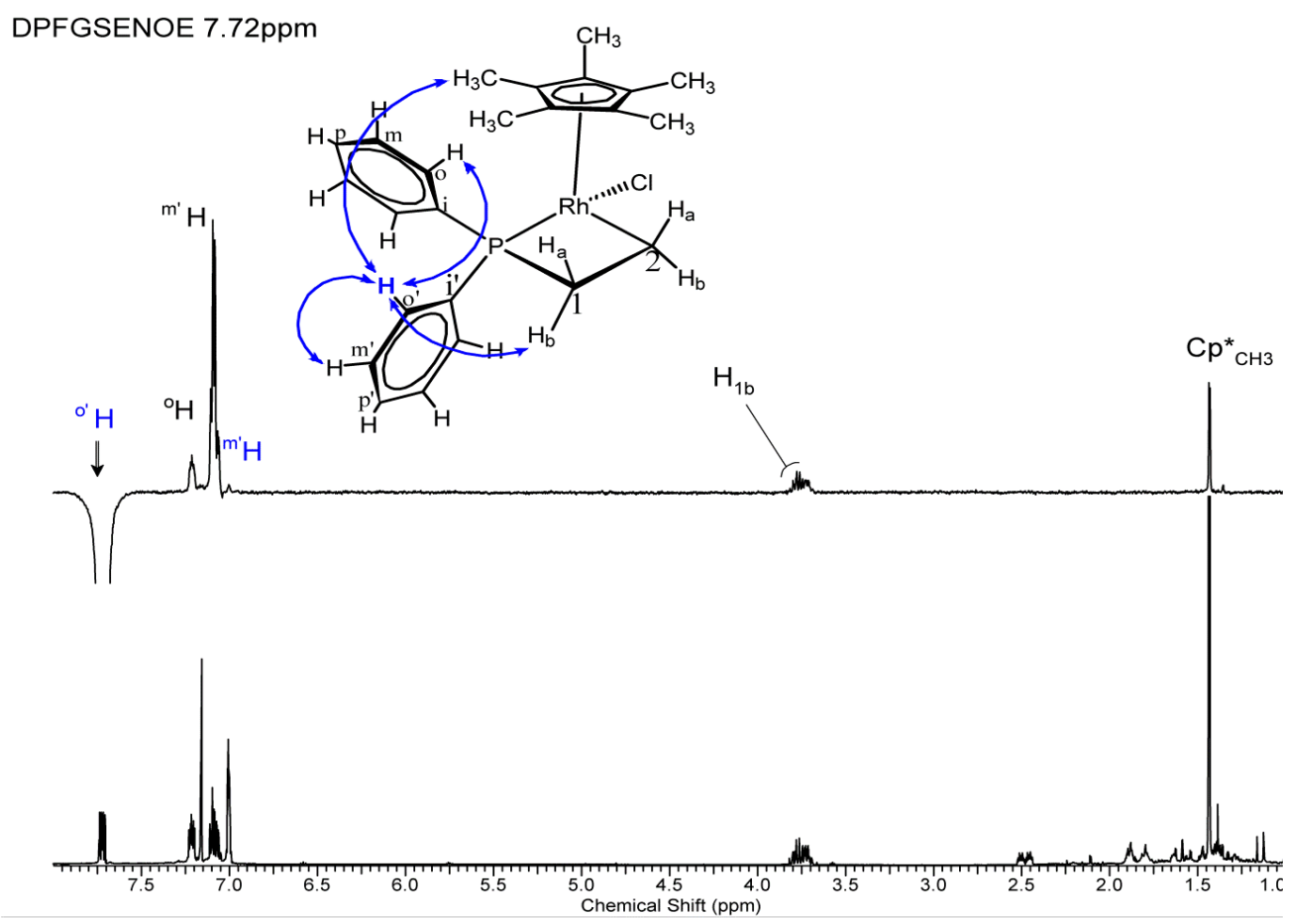

Figure 32a. DPFGSENOE spectra of irradiated ${ }^{1} \mathrm{H}$ signal at $7.72 \mathrm{ppm}$.

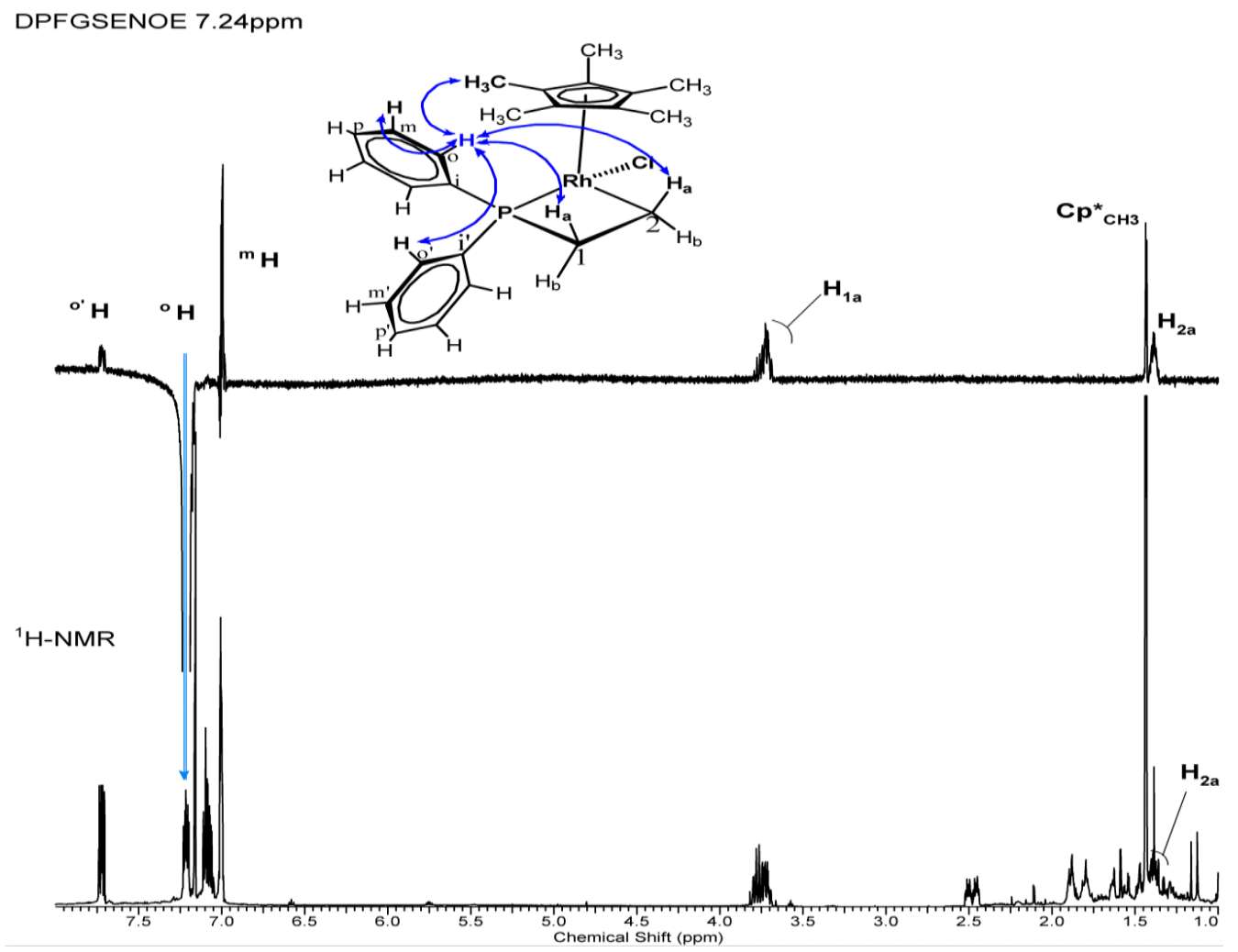

Figure 32b. DPFGSENOE spectra of irradiated ${ }^{1} \mathrm{H}$ signal at $7.24 \mathrm{ppm}$. 


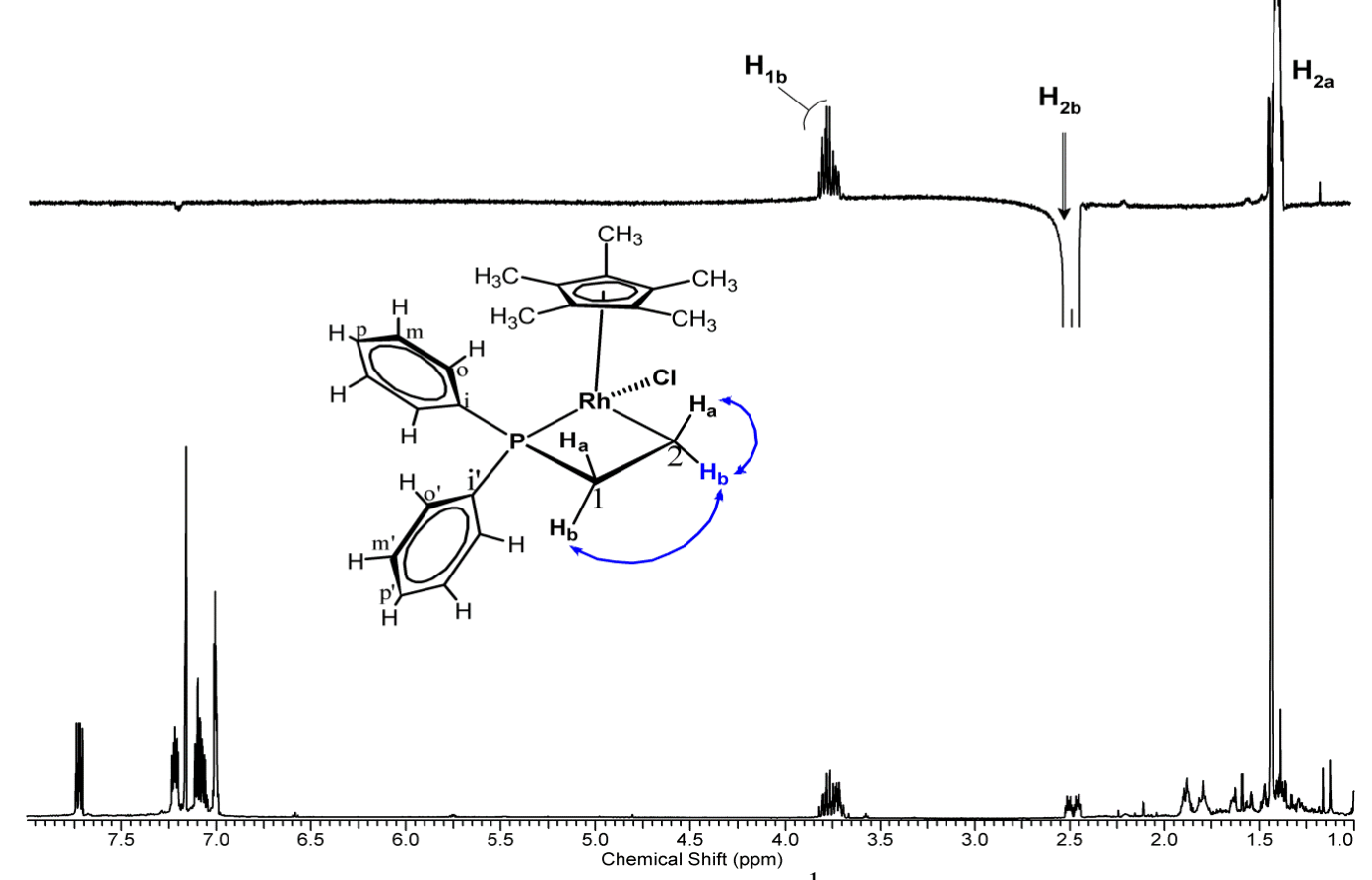

Figure 32c. DPFGSENOE spectra of irradiated ${ }^{1} \mathrm{H}$ signal at $2.48 \mathrm{ppm}$.

Lastly, the simulated (33a) and experimental (33b) splitting patterns for each of the methylene protons of the metallacycle were compared and were found to match (Figure 33). The experimental coupling pattern for $\mathrm{H}_{2 \mathrm{a}}$ (Figure 33b) was difficult to decipher due to an impurity peak overlapping the signal. From the TOCSY spectrum, only the peaks that correlate to the methylene protons of the metallacycle show up and the coupling pattern was deduced. The coupling values for protons, rhodium, and phosphorus couplings can be found in Figure 34 . The rhodium metallacycle was found to less stable than the iridium counterpart, so ESI-MS was not able to be determined for this structure. This follows the trend of increasing metal-carbon bond strength down a group of the periodic table. 
Calculated (a) and experimental (b) splitting patterns of the $1-\mathrm{CH}_{2}$ and 2- $\mathrm{CH}_{2}$ protons

back to back representations
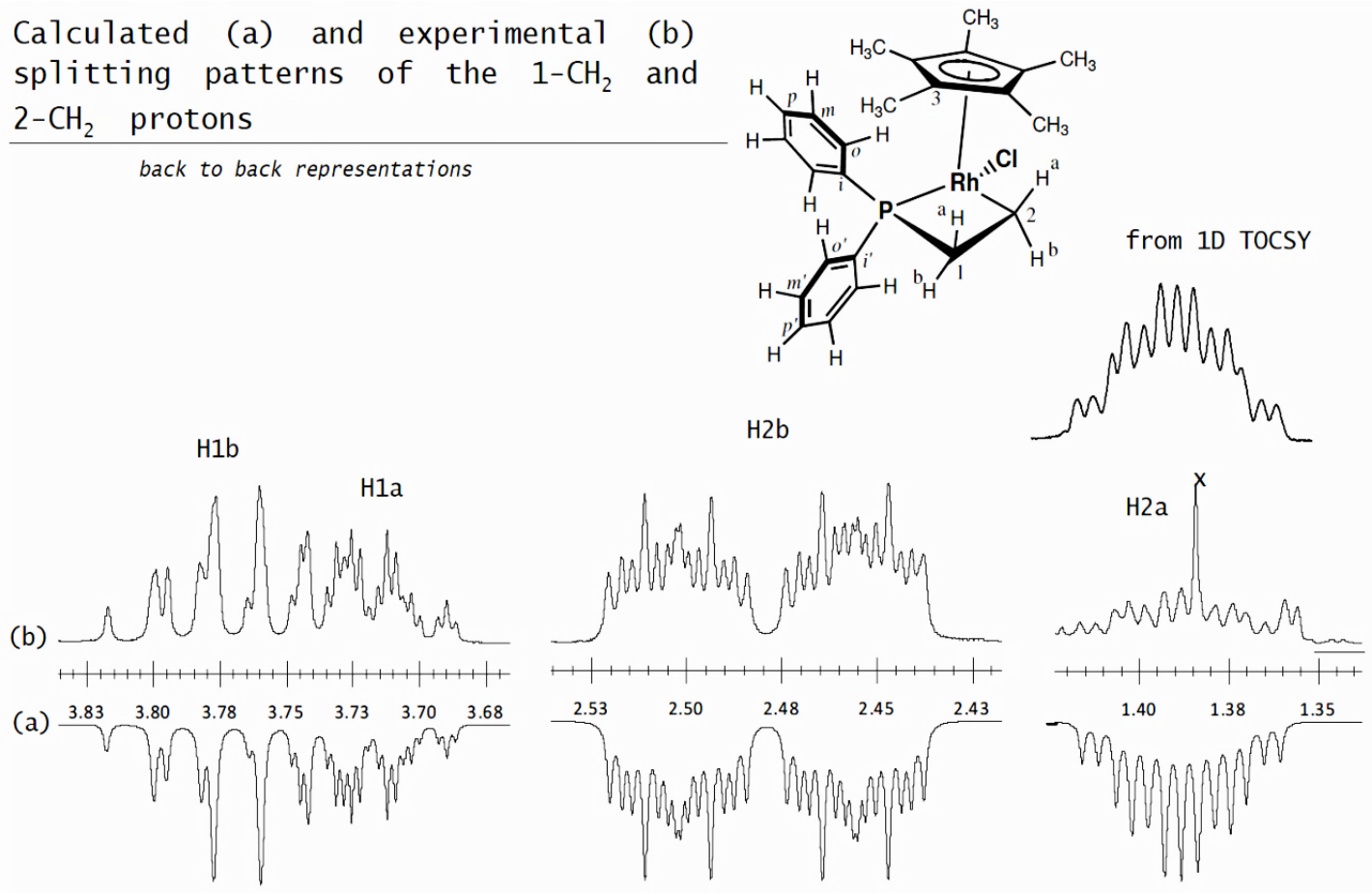

Figure 33. Simulated vs. experimental coupling constants for methylene protons of rhodium metallacycle.
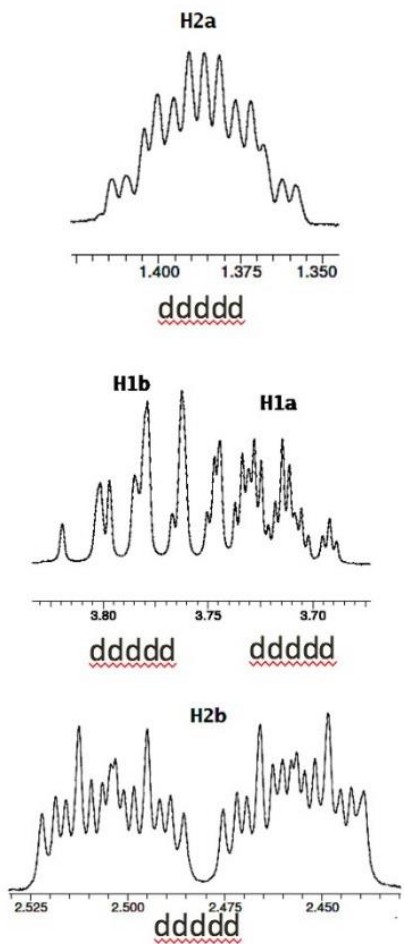

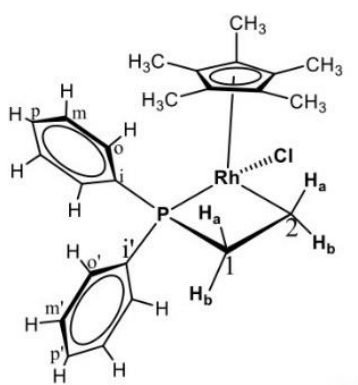

$\delta 3.72(\mathrm{H} 1 \mathrm{a})$

$\delta 3.78$ (H1b)

$\delta 1.39(\mathrm{H} 2 \mathrm{a})$

$\delta 2.48(\mathrm{H} 2 \mathrm{~b})$

Figure 34. ${ }^{2} \mathrm{~J}$ and ${ }^{3} \mathrm{~J}$ coupling constants of each ${ }^{1} \mathrm{H}$ signal generated from methylene protons of the rhodium metallacycle. 
Similar treatments with lithium and silver reagents gave the same rhodium metallacycle (Table 2). The ${ }^{31} \mathrm{P}$ NMR sprectra for the phenyllithium $(\mathrm{PhLi})$ and trimethylsilylmethyllithium ( $\mathrm{TMSCH}_{2} \mathrm{Li}$ ) treatments of the $\mathrm{Cp}^{*} \mathrm{RhCl}_{2} \mathrm{~PB}$ complex (Figures 35-36) that also show small residual peaks of other generated products.

Table 2. Additives reacted with $\left[\mathrm{Cp} * \mathrm{RhCl}_{2} \mathrm{~PB}\right]$ and corresponding metallacycle yields generated

\begin{tabular}{clc} 
Entry & Additive & Yield $^{a}$ \\
\hline 1 & $\mathrm{AgOAc}$ & $94 \%$ \\
2 & $\mathrm{PhLi}$ & $87 \%$ \\
3 & $\mathrm{TMSCH}_{2} \mathrm{Li}$ & $97 \%$
\end{tabular}

${ }^{a}$ Yields determined from ${ }^{31} \mathrm{P}$ NMR metallacycle resonances



Figure 35. $\left.{ }^{31} \mathrm{P} \mathrm{NMR} \mathrm{Cp} * \mathrm{RhCl}_{2}\left(\mathrm{Ph}_{2} \mathrm{PCH}_{2} \mathrm{CH}_{2} \mathrm{~B}^{\mathrm{BBN}}\right)\right)+$ 1eq. $\mathrm{PhLi}$ 


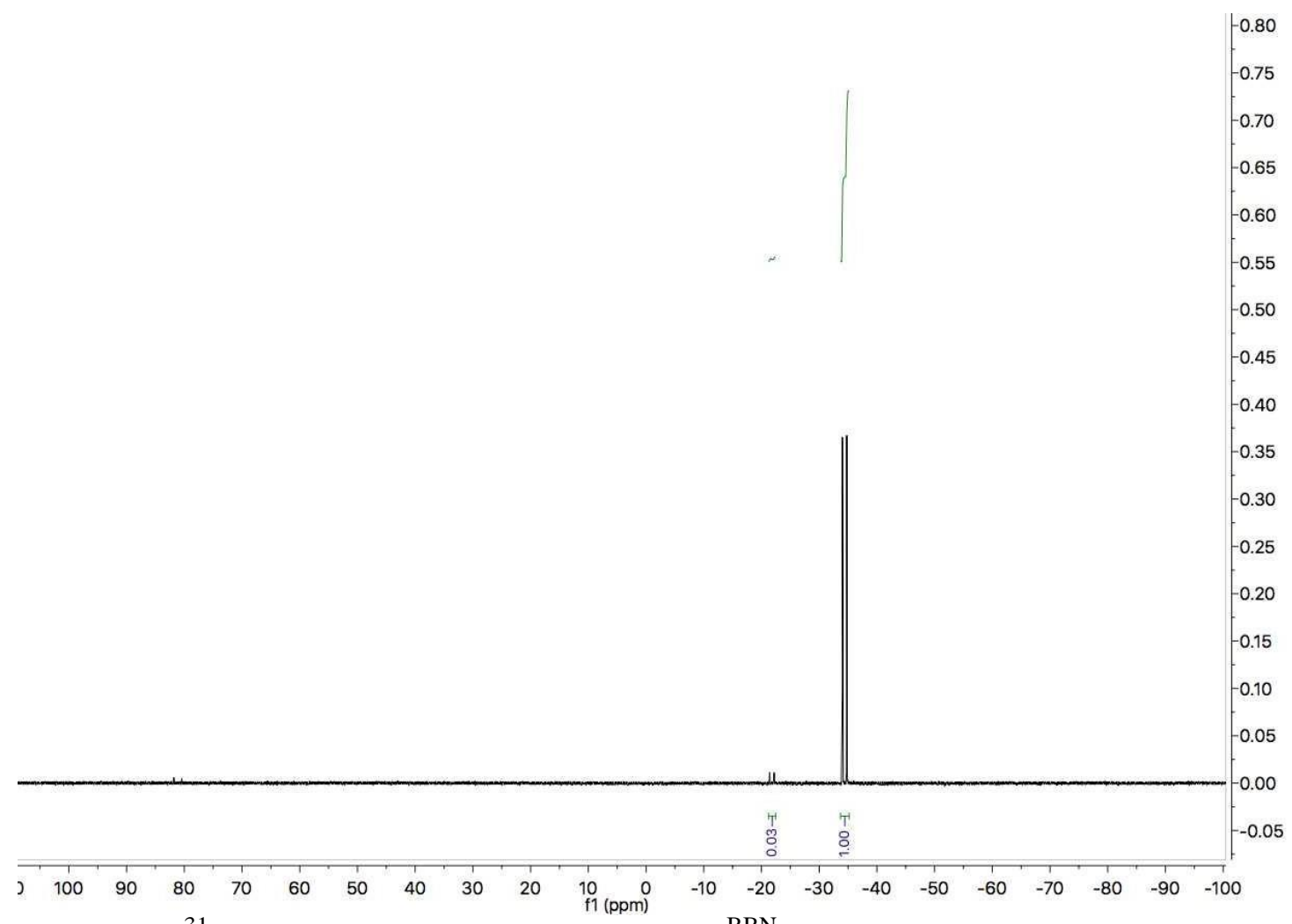

Figure 36. ${ }^{31} \mathrm{P} \mathrm{NMR} \mathrm{Cp} * \mathrm{RhCl}_{2}\left(\mathrm{Ph}_{2} \mathrm{PCH}_{2} \mathrm{CH}_{2}\left(\mathrm{~B}^{\mathrm{BBN}}\right)\right)+1$ eq. $\mathrm{TMSCH}_{2} \mathrm{Li}$

\section{$\underline{\text { Cobalt }}$}

The cobalt metallacycle (Scheme 16) was more complicated to synthesize as degradation would quickly occur, making spectroscopic identification difficult. This observation also follows the bond strength trend expected for a first row transition metal compared to a third row transition metal. The ${ }^{31} \mathrm{P}$ NMR showed one resonance for the phosphino-borane coordinated complex at $34 \mathrm{ppm}$ (Figure 37). Unfortunately, the ${ }^{31} \mathrm{P}$ NMR of the metallacyclic complex contains minor impurities, making it challenging for full characterization (Figure 38). Splitting patterns in the ${ }^{1} \mathrm{H}$ NMR were undiscernible due to broad peaks (Figure 39). The resonances $\mathrm{H}_{1 \mathrm{eq}}$ and $\mathrm{H}_{1 \text { ax }}$ showed a simplification in the splitting pattern when decoupled from ${ }^{31} \mathrm{P}$, indicative of their position on the metallacycle. The full characterization was complicated by broad signals that were found to overlap the other methylene resonances and degradation of the sample before 
other experiments such as TOCSY could be ran. Given the instability of the resulting metallacycle, an X-ray structure has not yet been acquired.

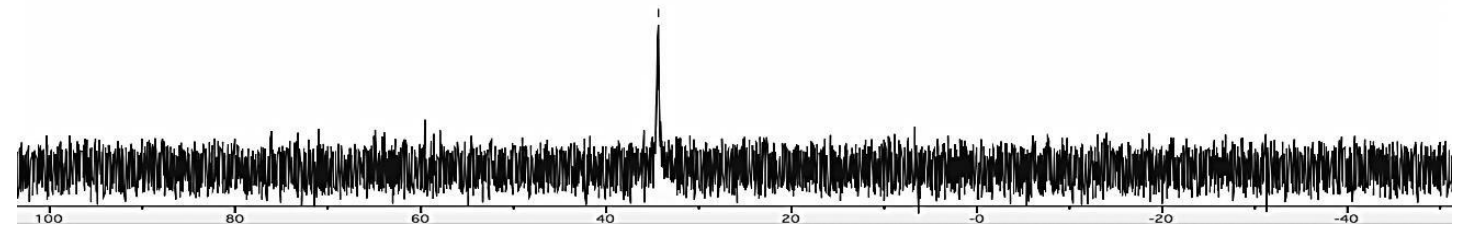

Figure 37. ${ }^{31} \mathrm{P}$ NMR of $\mathrm{Cp} * \mathrm{CoCl}_{2} \mathrm{~PB}$ complex $\left(\mathrm{PB}=\mathrm{Ph}_{2} \mathrm{PCH}_{2} \mathrm{CH}_{2} \mathrm{~B}^{\mathrm{BBN}}\right)$

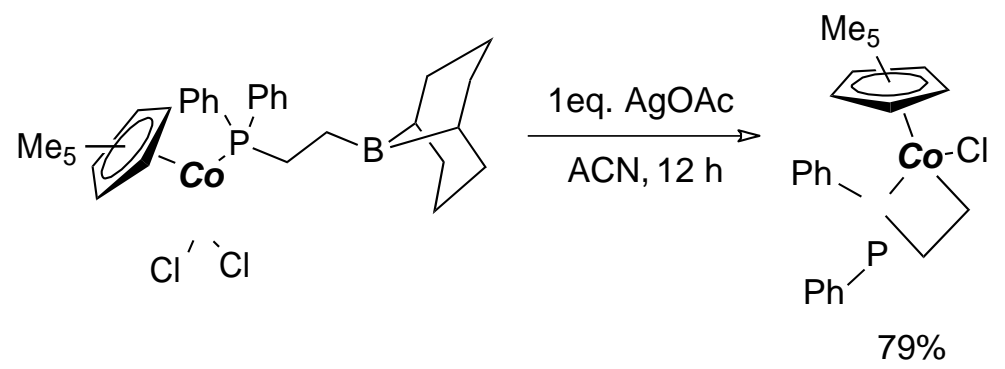

Scheme 16. Generating four-membered metallacycle from $\mathrm{Cp} * \mathrm{CoCl}_{2}\left(\mathrm{Ph}_{2} \mathrm{PCH}_{2} \mathrm{CH}_{2} \mathrm{~B}^{\mathrm{BBN}}\right)$ 


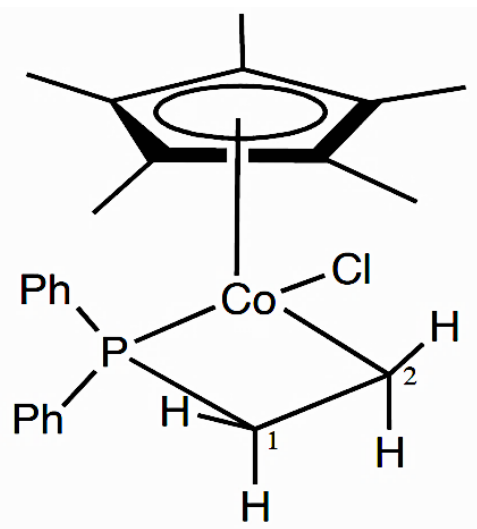

Figure 38. ${ }^{31} \mathrm{P}$ NMR of cobalt metallacycle

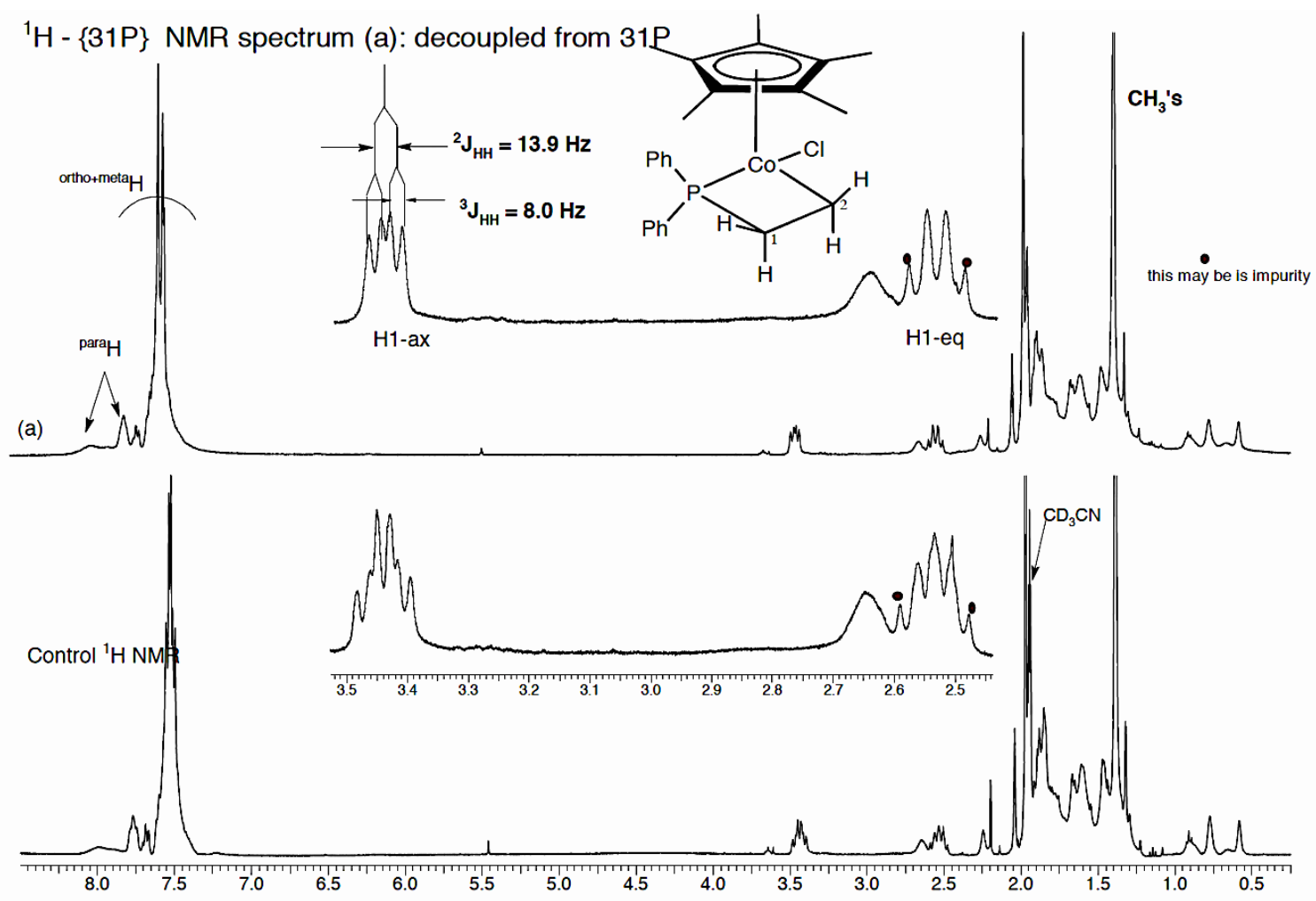

Figure 39. ${ }^{1} \mathrm{H}$ NMR of cobalt metallacycle generated and ${ }^{1} \mathrm{H}\left\{{ }^{31} \mathrm{P}\right\}$ NMR of cobalt metallacycle 


\section{Conclusion}

A series of cobalt, rhodium, and iridium metallacycles have been synthesized from their corresponding ambiphilic ligand complexes. While able to obtain full NMR characterization of the rhodium and iridium metallacycles, the stability of the cobalt metallacycles provided challenges for full characterizations. A summary of the ${ }^{31} \mathrm{P}$ NMR chemical shifts observed with the group IX metals and their corresponding PB complexes show a large upfield shift for each of the products generated (Table 2). The interest in using metal coordinated FLPs in catalysis continues, and the reactivity explored with silver and lithium reagents expands upon the alreadyestablished behavior known to FLP transition metal coordinated complexes.

Table 3. ${ }^{31} \mathrm{P}$ NMR shifts for group IX phosphino-borane and metallacycle complexes

\begin{tabular}{ccc} 
Metal complex & PBcomplex ${ }^{31}$ P shift $(\mathbf{p p m})$ & Metallacycle \\
\hline Cobalt & 34 & -23 \\
Rhodium & $33(\mathrm{~d}, \mathrm{~J}=232 \mathrm{~Hz})$ & $-34(\mathrm{~d}, \mathrm{~J}=121 \mathrm{~Hz})$ \\
Iridium & 0 & -65 \\
\hline
\end{tabular}

Free Ligand ${ }^{31} \mathrm{P}$ shift $(\mathrm{ppm})=-11$ 


\section{Experimental}

$\underline{\text { General Considerations }}$

${ }^{31} \mathrm{P},{ }^{13} \mathrm{C},{ }^{1} \mathrm{H}$, and ${ }^{1} \mathrm{H}\left\{{ }^{31} \mathrm{P}\right\} \mathrm{NMR}$ spectra were recorded on a $400 \mathrm{MHz}$ Agilent spectrometer or a $600 \mathrm{MHz}$ Varion Inova NMR spectrometer. The ${ }^{31} \mathrm{P}$ NMR was referenced to an external $\mathrm{H}_{3} \mathrm{PO}_{4}$ standard. Reactions were ran in an MBraun MB 200B glovebox under nitrogen atmosphere unless otherwise noted. All commercial reagents were used without further purification. Pentamethylcyclopentadienyliridium(III) chloride, dimer was purchased from Alpha Aesar and Pentamethylcyclopentadienylrhodium(III) chloride, dimer was purchased from Aldrich and used without further purification. Solvents used were dried on a SG Water glass contour solvent purification system unless otherwise noted. Crystals structures were acquired on a Bruker AXS D8 Venture X-ray diffractomer. Electrospray ionization (ESI) mass spectra were recorded on a Thermo-Finnigan LCQ DECA XP. High-resolution mass spectra were recorded on a ThermoFinnigan LTQ MS equipped with an ICR FTMS.

\section{Experimental procedures}

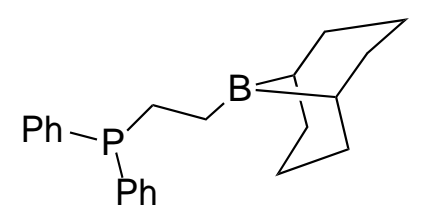

[2-(9-borabicyclo[3.3.1]non-9-yl)ethyl]diphenyl-phosphine

To a well-dried $100 \mathrm{~mL}$ round bottom flask, vinyldiphenylphosphine (1234 mg, $5.816 \mathrm{mmol}, 2$ eq.) was added under nitrogen atmosphere. To the same flask, 9-Borabicyclo[3.3.1]nonane dimer (855 mg, $2.908 \mathrm{mmol}, 1$ eq.) was added. THF (20 mL) was added to the mixture and sealed with a septum. The roundbottom was removed from the glovebox and heated at $60^{\circ} \mathrm{C}$ overnight $(\sim 12$ 
h). The white solid product was crashed out of solution by cooling down to $0^{\circ} \mathrm{C}$ for $30 \mathrm{~min}$. The reaction was then returned to nitrogen atmosphere, filtered, and rinsed with pentane (60\% yield).<smiles>Cc1ccc(C2(Cl)O[Ge](Cl)(Cl)OC2(Cl)c2ccc(C)cc2)cc1</smiles>

pentamethylcyclopentadienylcobalt(III) chloride dimer

A sample of $\mathrm{CoCl}_{2}(664 \mathrm{mg}, 5.1 \mathrm{mmol}, 1$ eq.) was added to a well-dried $50 \mathrm{~mL}$ round bottom flask under nitrogen atmosphere. $\left[\mathrm{Li}\left(\mathrm{C}_{5} \mathrm{Me}_{5}\right)\right](800 \mathrm{mg}, 5.6 \mathrm{mmol}, 1.1 \mathrm{eq}$.$) was added to the$ same round bottom flask. The reaction was stirred in $25 \mathrm{~mL}$ THF solvent for 1.5 hours. The solvent was removed under vacuo and the residue was extracted with pentane $(2 \times 25 \mathrm{~mL})$ and the extracts were filtered through a glass filter frit under nitrogen atmosphere. Hexachloroethane (2422 $\mathrm{mg}, 10.2 \mathrm{mmol}, 2$ eq.) was added to the filtrate and stirred for 30 minutes at room temperature. The resulting green precipitate was collected by filtration and dried under vacuo. The resulting $\left[\mathrm{Cp} * \mathrm{CoCl}_{2}\right]_{2}$ green solid is air stable (50\% yield).

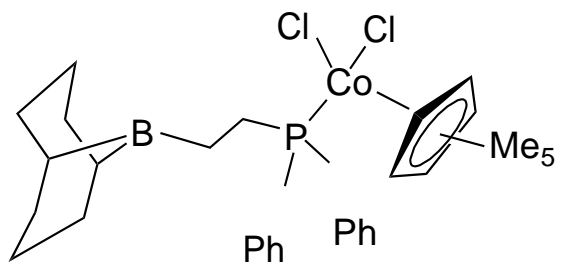

pentamethylcyclopentadienylcobalt(III)dichloride (9-borabicyclo[3.3.1]non-9-yl)ethyl]diphenylphosphine

To a well-dried 20-dram vial, $\left[\mathrm{Cp}^{*} \mathrm{CoCl}_{2}\right]_{2}(57 \mathrm{mg}, 0.1075 \mathrm{mmol}, 1$ eq.) was added under a nitrogen atmosphere. The phospino-borane ligand $(72 \mathrm{mg}, 0.215 \mathrm{mmol}, 2 \mathrm{eq}$.) was added to the same vial. The reaction was left to stir in $5 \mathrm{~mL}$ DCM for $\sim 3 \mathrm{hrs}$. The reaction was filtered through celite and the solvent was removed in vacuo (82.9\% yield). 


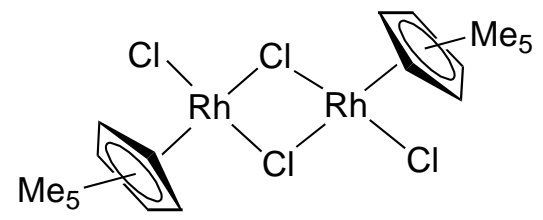

pentamethylcyclopentadienylrhodium(III) chloride dimer

To a well-dried $50 \mathrm{~mL}$ roundbottom flask, $\mathrm{RhCl}_{3} \bullet 3 \mathrm{H}_{2} \mathrm{O}(510 \mathrm{mg}, 1$ eq.) was added under ambient atmosphere. The septum-sealed round bottom was purged with Argon, then $\mathrm{Cp} *-\mathrm{H}(0.5$ $\mathrm{mL})$ with a gastight syringe, and Methanol $(12.5 \mathrm{~mL})$. The reaction was refluxed under Argon for $21 \mathrm{hr}$. The resulting red solid was filtered and washed with ether.

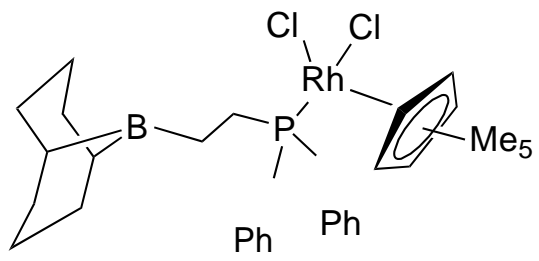

pentamethylcyclopentadienylrhodium(III)dichloride ～(9-borabicyclo[3.3.1]non-9-yl)ethyl] diphenyl-phosphine

To a well dried 20-dram vial, [Cp* $\left.\mathrm{RhCl}_{2}\right]$ (100 mg, 1eq.) was added under nitrogen atmosphere. To the same vial, $\mathrm{Ph}_{2} \mathrm{PCH}_{2} \mathrm{CH}_{2}(9-\mathrm{BBN})$ ligand (108 mg, 2 eq.) was added with $\mathrm{ACN}$ and left to stir for 2 hrs. The reaction was stopped and filtered through a celite filter. The solvent was removed in vacuo. A red solid was collected (98\% yield). X-ray quality crystal prepared by layering $\mathrm{THF} /$ pentane or $\mathrm{ACN} / \mathrm{Et}_{2} \mathrm{O}$.

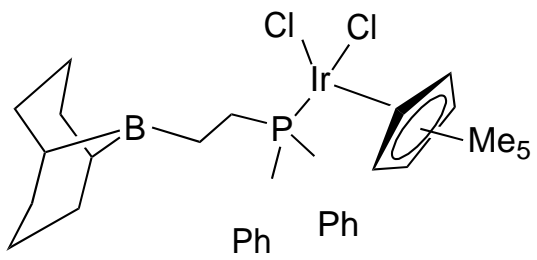


pentamethylcyclopentadienyliridium(III)dichloride diphenyl-phosphine

To a well dried $25 \mathrm{~mL}$ roundbottom flask, [Cp* $\left.\mathrm{IrCl}_{2}\right](0.014 \mathrm{mmol}$, 1eq. $)$ was added with benzene $(\sim 3 \mathrm{ml})$ to make a yellow solution. To the same flask, a benzene solution of $\mathrm{Ph}_{2} \mathrm{PCH}_{2} \mathrm{CH}_{2}(9-\mathrm{BBN})$ ligand $(0.028 \mathrm{mmol}, 2$ eq. $)$ was added. The solution became clear and was left to stir at room temperature for 2 hours. The solvent was then removed in vacuo and the solid washed with pentane to give a yellow solid.

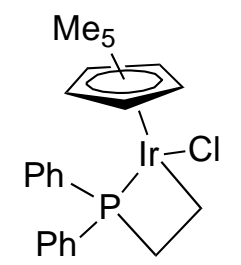

pentamethylcyclopentadienyliridium(III)chloride $\left(\kappa^{\mathrm{P}, \mathrm{C}}\right.$-diphenylphosphinoethylene $)$

To a well-dired 20-dram vial, $\mathrm{Cp}^{*} \mathrm{IrCl}_{2} \mathrm{~PB}$ (1 eq.) was dissolved with $\mathrm{C}_{6} \mathrm{D}_{6}$ to make an orange solution. To the solution, AgOAc (1 eq.) was added and the vial immediately covered with aluminum foil. The reaction was left to stir for 2 hours, filtered through celite to collect the filtrate, and NMR analysis was taken directly (90\% yield).

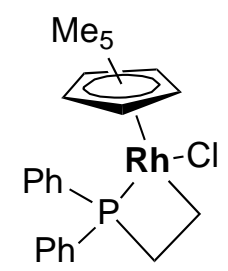

pentamethylcyclopentadienylrhodium(III)chloride $\left(\kappa^{\mathrm{P}, \mathrm{C}}\right.$-diphenylphosphinoethylene)

To a well-dried $20 \mathrm{~mL}$ vial, $\mathrm{Cp}^{*} \mathrm{RhCl}_{2} \mathrm{~PB}(30 \mathrm{mg}, 1$ eq., $0.0524 \mathrm{mmol})$ was added with $\mathrm{C}_{6} \mathrm{D}_{6}$ to afford a red solution. To the same vial, AgOAc (10 mg, 1.2 eq., $0.0629 \mathrm{mmol})$ was added and 
left to stir. The reaction was immediately covered in aluminum foil and left to stir for $24 \mathrm{hr}$. The reaction was stopped, and the brown/red solution was filtered through celite to give a red/orange filtrate taken directly for NMR analysis (94\% yield).

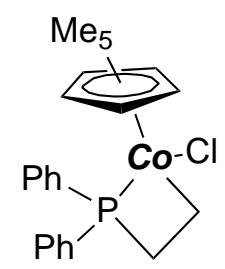

pentamethylcyclopentadienylcobalt(III)chloride $\left(\kappa^{\mathrm{P}, \mathrm{C}}-\operatorname{diphenylphosphinoethylene}\right)$

To a well-dried $20 \mathrm{~mL}$ vial, $\mathrm{Cp} * \mathrm{CoCl}_{2} \mathrm{~PB}(34 \mathrm{mg}, 1$ eq., $0.057 \mathrm{mmol})$ was added with $\mathrm{CD}_{3} \mathrm{CN}$ to afford a purple solution. To the same vial, AgOAc (10 mg, 1.1 eq., $0.062 \mathrm{mmol})$ was added and left to stir. The reaction was immediately covered in aluminum foil and left to stir for $24 \mathrm{~h}$. The reaction was stopped, and the brown solution was filtered through celite to give a brown filtrate taken directly for NMR analysis (79\% yield). 


\section{References}

1) Lewis GN (1923) Valence and the structure of atoms and molecules. Chemical Catalogue Inc.,New York, p 172

2) Brown, H. C., Schlesinger, H. I. \& Cardon, S. Z. J. Am. Chem. Soc. 1942, 64, 325-329.

3) Wittig G, Ru“ckert. Justus Liebigs Ann Chem 1950 566(2):101-113

4) Wittig, G. \& Benz, E. Chem. Ber. 1959, 92, 1999-2013.

5) Tochtermann, W. Angew. Chem. Int. Ed. Engl., 1966, 5, 351-371.

6) Welch, G. C., Juan, R. R. S., Masuda, J. D. \& Stephan, D. W. Science 2006, 314, 11241126.

7) Welch, G. C. \& Stephan, D. W., J. Am. Chem. Soc. 2007, 129, 1880-1881.

8) Spies, P.; Erker, G.; Kehr G.; Bergander, K.; Frohlich, R.; Grimme, S.; Stephan, D.W. Chem.Commun. 2007, 5072-5074.

9) McCahill, J. S. J.; Welch, G. C.; Stephan, D.W. Angew. Chem., Int. Ed. 2007, 46, 49684971.

10) Bouhadir, G., Amgoune, A. \& Bourissou, D. in Adv. Organomet. Chem, 2010, 58, 1-107.

11) Rathke, J.; Schaeffer, R. Inorg. Chem., 1972, 11, 1150.

12) Braunschweig, H.; Dirk, R.; Ganter, B. J. Organomet. Chem., 1997, 257, 545-546.

13) Gloaguen, Y.; Alcaraz, G.; Pecharman, A. F.; Clot, E.; Vendier, L.; Sabo-Etienne, S. Angew. Chem. Int. Ed., 2009, 48, 2964.

14) Thangavelu, S. G.; Hocker, K. E.; Cooke, S. R.; Muhoro, C. N., J. Organomet. Chem. 2008, 693, 562.

15) a.) Spies, P.; Erker, G.; Kehr, G.; Bergander, K.; Froehlich, R.; Grimme, S.; Stephan, D. 
W. Chem. Commun. 2007, 5072. b.) Spies, P.; Kehr, G.; Bergander, K.; Wibbeling, B.; Froehlich, R.; Erker, G. Dalton Trans., 2009, 1534.

16) Fischbach, A.; Bazinet, P. R.; Waterman, R.; Tilley, T. D. Organometallics, 2008, 27, 1135.

17) Schmidbaur, H.; Sigl, M.; Schier, A., J. Organomet. Chem., 1997, 529, 323.

18) Braunschweig, H.; Dirk, R.; Ganter, B., J. Organomet. Chem., 1997, 257, 545-546.

19) Bontemps, S.; Bouhadir, G.; Apperley, D. C.; Dyer, P. W.; Miqueu, K.; Bourissou, D. Chem. Asian J., 2009, 4, 428.

20) Bontemps, S.; Bouhadir, G.; Miqueu, K.; Bourissou, D. J. Am. Chem. Soc., 2006, 128, 12056.

21) Stephan, D. W. Frustrated Lewis Pairs. J. Am. Chem. Soc., 2015, 137, 10018-10032.

22) a.) Spies, P.; Schwendemann, S.; Lange, S.; Kehr, G.; Fröhlich, R.; Erker, G. Angew. Chem., Int. Ed., 2008, 47, 7543-7546. b.) Wang, H. D.; Fröhlich, R.; Kehr, G.; Erker, G. Chem. Commun., 2008, 5966-5968. c.) Chase, P. A.; Welch, G. C.; Jurca, T.; Stephan, D. W. Angew. Chem., Int. Ed. 2007, 46, 8050-8053. d.) Mahdi, T.; Stephan, D. W. J. Am. Chem. Soc. 2014, 136, 15809-15812. e.) Scott, D. J.; Fuchter, M. J.; Ashley, A. E. J. Am. Chem. Soc. 2014, 136, 15813-15816. f.) Chernichenko, K.; Madarász, Á.; Pápai, I.; Nieger, M.; Leskelä, M.; Repo, T. Nat. Chem., 2013, 5, 718-723. g.) Segawa, Y.; Stephan, D. W. Chem. Commun., 2012, 48, 11963-11965. h.) Mahdi, T.; Heiden, Z. M.; Grimme, S.; Stephan, D. W. J. Am. Chem. Soc. 2012, 134, 4088-4091.

23) Chen, D.; Klankermayer, J. Chem. Commun. 2008, 2130-2131.

24) Chen, D.; Wang, Y.; Klankermayer, J. Angew. Chem., Int. Ed., 2010, 49, 9475-9478.

25) Ghattas, G.; Chen, D.; Pan, F.; Klankermayer, J. Dalton Trans., 2012, 41, 9026-9028. 
26) Lindqvist, M.; Borre, K.; Axenov, K.; Kótai, B.; Nieger, M.; Leskelä, M.; Pápai, I.; Repo, T. J. Am. Chem. Soc., 2015, 137, 4038-4041.

27) Mömming, C. M.; Otten, E.; Kehr, G.; Fröhlich, R.; Grimme, S.; Stephan, D. W.; Erker, G. Angew. Chem., Int. Ed., 2009, 48, 6643-6646.

28) Otten, E.; Neu, R. C.; Stephan, D. W. J. Am. Chem. Soc., 2009, 131, 9918-9919.

29) Cardenas, A.; Culotta, B.; Warren, T.; Grimme, S.; Stute, A.; Fröhlich, R.; Kehr, G.;

Erker, G. Angew. Chem., Int. Ed., 2011, 50, 7567-7571.

30) Sajid, M.; Klose, A.; Birkmann, B.; Liang, L. Y.; Schirmer, B.; Wiegand, T.; Eckert, H.; Lough, A. J.; Frohlich, R.; Daniliuc, C. G.; Grimme, S.; Stephan, D. W.; Kehr, G.; Erker, G. Chem. Sci., 2013, 4, 213-219.

31) Farrell, J. M.; Posaratnanathan, R. T.; Stephan, D. W. Chem. Sci., 2015, 6, 2010-2015.

32) Vergnaud, J.; Grellier, M.; Bouhadir, G.; Vendier, L.; Sabo-Etienne, S.; Bourissou, D. Organometallics 2008, 27, 1140

33) Vajpayee, V.; Popp, B.V. unpublished results

34) M. H. Thibault, J. Boudreau, S. Mathiotte, F. Drouin, O. Sigouin, A. Michaud and F. G. Fontaine, Organometallics, 2007, 26, 3807-3815

35) B. R. Barnett, C. E. Moore, A. L. Rheingold and J. S. Figueroa, J. Am. Chem. Soc., 2014, $136,10262-10265$.

36) Ostapowicz, T. G., Merkens, C., Hölscher, M., Klankermayer, J. \& Leitner, W.. J. Am. Chem. Soc., 2013, 135, 2104-2107. 


\section{$\underline{\text { Appendix }}$}

\section{Iridium NMR data}

${ }^{13} \mathrm{C}-{ }^{31} \mathrm{P}$ coupling constants



Figure A-1a. ${ }^{13} \mathrm{C}$ NMR spectra of iridium metallacycle showing ${ }^{13} \mathrm{C}-{ }^{31} \mathrm{P}$ coupling

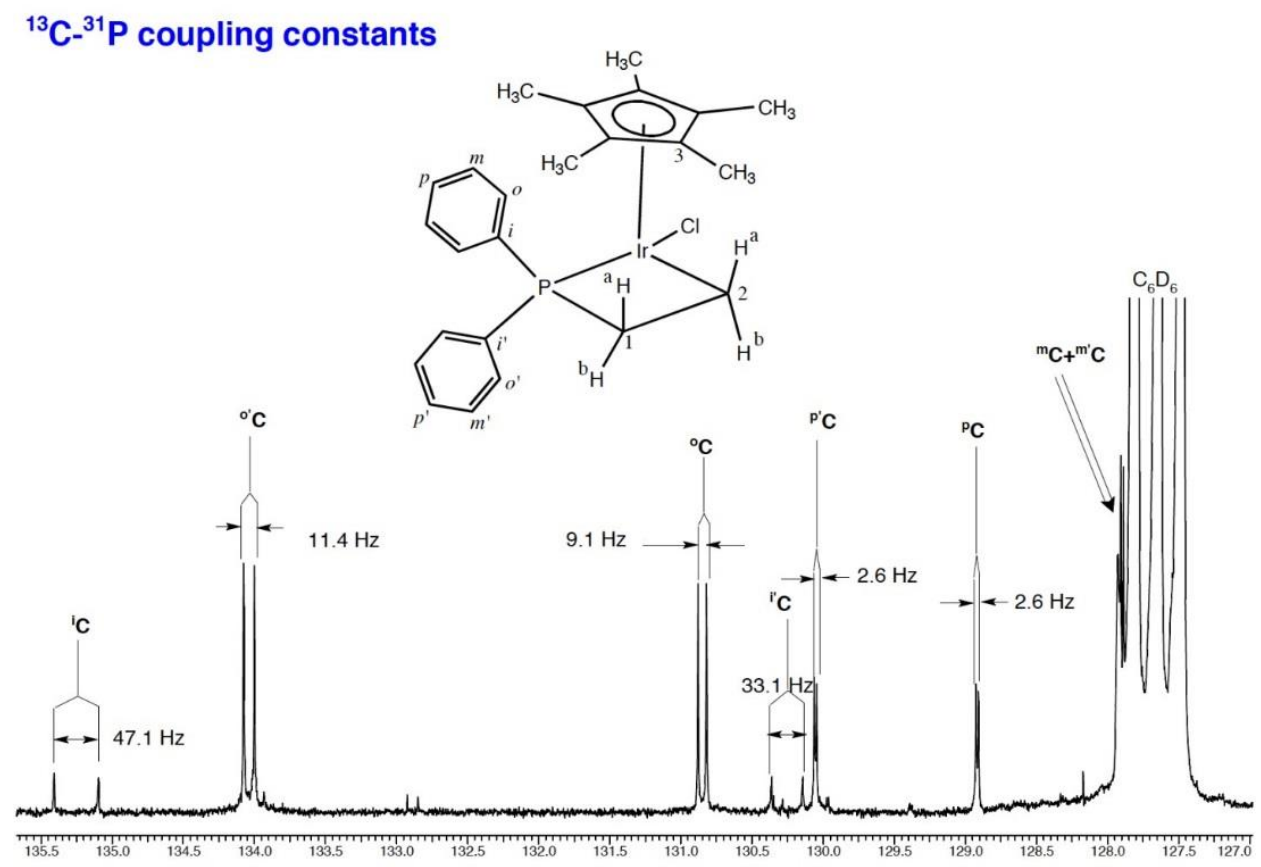

Figure A-1b. ${ }^{13} \mathrm{C}$ NMR expanded spectra of aromatic region showing ${ }^{13} \mathrm{C}-{ }^{31} \mathrm{P}$ coupling 


\section{Rhodium NMR data}

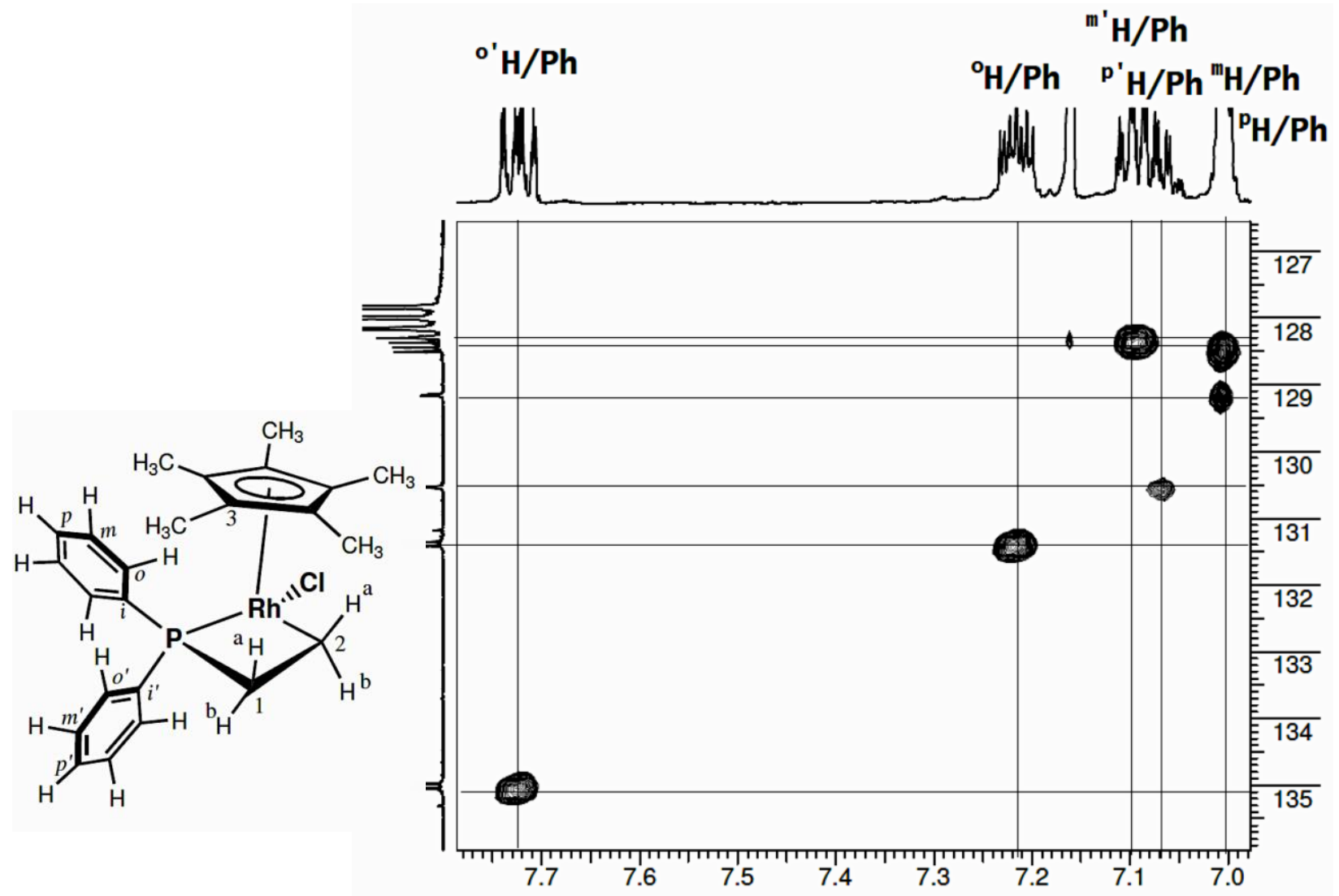

Figure A-2. gHSQCAD of aromatic region showing one bond $\left({ }^{1} \mathrm{~J}_{\mathrm{HC}}\right)$ correlations on phenyl rings 
Two $\left({ }^{2} \mathrm{~J}_{\mathrm{HC}}\right)$ and three bond $\left({ }^{3} \mathrm{~J}_{\mathrm{HC}}\right)$ gHMBCAD correlations
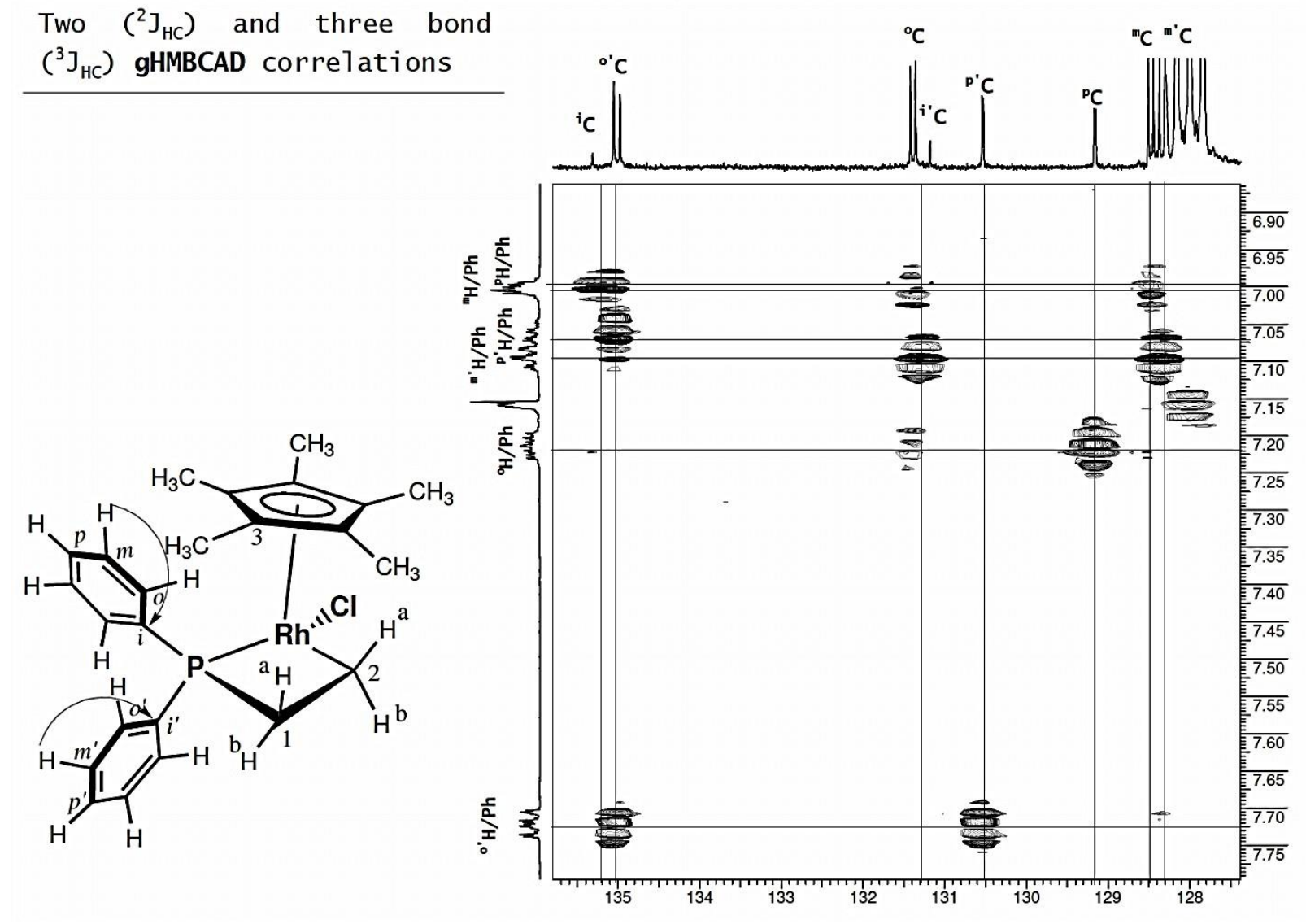

Figure A-3. gHMBCAD of aromatic region showing two $\left({ }^{2} \mathrm{~J}_{\mathrm{HC}}\right)$ and three $\left({ }^{3} \mathrm{~J}_{\mathrm{HC}}\right)$ correlations on phenyl rings 